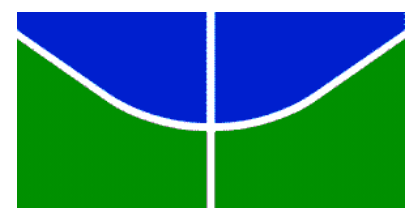

Universidade de Brasília

Instituto de Psicologia

Departamento de Psicologia Clínica

Programa de Pós-Graduação em Psicologia Clínica e Cultura

\title{
PREVENINDO O USO ABUSIVO DE DROGAS: UMA ANÁLISE DA DIFUSÃO DO PROGRAMA FAMÍLIAS FORTES NO BRASIL
}

Ana Aparecida Vilela Miranda

Brasília, junho de 2016. 


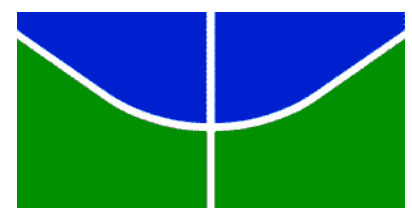

Universidade de Brasília

Instituto de Psicologia

Departamento de Psicologia Clínica

Programa de Pós-Graduação em Psicologia Clínica e Cultura

\section{PREVENINDO O USO ABUSIVO DE DROGAS: UMA ANÁLISE DA DIFUSÃO DO PROGRAMA FAMÍLIAS FORTES NO BRASIL}

Ana Aparecida Vilela Miranda

Dissertação apresentada ao Programa de Pós-Graduação em Psicologia Clínica e Cultura da Universidade de Brasília como requisito parcial para obtenção do Grau de Mestre.

Orientadora: Prof ${ }^{a}$. Dra ${ }^{\mathrm{a}}$. Sheila Giardini Murta

Brasília, junho de 2016 
Trabalho apresentado ao Programa de Pós-Graduação em Psicologia Clínica e Cultura da Universidade de Brasília, sob a orientação da Professora Dra. Sheila Giardini Murta.

\section{Banca Examinadora:}

Prof $^{a}$. Dr ${ }^{\mathrm{a}}$. Sheila Giardini Murta

Universidade de Brasília - UnB

Presidente da banca

Prof $^{a}$ Dra $^{\mathrm{a}}$. Márcia Helena da Silva Melo Bertolla

Universidade de São Paulo - USP

Membro Titular

Prof. Dr. Paulo Carlos Du Pin Calmon

Universidade de Brasília - UnB

Membro Titular

Prof $^{a} \operatorname{Dr}^{a}$. Maria Inês Gandolfo Conceição

Universidade de Brasília - UnB

Membro Suplente 
“(...) ainda que suas carreiras lhes imponham percalços e possam até embranquecerlhes prematuramente os cabelos, jamais permitam que a imaginação e o idealismo sejam sabotados pelas armadilhas do cotidiano e da conformidade."

Celso Amorim, em "Conversas com Jovens Diplomatas" 


\section{AGRADECIMENTOS}

A vida é uma caixinha de surpresas, a maioria delas são surpresas muito boas. E a melhor de todas são as pessoas que entram em nossas vidas e deixam um pouco de si, levando um pouco de nós, numa eterna transformação. Sempre falo para minha psicóloga que meu maior medo é nunca mudar. E essa jornada do mestrado me transformou profundamente. Por isso, tenho muito o que agradecer aqui, mesmo tendo que ser breve.

Minha imensa gratidão primeiramente a Deus, por guiar meu caminho, me dando força e coragem para chegar até aqui.

À minha querida orientadora $\operatorname{Prof}^{\mathrm{a}} \operatorname{Dr}^{\mathrm{a}}$ Sheila Murta, que tem me acolhido nesses longos anos de trabalho juntas, acompanhando meu crescimento. Por ser essa pessoa que sempre está me inspirando a querer ir continuamente mais além. Por sua paciência e confiança constante em mim. Pelos momentos de acolhida, partilha e incentivo. Por ter me apresentado à prevenção. São tantos agradecimentos, que seria necessário escrever um livro. Por isso me limito agora a um sincero obrigada por tudo.

Aos meus pais, Moisés e Cida, pelo apoio incondicional em todos os momentos que vivi para chegar até aqui. Por sempre acreditarem em mim, me incentivando nos estudos e na vida. Tenho muito orgulho de vocês.

À minha irmã Ana Paula, por me aturar em todos os momentos de estresse. Por suas batidinhas no ombro em sinal de carinho. Por ser mais que uma irmã.

Ao Carlos, meu noivo/namorado, por me dar forças e coragem para sempre ir além, e por me acalmar nos momentos de desespero. Por me incentivar e ser meu refúgio nos momentos de tristeza.

Aos meus familiares, que tanto me apoiaram ao longo da minha trajetória acadêmica. Pelas orações, apoio e inspirações.

À Larissa, por todo carinho e apoio, desde antes mesmo do mestrado. Por ser uma pessoa inspiradora em todos os sentidos, seja profissional ou pessoal.

À Ana Paula, minha terapeuta que tem me encorajado muito nesses últimos tempos.

À Jordana e Bruno, por serem excelentes amigos, confidentes e colegas de profissão que sempre estavam prontos para me ajudar e aconselhar.

À Cristineide, José Marcelo, Dr $^{\mathrm{a}}$ Tania, Arthur, Karine, Janaína, Leonardo, Adriano, Marcos, Jordana, Larissa, Samia, Priscila, Juliana e Nayara, membros do Grupo de Estudos em Prevenção e Promoção de Saúde no Ciclo de Vida-GEPPS-Vida por todo apoio, motivação e ajuda nessa caminhada.

À Samia, que tanto tem me inspirado com sua coragem, força de vontade, determinação e competência.

À Raquel, pela ajuda em compreender tantas coisas. Foi um prazer tê-la conhecido na disciplina Políticas Públicas em Perspectiva Comparada.

Aos Professores Dr. Denilson Bandeira e Dr. Paulo Calmon, por serem uma fonte de novos conhecimentos maravilhosos, que tanto me ajudou ao longo do mestrado. 
Aos meus queridos alunos de Psicologia Preventiva, acho que aprendi mais com vocês do que ensinei.

Aos amigos Juliana e Rodrigo, que além de companheiros de vida, me ajudaram muito nessa dissertação. Obrigada por estarem na minha vida.

À Isabela e Julianne, pelo apoio em algumas etapas de análise e transcrição dos dados da pesquisa.

Ao grupo de pesquisa do projeto Avaliação de Efetividade, Qualidade da Implementação e Validade Social do Programa Famílias Fortes, representados pela Profa. Sheila Murta, Prof. Dr. Fábio Iglesias, Prof. Dr. Luís Gustavo, Larissa, Viviane, Adriano, João Luís, Cristineide, Danielle e Karina pelos debates e conhecimentos compartilhados.

Aos participantes dessa pesquisa por todo apoio e disponibilidade.

Aos professores, funcionários e colegas da Universidade de Brasília, por toda contribuição e apoio.

Aos membros da banca, Prof ${ }^{a}$. Dr ${ }^{\mathrm{a}}$. Márcia Melo, Prof. Dr. Paulo Calmon, Prof ${ }^{\mathrm{a}}$. Dra ${ }^{\mathrm{a}}$. Inês Gandolfo, pelo aceite ao convite.

À Fundação de Coordenação de Aperfeiçoamento de Pessoal de Nível Superior (CAPES), pelo apoio financeiro que possibilitou esse e tantos outros projetos. 


\section{SUMÁRIO}

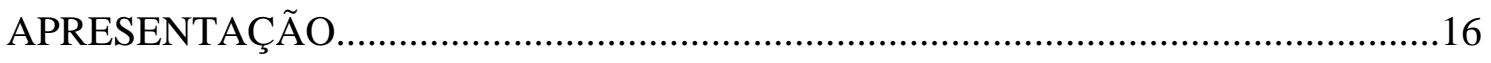

MANUSCRITO 1 - A pesquisa em prevenção ao uso de substância entre adolescentes: onde estamos e para onde devemos ir..............................................21

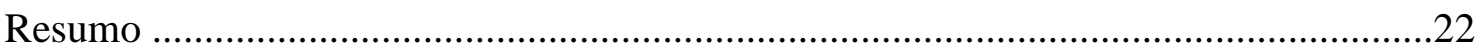

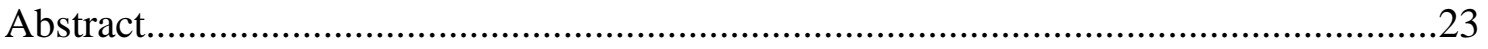

A pesquisa em prevenção ao uso de substância entre adolescentes: onde estamos e para

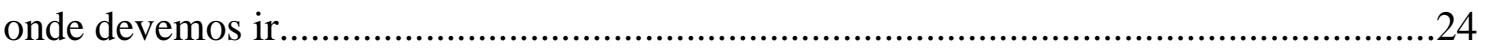

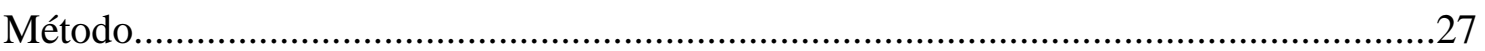

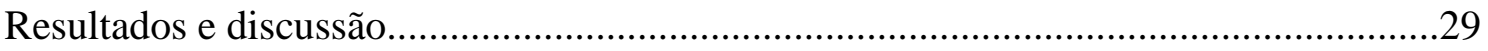

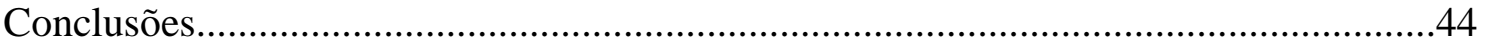

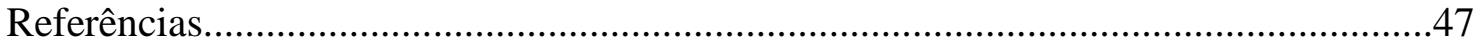

MANUSCRITO 2 - Difusão de programas preventivos em saúde mental: da

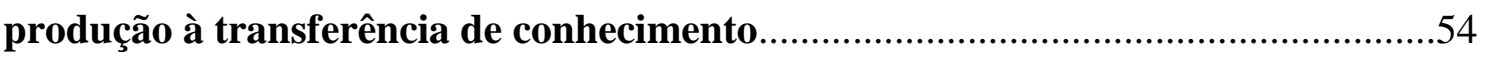

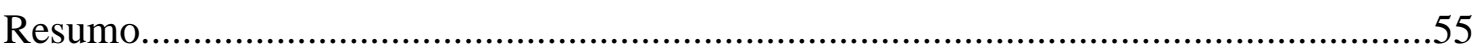

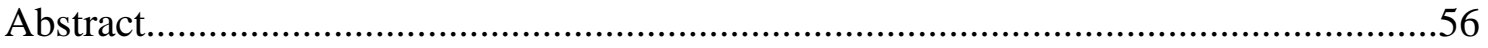

Difusão de programas preventivos em saúde mental: da produção à transferência de conhecimento .57

Difusão

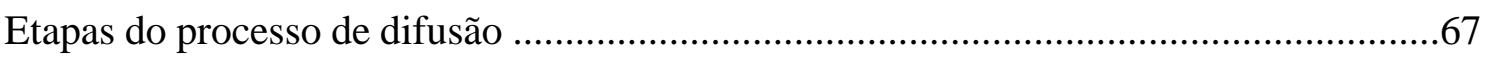

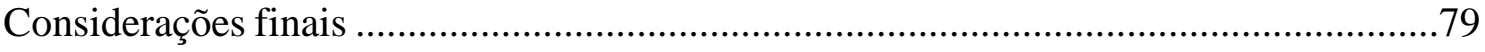

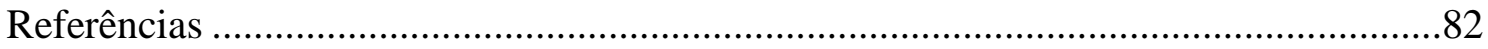

MANUSCRITO 3 - A Difusão do Programa Famílias Fortes: um estudo baseado em

Teoria Fundamentada

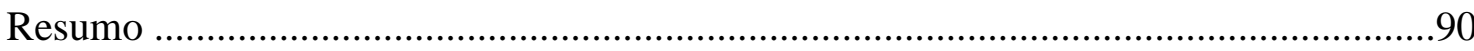

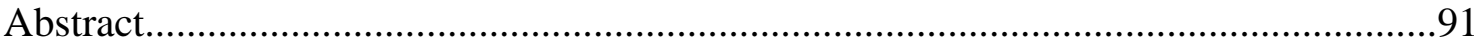


A Difusão do Programa Famílias Fortes: um estudo baseado em Teoria

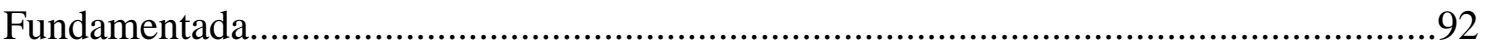

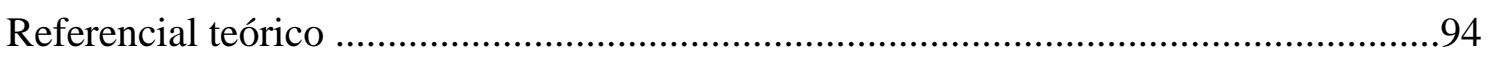

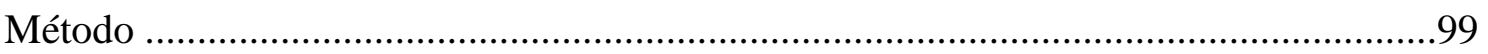

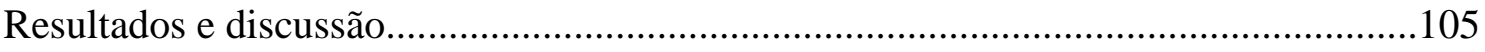

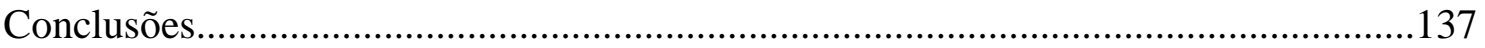

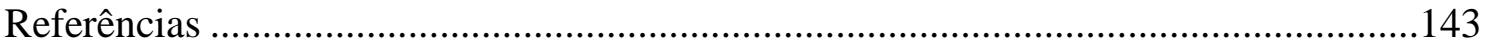

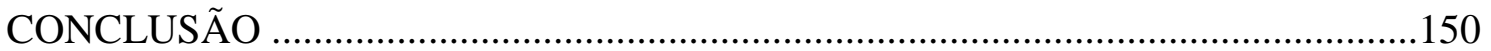

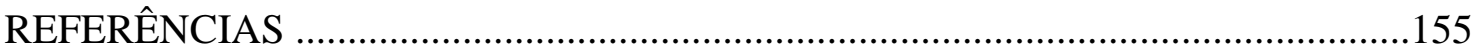

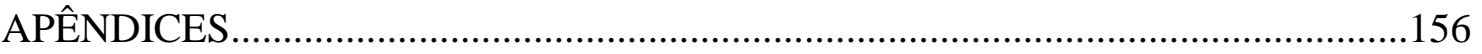




\section{LISTA DE TABELAS}

\section{Manuscrito 1}

Tabela 1. Resultado do uso de drogas entre adolescentes.

Tabela 2. Fatores de risco ao uso de drogas e relacionados ao número de ocorrências nos textos analisados.

Tabela 3. Fatores de proteção ao uso de drogas relacionados ao número de ocorrências nos textos analisados.

\section{Manuscrito 2}

Tabela 1. Características da Implementação

Tabela 2. Guia para o planejamento da sustentabilidade (adaptado de Shediac-Rizkallah \& Bone, 1998)

\section{Manuscrito 3}

Tabela 1. Barreiras e facilitadores do processo de difusão do PFF para o Brasil 


\section{LISTA DE FIGURAS}

\section{Manuscrito 1}

Figura 1. Representação gráfica das etapas do ciclo de prevenção.

Figura 2. Ciclo da pesquisa em prevenção ao abuso de drogas

\section{Manuscrito 2}

Figura 1. Ciclo de pesquisa em prevenção (baseado em Mrazek \& Haggerty, 1994)

Figura 2. Elementos que caracterizam a difusão (baseado em Rogers, 1995/1962)

\section{Manuscrito 3}

Figura 1. Fatores influentes na Implementação (adaptado de Santos, \& Murta, 2015)

Figura 2. Modelo lógico do Programa Famílias Fortes

Figura 3. Temas das sessões do Programa Famílias Fortes

Figura 4. Marcadores da História do Programa Famílias Fortes no Brasil (2012-2015)

Figura 5. Aspectos influentes na sustentabilidade 


\section{LISTA DE APÊNDICES}
A. Protocolo de entrevista
B. Parecer CEP-IH
C. Termo de Consentimento Livre Esclarecido 


\section{LISTA DE SIGLAS}

AC - Acre

APA - American Psychological Association

AIDS - Síndrome da Imunodeficiência Adquirida

CAPS - Centro de Atenção Psicossocial

CEP-IH - Comitê de Ética em Pesquisa em Ciências Humanas e Sociais

CE - Ceará

CRAS - Centros de Referência em Assistência Social

COSE - Centro de Orientação Socioeducativo

DALY - Disability-Adjusted Life Year

DF - Distrito Federal

EAD - Educação a Distância

EUA - Estados Unidos da América

HIV - Vírus da Imunodeficiência Humana

MDSA - Ministério do Desenvolvimento Social e Agrário

MS - Ministério da Saúde

NUTE - Núcleo Multiprojetos de Tecnologia Educacional

PAIF - Programa de Atenção Integral à Família

PFF - Programa Famílias Fortes

PNAD - Política Nacional sobre Drogas 
SC - Santa Catarina

SENAD - Secretaria Nacional de Políticas sobre Drogas

SFP - Strengthening Families Program

SP - São Paulo (estado)

SUAS - Sistema Único de Assistência Social

TCLE - Termo de Consentimento Livre e Esclarecido

UE - União Europeia

UFSC - Universidade Federal de Santa Catarina

UK - Unided Kingdom (Reino Unido)

UNODC - Escritório das Nações Unidas sobre Drogas e Crime

OMS - Organização Mundial de Saúde

WHO - World Health Organization 


\section{RESUMO}

O uso de drogas entre adolescentes vem preocupando diversos segmentos da sociedade. A ausência de informação somada a uma campanha alarmista quanto ao uso de substâncias ilícitas tem dado relevo ao tema. Em adição a isso, há uma lacuna na literatura nacional acerca de programas de prevenção baseados em evidências. Tendo em vista que fatores de risco e proteção do uso de drogas incluem variáveis familiares, dentre outras, programas voltados ao fortalecimento de vínculos familiares seriam estratégias preventivas pertinentes para responder às demandas de prevenção previstas na Política Nacional sobre Drogas. O objetivo geral dessa dissertação é descrever o processo de difusão de um programa de prevenção do uso de substâncias no Brasil, denominado Programa Famílias Fortes, perpassando o ciclo de pesquisa em prevenção das drogas. Trata-se de um programa de origem estrangeira, adotado pelo Ministério da Saúde em 2013, e posteriormente implementado em diversas cidades brasileiras. Esta dissertação tem como embasamento teórico a Teoria da Difusão de Inovações e é composta por três estudos. O Estudo 1 buscou avaliar a literatura nacional na área de prevenção ao uso de substância, por meio de uma revisão integrativa da literatura. Esse estudo abordou o ciclo de pesquisa em prevenção e investigou cada etapa do processo. Foram localizados 40 artigos que atenderam aos critérios de inclusão. Os dados evidenciaram que ainda há poucas iniciativas relativas às últimas etapas do ciclo de pesquisa em prevenção (desenvolvimento de intervenção, avaliação de eficácia e efetividade e difusão), sendo que muitos estudos encontram-se nas primeiras etapas do ciclo (avaliação de necessidade e fatores de risco e proteção) e são referentes a estudos de revisão de literatura. O Estudo 2 , de natureza teórica, buscou explorar o conceito de difusão e suas características históricas e conceituais, a partir das contribuições de Everett Rogers e autores contemporâneos. Por fim, o Estudo 3 investigou o processo de difusão do Programa Famílias Fortes para o Brasil por meio de uma abordagem qualitativa baseada em Teoria Fundamentada. Os dados foram coletados por meio de entrevistas com gestores, análise de documentos e observação de reuniões de equipes de trabalho. A análise dos dados foi realizada por meio do software NVIVO. Os resultados indicaram que o Programa Famílias Fortes foi adotado por ter sido percebido como compatível com a realidade brasileira, vantajoso em relação a outras estratégias preventivas e com evidências de efetividade. Foram constatados desafios na implementação do programa no país, como escassez de recursos humanos, financeiros e materiais; cultura voltada ao tratamento e não à prevenção; e instabilidade no contexto político. Por outro lado, aspectos facilitadores da difusão foram identificados, incluindo a coerência do Programa Famílias Fortes com as necessidades da população, metodologia consistente e resultados visíveis aos implementadores e participantes. São recomendados estudos de avaliação da efetividade do Programa Famílias Fortes e discutidas implicações destes achados para práticas de gestão e pesquisa em difusão de programas preventivos.

Palavras-chave: Uso de Substâncias, Programas de Prevenção, Difusão de Inovação, Adolescência, Teoria Fundamentada 


\begin{abstract}
Drug abuse among adolescents is worrying many segments of society. The lack of information coupled with an alarmist campaign on the use of illicit substances has given prominence to the issue. In addition, there is a gap in the national literature about evidence-based prevention programs. Considering that the risk and protective factors of drug use include family variables, among others, programs aimed at strengthening family ties would be relevant preventive strategies to meet the demands of prevention set out in the National Policy on Drugs. The overall objective of this dissertation is to describe the diffusion process of a program of substances use prevention in Brazil, called Strengthening Families Program, going through the research cycle in drug prevention. This is a foreign program, adopted by the Health Ministry in 2013, and subsequently implemented in several Brazilian cities. This dissertation is based on the Theory of Diffusion of Innovation and is consisted of three studies. Study 1 was to evaluate the national literature in the substance use prevention's area through an integrative literature review. This study addressed the research cycle in prevention and investigated each step of the process. Forty articles that attend the inclusion criteria were found. The data showed that there are still few initiatives on the last stages of the research cycle in prevention (intervention development, efficacy, effectiveness and dissemination evaluation), given that many studies are in the early stages of the cycle (assessment of need and risk and protective factors) and are related to literature review studies. Study 2, of a theoretical nature, sought to explore the concept of Diffusion of innovations and its historical and conceptual characteristics, from the contributions of Everett Rogers and contemporary authors. Finally, Study 3 investigated the diffusion process of Strengthening Families Program to Brazil through a qualitative approach based on Grounded Theory. Data were collected through interviews with managers, documents analysis and working teams meetings observation. Data analysis was performed using NVIVO software. The results indicated that the Strengthening Families Program was adopted because it was perceived as compatible with Brazilian reality, advantageous compared to other preventive strategies and with evidences of effectiveness. Challenges have been encountered in the implementation of this program in the country, such as lack of human, financial and material resources; culture focused on treatment rather than prevention; and instability in the political context. Otherwise, facilitating aspects of the spread have been identified, including the coherence of the Strengthening Families Program with population needs, consistent methodology and visible results to implementers and participants. Studies are recommended to assess the effectivity of the Strengthening Families Program and implications of these findings are discussed for management practices and research on preventive programs diffusion.
\end{abstract}

Keywords: Substance use, Prevention Programs, Diffusion of Innovations, Adolescence, Grounded Theory 


\section{APRESENTAÇÃO}

Dalton, Elias e Wandersman (2007) apresentam a seguinte história em seu livro sobre prevenção: um homem estava próximo a um rio socorrendo algumas pessoas que estavam se afogando. Uma mulher ao passar por ali viu o que ele estava fazendo e foi ajudá-lo. Mas, apesar de todo trabalho árduo e constante, mais pessoas precisavam ser socorridas. A condição ficava cada vez mais desesperadora. Em dado momento, a mulher perguntou ao homem como aquelas pessoas estavam caindo no rio, mas o homem não sabia. A mulher então perguntou por que ele não ia ver o que estava acontecendo, e ele respondeu que não podia, pois tinha muito que se fazer naquele local que ele estava, se ele parasse mais pessoas seriam perdidas. Ela concordou com ele, mas após algum tempo, ela decidiu ver o que estava acontecendo. Ela pensou que muitas pessoas seriam perdidas se ela fosse, mas talvez ela conseguisse parar o fluxo de pessoas que estavam caindo no rio. Rio acima ela viu que uma parte do caminho levava as pessoas a um declive e este diretamente para dentro do rio. Ela então percebeu que era ali que ela deveria estar, seu trabalho não era o de socorrer as pessoas que caiam no rio e estavam se afogando, mas evitar, o quanto fosse possível, que as pessoas caíssem. Ela trabalharia redirecionando as pessoas de seu curso e poderia tentar também mudar o caminho.

Apresentei essa história em 2014 como justificativa para meu ingresso no Mestrado em Psicologia Clínica e Cultura. Tive a oportunidade de conhecê-la nas aulas da disciplina Psicologia Preventiva. Essa história me marcou desde então. Minha história com a prevenção é anterior ao conhecimento dessa história, de 2010, quando entrei para o projeto de pesquisa da Professora Sheila sobre prevenção à violência no namoro. Lá encontrei meu lar. Percebi nesse projeto diversas vulnerabilidades que apenas ouvia falar, mas percebi o poder da prevenção. Percebi que a mudança era possível, antes que coisas piores acontecessem, como na história. E, mesmo hoje, na clínica, percebo, mais forte 
ainda, o quanto a prevenção e a promoção em saúde podem ser uma solução para tanto sofrimento.

Quando iniciei o Mestrado em Psicologia Clínica e Cultura tinha apenas uma certeza: queria trabalhar com prevenção, empoderamento e políticas públicas. Não tinha ideia sobre como fazê-lo. Então, surgiu a oportunidade de trabalhar com o Programa Fortalecendo Famílias, hoje Programa Famílias Fortes (PFF). Não tive a oportunidade de estudar diretamente o empoderamento, mas descobri muito mais.

O PFF chegou ao Brasil como uma iniciativa inovadora para as políticas públicas, eu considero, pois, representava uma mudança de paradigma, voltado à prevenção e não ao tratamento. Devo admitir que nunca tinha pensado em trabalhar com o tema drogas. Não era algo que me chamava a atenção, e estava imersa no paradigma anterior sobre "guerra às drogas", talvez por isso nunca tivesse me interessado por esse tema. Porém, trabalhar com um programa de prevenção em nível nacional era um sonho, mesmo que demonstrado através de um pesadelo. Explico melhor. Bom, para compreender melhor o assunto, recorri à Ciência Política. No primeiro semestre do mestrado cursei duas disciplinas no Instituto de Ciência Política (IPOL) da UnB. Era outro mundo. Agora explico o pesadelo. Sonhei, certo dia, num desses em que estava desesperada achando que não conseguiria passar nas disciplinas, que estava no IPOL e deveria chegar ao IP, mas para isso deveria atravessar um abismo. Foi um sonho muito ruim. Mesmo não sendo psicanalista, o sonho representou muito o que estava vivendo, para mim aquela transição era muito complexa, muitas coisas a aprender. Mas, no final, foi uma jornada incrível, que valeu o esforço.

Nesse mesmo ano, participei do Congresso Previne (2014) e novas mudanças foram ocasionadas, conheci esse "novo" paradigma sobre drogas e me aprofundei cada vez mais nos meus estudos. Além do mais, o PFF por si só é encantador. Uma vez que, 
não é apenas um programa de prevenção às drogas, é um programa de promoção de saúde mental, de fortalecimento de vínculos, e de promoção de habilidade sociais. Teoria e técnica são coerentes entre si. E, aparentemente, apresenta validade social.

Além do mais, o paradigma da prevenção vem sendo tratado como um dos eixos principais para se solucionar problemas decorrentes do uso de substâncias (UNODC, 2014; WHO, 2004). As diretrizes internacionais (UNODC, 2014) têm sido taxativas ao recomendarem a prevenção como foco de políticas públicas mais eficazes, apesar de apresentarem que ainda existem lacunas a serem preenchidas nesse campo. Porém, o que apresentam está de acordo com as diretrizes estipuladas pela Organização Mundial em Saúde (WHO, 2004) em que se define que as políticas em saúde devem se pautar na promoção da saúde, prevenir doenças e promover o bem-estar da população. De acordo com o documento do Escritório das Nações Unidas sobre Drogas (UNODC, 2014), o principal objetivo ao se prevenir o uso de drogas é a busca de um desenvolvimento saudável e seguro do indivíduo: "um sistema eficaz de prevenção do uso de drogas contribui significativamente para que crianças, jovens e adultos participem de forma positiva nas atividades familiares, escolares, comunitárias e no ambiente de trabalho" (UNODC, 2014, p.5).

Outrossim, consta-se que iniciativas em prevenção no Brasil estão muito aquém de países desenvolvidos. Uma vez que há evidências da associação entre pobreza e doenças mentais (WHO, 2004), investir na prevenção é investir no desenvolvimento social do país. Por isso, esse trabalho também se mostra inovador ao propor uma abordagem voltada a conhecer os aspectos da difusão do PFF no Brasil, considerando-se a literatura na área e o momento histórico brasileiro em que vem apresentando ora avanços, ora retrocessos em suas políticas sociais. 
Dessa forma, o objetivo desta dissertação é (a) descrever a produção nacional de pesquisas em prevenção ao uso de drogas e (b) analisar o processo de difusão do PFF no Brasil. Para isso, esta dissertação está organizada em três manuscritos.

O Manuscrito 1 é uma revisão integrativa da literatura em prevenção ao uso de drogas. Baseou-se no ciclo de pesquisa em prevenção, passando pela caracterização do problema das drogas entre adolescentes no Brasil; os fatores de risco e proteção ao uso de drogas; programas que têm sido desenvolvidos e publicados na literatura nacional; estudos que avaliam a eficácia e efetividade de programas.

O Manuscrito 2 corresponde a um estudo teórico sobre a literatura em difusão. Discutem-se conceitos e teorias acerca da difusão de programas preventivos em saúde mental. Compara-se e descreve-se teorias divergentes e convergentes sobre o tema, tendo por eixo a Teoria da Difusão de Inovações.

O Manuscrito 3 abarca a análise do processo de difusão, as características da inovação que levaram a adoção do PFF no Brasil, sua trajetória no país, e as características de processo: disseminação, adoção, implementação e sustentabilidade do programa à realidade brasileira.

Espero que os achados desta dissertação contribuam para o avanço da pesquisa em difusão no Brasil, de forma a ser útil tanto para pesquisadores quanto para o público leigo. Sabemos que a academia precisa comunicar-se com a prática. E, como no meu sonho, a menor distância entre abismos é uma ponte. Espero que este estudo possa ser uma ponte e incentive a propagação de práticas preventivas baseadas em evidência. Que o conhecimento não se restrinja a um único público. E, no momento histórico em que vivemos, de muita desesperança, a prevenção vem na contramão do que é injusto, e a 
favor do futuro, e por isso não nos esqueçamos: "O Brasil não pode renunciar à sua grandeza" (Celso Amorim, 2011).

\section{Referências}

Amorim, C. (2011) Conversas com jovens diplomatas. Benvirá: São Paulo.

Dalton, J. H., Elias, M. J., \& Wandersman, A. (2007). Community Psychology: linking individuals and communities. Thomsom Wadsworth: Belmont, California.

UNODC (2014) Diretrizes internacionais sobre a prevenção do uso de drogas.

WHO, World Health Organization. (2004). Prevention of mental disorders:

effective interventions and policy options. Summary Report, Genebra. 


\section{MANUSCRITO 1}

A pesquisa em prevenção ao uso de substância entre adolescentes: onde estamos e para onde devemos ir 


\section{Resumo}

O presente estudo buscou traçar o ciclo de pesquisa em prevenção do abuso de substâncias entre adolescentes, utilizando-se da revisão integrativa como método de pesquisa. Foram encontrados 93 artigos e selecionados 40, dos quais nove abordavam a descrição do problema, 23 fatores de risco e proteção, seis eram relativos à etapa de desenvolvimento de intervenções preventivas, um de avaliação de eficácia e efetividade e nenhum era relacionado a etapa de difusão de programas de prevenção do abuso de substâncias. Conclui-se existir uma escassez na literatura de produções acerca de intervenções para prevenção do abuso de drogas avaliadas de forma sistemática que poderiam ser implementadas em larga escala no Brasil.

Palavras-chave: prevenção, abuso de substâncias, adolescência, saúde mental. 


\begin{abstract}
This study aimed to drop the research cycle in prevention of substance abuse among adolescents, using the integrative review as research method. 93 articles were found and 40 was select, of which nine shows the description of the problem, 23 factors of risk and protection, six were on the stage of development of preventive interventions, one os assessment of efficiency and effectiveness and none were related to diffusion step of programs to prevent substance abuse. We conclude that there is a shortage in the literature of production of drug abuse preventive interventions evaluated in a systematic manner that could be implemented on scale up in Brazil.
\end{abstract}

Keywords: prevention, substance abuse, adolescence, mental health. 


\section{A pesquisa em prevenção do uso de substância entre adolescentes: onde estamos e para onde devemos ir}

A adolescência, tanto no Brasil como no mundo, tem sido marcada pela exposição a vulnerabilidades, que vão desde envolvimento em comportamentos de risco até a ausência de oportunidades de desenvolvimento saudável, tais como ausência de educação, emprego, lazer etc. (Cerqueira-Santos, Melo-Neto, \& Koller, 2014; Murta, Conceição, Abreu, Miranda, \& Correa, 2015). Uma vulnerabilidade à qual os adolescentes estão expostos que merece destaque é o uso abusivo de substâncias. De fato, o uso de álcool e outras drogas se configura como problema nessa faixa etária, ainda mais quando associado a outros fatores que o agravam, como o envolvimento em comportamentos de risco que podem comprometer a saúde física ou mental, tais como dirigir embriagado, se envolver em comportamentos sexuais de risco ou de violência, entre outros (Murta et al., 2015).

Além do mais, o uso da droga muitas vezes se apresenta não como causa, mas como consequência de injustiça social, preconceito, ausência de cumprimento dos direitos sociais, violência, problemas familiares, ausência de contextos de lazer, propagandas favoráveis ao uso, pressão por pares (Moreira, Vóvio, \& De Micheli, 2015; Pratta \& Santos, 2013; Schenker \& Minayo, 2005). Por isso, ações de caráter preventivo a esses fatores de risco e ações de promoção de comportamentos e habilidades saudáveis são boas opções de intervenção.

Compreende-se por prevenção a intervenção que ocorre antes do início de um problema ou doença acontecer (Muñoz, Mrazek, \& Haggerty, 1996). Sobre ações preventivas, o documento das Nações Unidas sobre Prevenção ao uso de Drogas (UNODC, 2014), apresenta como objetivo principal ações que visam a proteção dos 
indivíduos dos efeitos nocivos que se correlacionam às drogas. Ao invés de evitar o uso, busca-se a proteção em meio a situações de vulnerabilidade, fornecendo recursos para que o adolescente cresça de forma mais saudável.

O documentado das Nações Unidas (UNODC, 2014) também aponta que um sistema eficaz de prevenção deve conter uma ação integrada de intervenções e políticas baseadas em evidências científicas, contemplando diversos componentes, em nível individual, familiar e coletivo, já que o problema é multifacetado. Essa característica requer, então, não apenas uma intervenção, mas um conjunto de ações integradas.

As propostas baseadas em evidências científicas contemplam programas de prevenção que passam por um rigoroso processo de desenvolvimento até chegar a vários públicos e requerem uma série de passos cuidadosamente planejados e implementados. Esse processo é chamado de ciclo de pesquisa em prevenção e é composto por seis etapas: identificação do problema, identificação dos fatores de risco, teste piloto ou desenvolvimento da intervenção, estudos de eficácia, estudos de efetividade, e difusão (Mrazek \& Haggerty, 1994; Muñoz, Mrazek, \& Haggerty, 1996).

O primeiro passo requer a identificação e definição do problema por meio de avaliação de necessidades da população-alvo. O segundo passo é identificar os fatores de risco e proteção associados ao que se buscará prevenir. Com base nos dados dessas duas primeiras etapas passa-se a terceira etapa, que consiste em desenvolver e testar a aceitabilidade e viabilidade da intervenção preventiva, conduzindo testes-piloto. O quarto passo corresponde aos testes de eficácia que são avaliações dos efeitos da intervenção em condições ideais de implementação. O quinto passo refere-se aos testes de efetividade, que se caracterizam por investigações dos efeitos do programa em situações reais de implementação, quando multiplicadores são preparados para replicar o programa. O sexto 
e último passo corresponde à difusão do programa para outros contextos (Mrazek \& Haggerty, 1994).

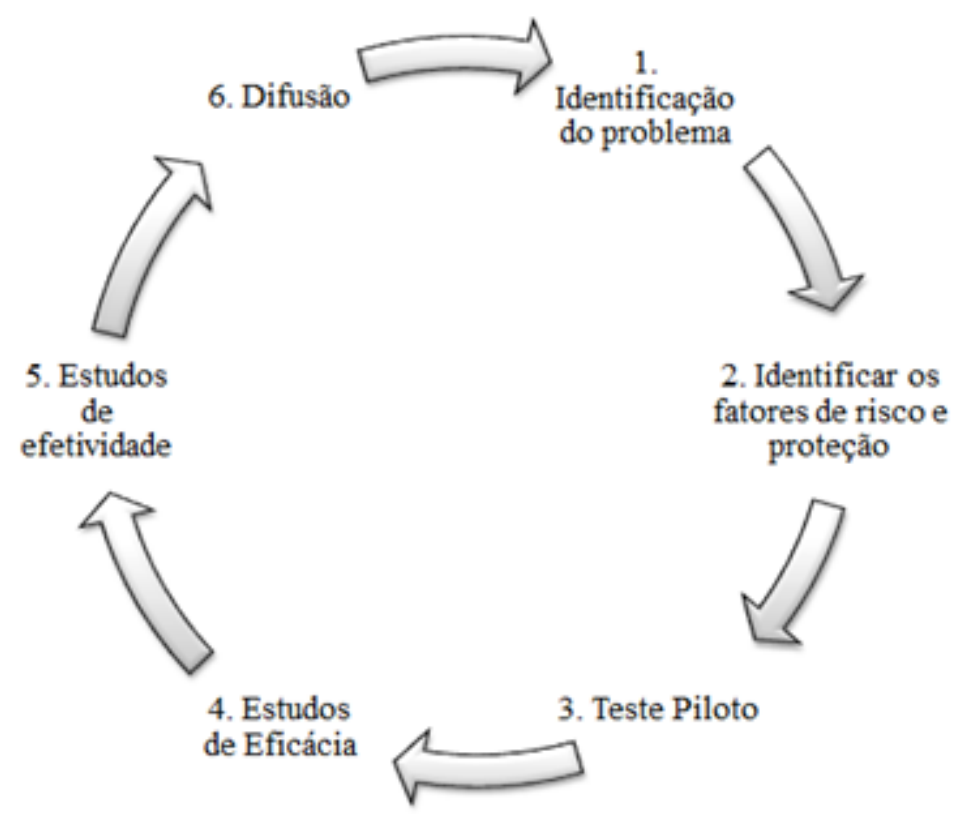

Figura 2. Representação gráfica das etapas do ciclo de prevenção

No Brasil, tem-se percebido que ainda são escassos programas que chegam às últimas fases do ciclo de pesquisa em prevenção, quais sejam, estudos de eficácia, efetividade e difusão. Em revisão sistemática da área, Abreu (2012) encontrou 256 artigos que tinham por tema estudos de fundamentação, ou seja, artigos conceituais, pesquisa básica, ou revisão de literatura quanto ao tema prevenção, representando 68,45\% das pesquisas em saúde mental. Foram também encontrados 31 artigos que abordavam programas de prevenção, destes, apenas 11 apresentaram resultados avaliados sistematicamente, de forma a representar $2,94 \%$ da produção nacional em saúde mental. Nesta revisão, nenhum artigo foi encontrado relativo à difusão de programas preventivos. Porém, na literatura brasileira tem-se notícia do estudo de Melo (citado por Melo \& Izbini, 2015) em que o tema foi trabalhado em tese de pós-doutoramento da primeira autora. 
Similarmente, no estudo de Canolleti e Soares (2004), cujo objetivo era o de analisar sistematicamente publicações sobre a prevenção do consumo de drogas no período de 1991 a 2001, encontrou 122 artigos, sendo 94 referentes à orientação sobre drogas e 28 descrevendo desenvolvimentos de projetos. Dos 28 artigos encontrados grande parte se utilizavam de dinâmicas de grupo e discussão (oito artigos cada), oficinas (sete), elaboração de material informativo (seis), jogos (quatro), entre outras iniciativas. A hipótese do estudo era a de que a preocupação com o tema das drogas veio a partir da epidemia de Aids na década de 1990. Até essa data pouco se estudava sobre o tema. Por conta da ausência de estudos na área, difundiram-se diversos equívocos sobre as drogas, além de negligência e descaso do Estado. A partir dos estudos sobre HIV/Aids começouse a inserir usuários de drogas em programas de prevenção, mas com o objetivo de conter a epidemia de transmissão de HIV.

Tendo isso em vista, o presente estudo vem ao encontro dos estudos de Abreu (2012) e Canolleti e Soares (2004) buscando situar o estado da arte da pesquisa em prevenção ao abuso de substâncias entre adolescentes nos anos de 2001 a 2015.

Para o presente estudo, considerou-se como problema de pesquisa as seguintes perguntas: (1) como se distribui a literatura científica nacional relativa à prevenção primária ao abuso de álcool e outras drogas entre adolescente nas fases do ciclo de pesquisa em prevenção entre os anos 2001-2015? (2) Quais as principais características dos estudos encontrados em cada uma das etapas do referido ciclo?

\section{Método}

Foi realizada uma revisão integrativa da literatura nacional referente às etapas do ciclo de pesquisa em prevenção com foco em estudos sobre prevenção do abuso de álcool e outras drogas entre adolescentes entre os anos 2001-2015. 


\section{Seleção dos artigos}

O processo de seleção dos artigos consistiu na busca de artigos nacionais, publicados em revistas indexadas nas plataformas SciELO, PubMed, BVS, PsyInfo. As palavras-chave utilizadas para identificação dos fatores de risco e proteção foram: "fatores de risco" OR "fatores de proteção" AND "abuso/uso de substâncias" OR “drogas” OR “álcool”.

Para a busca de artigos de programas de prevenção, as seguintes palavras-chave foram utilizadas: "fatores de risco", "fatores de proteção", "abuso/uso de substâncias", “drogas", “álcool”, “abuso de drogas", “uso indevido de substâncias”, "uso indevido de substâncias", “drug abuse", “substance abuse", “desenvolvimento de programas", “prevenção primária”, “avaliação de programas”, “program evaluation”, “program development", "health promotion primary", “adolescente", “juventude”, “adolescent", "Brazil".

\section{Critérios inclusão e exclusão}

Os critérios de inclusão foram: artigos referentes a programas de prevenção primária do uso de drogas; intervenções psicossociais, educacionais ou familiares; restrito à adolescência, definida pela faixa etária compreendida entre 10 a 19 anos (World Health Organization, 2015); e ser referentes a estudos publicados entre os anos 2001 a 2015.

Os critérios de exclusão foram: programas referentes à prevenção ao HIV/AIDS e outras doenças correlatas ao uso de drogas; transtornos mentais associados ao uso de drogas; intervenções para tratamento com usuários de drogas; resenhas; intervenções/tratamentos relacionados ao uso de drogas; programas de prevenção em áreas diversas à saúde como gestão de agronegócios; intervenções em prevenção secundária ou terciária com o uso de tecnologias biomédicas de intervenção; e estudos que associem prevenção a tratamento (Abreu, 2012). 


\section{Procedimentos de extração dos dados}

Os critérios de análise foram: caracterização do problema e sua prevalência (estudos teóricos, conceituais, de levantamento de dados, epidemiológicos que buscam identificar o problema e sua frequência); fatores de risco e proteção (artigos que tratam das condições que favorecem ou aumentam a vulnerabilidade da população para determinada doença); estudos piloto (artigos que versam sobre o desenvolvimento de uma inovação, podendo ser relatos de pesquisa ou pesquisas pré-experimentais); estudos sobre eficácia e efetividade dos programas (estudos que analisam a implementação de programas preventivos por meio de estudos experimentais ou quase-experimentais); e difusão (estudos que analisam a expansão de um programa para outros contextos). A busca e análise foram realizadas por duas pesquisadores treinadas na área.

\section{Resultados e Discussão}

Nessa revisão foram encontrados 93 artigos. Desses, 40 foram analisados após a verificação dos critérios de inclusão e exclusão, dos quais nove foram classificados como caracterizando o problema e sua prevalência; 23 se referiam a fatores de risco e proteção; seis tratavam de programas de prevenção; um artigo correspondia a um estudo quaseexperimental, e uma revisão sistemática. Nenhum artigo encontrado correspondeu à fase de difusão. A Figura 1 sumariza esses dados. 


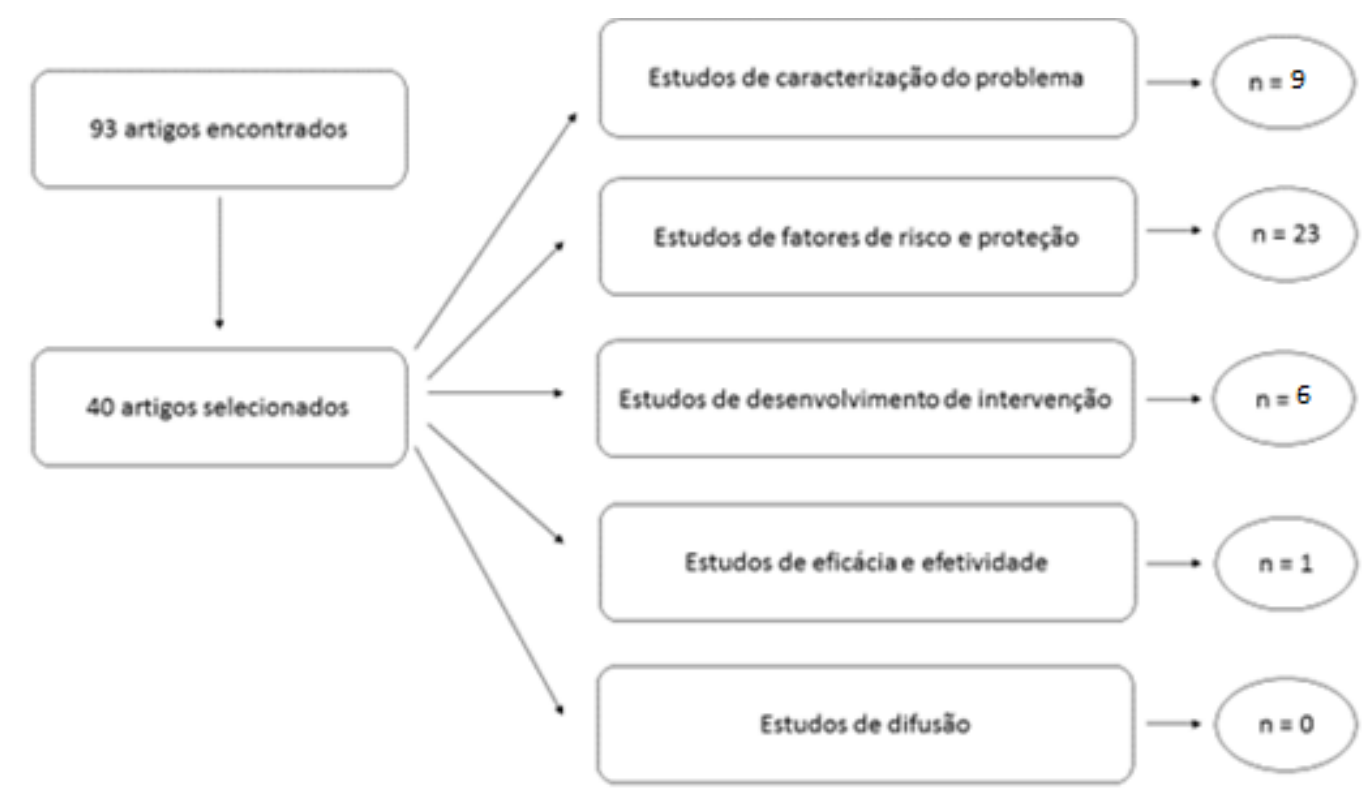

Figura 2. Ciclo da pesquisa em prevenção do abuso de drogas

\section{Caracterização do problema e sua prevalência}

A Tabela 2 apresenta resultados para os padrões de uso de drogas entre adolescentes encontrados em levantamentos de dados. Percebe-se um padrão de uso de álcool entre adolescentes variando de $60,5 \%$ a 79,6\% para uso na vida. Para uso frequente há dados com variação significativa, em que Malta et al. (2011) encontram uma prevalência de 27,3\%, enquanto Teixeira et al. (2009) e Carlini et al. (2010) encontram uma média de 2,4\% e 2,7\%. Malta et al. (2011) e Locatelli et al. (2011) encontraram dados elevados para binge drink (cinco doses ou mais de álcool por vez). O uso de outras substâncias psicoativas, como maconha, cocaína, crack, solventes, LSD, entre outros, teve uma margem de uso na vida entre 25,5\%, nos estudos de Carlini et al. (2001) e 15,2\% nos estudos de Teixeira et al. (2009). 


\section{Tabela 2.}

Resultados para os padrões de uso de drogas entre adolescentes encontrados em levantamentos de dados

\begin{tabular}{|c|c|c|c|c|c|c|c|c|c|c|}
\hline Autor e ano & Participantes & Idade & Onde & Substância & Uso na vida & Uso no ano & $\begin{array}{c}\text { Uso no } \\
\text { Mês }\end{array}$ & $\begin{array}{c}\text { Uso } \\
\text { Frequente }\end{array}$ & Uso pesado & Binge drink \\
\hline $\begin{array}{l}\text { Baus, Kupek e } \\
\text { Pires, } 2002\end{array}$ & 478 & 13 a 18 anos & $\begin{array}{c}\text { Florianópolis } \\
\text { SC }\end{array}$ & Álcool & $86,60 \%$ & & & $24,20 \%$ & & \\
\hline \multirow{2}{*}{$\begin{array}{l}\text { Carlini et al, } \\
2010\end{array}$} & \multirow{2}{*}{50.890} & \multirow{2}{*}{10 a 19 anos } & \multirow{2}{*}{$\begin{array}{l}27 \text { capitais } \\
\text { brasileiras }\end{array}$} & Álcool & $60,50 \%$ & $42,40 \%$ & $21,10 \%$ & $2,70 \%$ & $1,60 \%$ & \\
\hline & & & & $\begin{array}{l}\text { Outras } \\
\text { drogas }\end{array}$ & $25,50 \%$ & $10,60 \%$ & $5,50 \%$ & $0,80 \%$ & $1,10 \%$ & \\
\hline Malta et al, 2011 & 60.973 & $\begin{array}{l}\text { Alunos do nono } \\
\text { ano }\end{array}$ & $\begin{array}{l}27 \text { capitais } \\
\text { brasileiras }\end{array}$ & Álcool & $71,40 \%$ & & & $27,30 \%$ & & $22,10 \%$ \\
\hline $\begin{array}{l}\text { Locatelli et al, } \\
2011\end{array}$ & 2.613 & 15 a 17 anos & São Paulo & Álcool & $88 \%$ & & $51 \%$ & & & $33 \%$ \\
\hline \multirow{3}{*}{$\begin{array}{l}\text { Lopes e } \\
\text { Rezende, } 2013\end{array}$} & \multirow{3}{*}{407} & \multirow{3}{*}{14 a 18 anos } & \multirow{3}{*}{ Maceió } & Álcool & $79,60 \%$ & $68,10 \%$ & $23,30 \%$ & $10,80 \%$ & $9,80 \%$ & \\
\hline & & & & Cigarro & $24,60 \%$ & $16,50 \%$ & $4,90 \%$ & $0,70 \%$ & $2,50 \%$ & \\
\hline & & & & Maconha & $4,70 \%$ & $2,20 \%$ & $0,20 \%$ & $0,20 \%$ & $0,50 \%$ & \\
\hline \multirow{2}{*}{$\begin{array}{l}\text { Nappo et al } \\
2012\end{array}$} & \multirow{2}{*}{50.890} & \multirow{2}{*}{$\begin{array}{l}\text { Alunos do ens } \\
\text { fund e médio }\end{array}$} & \multirow{2}{*}{$\begin{array}{l}27 \text { capitais } \\
\text { brasileiras }\end{array}$} & Crack & $0,60 \%$ & $0,40 \%$ & & & & \\
\hline & & & & Álcool & $60,50 \%$ & $42,40 \%$ & & & & \\
\hline $\begin{array}{l}\text { Vieira et al, } \\
2007^{\mathrm{a}} \\
\text { Vieira et al, } \\
2007 \mathrm{~b}\end{array}$ & 1.990 & 11 a 21 anos & Paulinia, SP & Álcool & $62,20 \%$ & $17,30 \%$ & & & & \\
\hline \multirow[b]{2}{*}{$\begin{array}{l}\text { Teixeira et al, } \\
2009\end{array}$} & \multirow[b]{2}{*}{415} & \multirow[b]{2}{*}{13 a 15 anos } & \multirow[b]{2}{*}{ Goianá, MG } & Álcool & $64,60 \%$ & $49,60 \%$ & $29,20 \%$ & $12,80 \%$ & $8,20 \%$ & \\
\hline & & & & $\begin{array}{l}\text { Outras } \\
\text { drogas }\end{array}$ & $15,20 \%$ & $9,40 \%$ & $5,10 \%$ & $2,40 \%$ & $2,20 \%$ & \\
\hline
\end{tabular}


Os estudos de Baus, Kupek e Pires (2002), Carlini et al. (2010), e Malta et al. (2011) constataram maior prevalência de uso de álcool e outras drogas entre estudantes de escolas privadas. Os dados apontaram uma prevalência de uso de álcool de 75,7\% para experimentação entre alunos de escola privada e 70,3\% entre estudantes de escola pública, porém com uso pesado maior entre alunos de escola pública $(0,8 \%$ alunos de escola particular e 1,2\% de uso entre estudantes de escola pública) (Carlini et al., 2010; Malta et al., 2011). O uso de outras drogas na vida (como maconha, cocaína, crack, inalantes e solventes) correspondeu a 30,2\% para alunos de escola particular e $24,2 \%$ de uso entre estudantes de escola pública (Carlini et al., 2010).

Esses dados são discutidos à luz da facilidade de recursos que os adolescentes de classes mais altas encontram para consumir as drogas. Além do mais, muitas vezes a experimentação ocorre no ambiente familiar, sendo oferecido pelos próprios pais, como o caso do álcool. Uma limitação encontrada nos estudos de Carlini et al. (2010), foi a ausência de alunos nas escolas públicas no dia da coleta de dados, além da questão da evasão escolar. Apesar disso, fica claro que o problema das drogas não atinge apenas uma classe social. Dessa forma, programas de prevenção devem considerar os diversos aspectos que envolvem o tema.

Outro dado encontrado foi que não houve diferença estatística significativa de uso entre gêneros, com um percentual maior entre meninos para uso de álcool e solventes e para meninas uma taxa mais elevada de uso de ansiolíticos e remédios para emagrecer (Baus, Kupek \& Pires, 2002; Carlini et al., 2010). Em relação à idade, apesar de o uso de drogas ser maior entre alunos acima de 16 anos (42,8\% de uso na vida), também foram constatados relatos entre estudantes de 10 a 12 anos (10,4\%). Alguns estudos (Carlini et al., 2010; Laranjeira, 2007) apontam que essa faixa é onde ocorre a primeira 
experimentação de drogas. No estudo de Laranjeira (2007), 78\% dos casos ocorreram antes dos 15 anos e $22 \%$, antes dos 10 anos.

Leis fracas, pouca fiscalização, escassez de programas preventivos são algumas das razões concluídas por Locatelli et al. (2011) para a alta incidência de abuso de substâncias entre os adolescentes no Brasil. De fato, o uso de substâncias não se restringe aos adultos, e está cada vez mais presente na vida dos adolescentes.

Estudos com levantamento de dados, em que os adolescentes são consultados sobre o uso de substâncias é uma etapa importante para a avaliação de necessidades, e assim a subsequente construção de metodologias de intervenção (Murta \& Santos, 2015). Os dados epidemiológicos trazem uma direção sobre onde o problema se encontra e qual a sua gravidade, permitindo assim um panorama de quais ações são necessárias.

\section{Fatores de Risco e Proteção}

A análise dos dados dos 23 estudos encontrados permitiu a categorização dos fatores de risco em três eixos principais: (1) indivíduo; (2) família e (3) comunidade. O eixo indivíduo traz fatores como ausência de habilidades sociais, baixa autoeficácia e baixa autoestima, curiosidade, sentimentos de solidão ou depressão e manejo social inadequado. O eixo família compreende a ausência dos pais na vida do filho; estilos parentais negligente, indulgente ou autoritário; vínculo pobre, apego inseguro; poucos momentos de lazer em família e ausência de diálogo franco. O eixo comunidade engloba a ausência de recursos oferecidos ao jovem, como poucos lugares para lazer, falta de oportunidades de trabalho e baixa perspectiva para a vida futura. A síntese desses fatores pode ser observada na Tabela 2, com o número de subcategorias por item e quantidade de ocorrências nos textos analisados. 
Tabela 2

Fatores de risco ao uso de drogas relacionados ao número de ocorrências nos textos analisados

\begin{tabular}{|c|c|c|c|c|c|}
\hline Individuais & Ocorrências & Familiares & Ocorrências & Comunitários & Ocorrências \\
\hline $\begin{array}{l}\text { Pressão por pares/ } \\
\text { pertencer a um grupo }\end{array}$ & 11 & Problemas familiares & 13 & $\begin{array}{l}\text { Pertencer a } \\
\text { comunidades } \\
\text { desfavorecidas/ } \\
\text { ausência de recursos }\end{array}$ & 8 \\
\hline $\begin{array}{l}\text { Ausência de } \\
\text { habilidades sociais }\end{array}$ & 5 & Vínculos Pobres & 11 & $\begin{array}{l}\text { Ausência de } \\
\text { informação }\end{array}$ & 5 \\
\hline Curiosidade & 3 & $\begin{array}{l}\text { Estilo parental } \\
\text { negligente, autoritário } \\
\text { ou indulgente }\end{array}$ & 10 & Mídia & 4 \\
\hline Problemas escolares & 2 & $\begin{array}{l}\text { Exemplo dos pais } \\
\text { e/ou responsáveis/ } \\
\text { pessoas próximas }\end{array}$ & 9 & Fácil acesso & 3 \\
\hline Não praticar esportes & 1 & $\begin{array}{l}\text { Pais que passam } \\
\text { pouco tempo com } \\
\text { filhos/negligência } \\
\text { familiar }\end{array}$ & 5 & $\begin{array}{l}\text { Empobrecimento } \\
\text { social }\end{array}$ & 1 \\
\hline $\begin{array}{l}\text { Ausência de sentido } \\
\text { na vida }\end{array}$ & 1 & & & $\begin{array}{l}\text { Falta de oportunidade } \\
\text { de lazer e trabalho }\end{array}$ & 1 \\
\hline
\end{tabular}

Macedo, Aygnes, Barbosa e Luís (2014), em um estudo qualitativo, grupos focais, com 19 estudantes do $7^{\circ}$ ano (até 12 anos) de uma escola pública de uma favela de Ribeirão Preto, SP, apontaram diversos fatores de risco ao uso precoce de drogas entre os adolescentes. Os jovens afirmaram que o primeiro contato com o álcool é em casa com os pais ou responsáveis. Esses jovens assistem aos familiares consumindo a substância e outras drogas cotidianamente, podendo acessá-las com facilidade nesses lugares, inclusive por incentivo dos pais (caso do álcool). Os adolescentes também convivem com as consequências do uso da droga em seu cotidiano, como morte por doenças relacionadas ao abuso de substância e violência por parte de traficantes e policiais, como mostra o relato de um dos participantes do estudo "eu já vi a polícia bater no meu pai [...] ele tava usando na hora que viram, amassou o portão da minha casa de tanto a polícia bater no meu pai" (p. 100). Ademais, os adolescentes relataram o problema da desigualdade social 
enfrentada, falta de oportunidade e de perspectivas de vida, violência cotidiana, entre outros problemas. Percebem as drogas como algo danoso, mas acaba sendo um caminho a seguir, por ausência de outros modelos de vida ou perspectivas de vida futura (Macedo et al., 2014). Como afirmado por uma jovem:

"Encheu de polícia ali na favela, onde morava, revistando a casa de todo mundo procurando meu primo. Então o meu primo estava dentro da casa da minha tia, ele teve que fugir, a polícia estava subindo eu vi o colega dele assobiando e eu assobiei e ele já correu, pulou a janela e caiu. Aí no dia seguinte ele me levou na pizzaria" (Macedo et al. 2014, p. 102).

Ao encontro desse estudo estão os achados de Costa, Camurça, Braga e Tatmatsu (2012). A pesquisa qualitativa com jovens (não especificam quantos) de 15 a 19 anos de Fortaleza, CE, consistiu na discussão em grupo focal, sobre os motivos que levam o jovem a usar drogas. Os adolescentes relatam que os fatores predisponentes ao uso seriam a influência do grupo em que está inserido (pressão por pares), conflitos familiares, uso pelos pais ou responsáveis, vínculos pobres, influência da mídia, com propagandas favoráveis ao uso ou que despertam a curiosidade, e informações superficiais. Esses jovens apresentam ainda o traficante como modelo de vida.

O estudo correlacional de Baus, Kupek e Pires (2002) descreveu a realidade de Florianópolis, em um estudo com 478 estudantes de escola pública de 13 a 18 anos. O questionário analisado apontou correlação entre o uso de drogas e separação dos pais, e que os problemas familiares na infância (que precedem e continuam com a separação) ocasionava o aparecimento de problema com as drogas e envolvimento com colegas. Também, nesse estudo, foi correlacionado alto uso de remédios para emagrecer entre adolescentes do sexo feminino. 
Ao encontro desses resultados estão os estudos de Benchava et al. (2011), Broecker e de Jou (2007), Claro et al. (2014), Domingues (2011), Ferreira (2013), Freire e Gomes (2012), Loyola et al. (2009) que afirmam ser o estilo parental ou problemas relacionados a vínculos familiares um desencadeante potencial para o uso de drogas. Esses autores apontam que quando os pais são permissivos demais ou autoritários e controladores, maiores são as chances dos filhos usarem drogas. A ausência de responsividade, empatia, limites, ou afeto levam os jovens a buscarem, nos amigos e nas drogas, o apoio que necessitam para enfrentar os problemas, ou uma forma de fuga aos conflitos.

Adicionalmente, a adolescência é uma fase em que o jovem está estabelecendo sua identidade. Quando os pais são autoritários ou permissivos, os jovens acabam não encontrando espaço para um diálogo franco sobre si e sobre o mundo que os cerca. É nessa fase também que os grupos de amigos se tornam mais importantes, e os jovens nem sempre têm habilidades para lidar com a pressão dos pares. Destarte, as drogas podem ser uma forma de entrada para um grupo. Sem apoio familiar e sem habilidades de autoeficácia, o uso de drogas pode se tornar um problema (Andrade, \& Ramos, 2011; Baus et al. 2002; Schenker \& Minayo, 2005)

Em sua revisão integrativa da literatura sobre crianças e adolescentes usuários de crack moradores de rua, Claro et al. (2014) apontam que para sobreviver, essas crianças e adolescentes acabam entrando no mundo das drogas por ausência de alternativas. Os indivíduos saem de suas casas em decorrência da miséria, abusos físicos, sexuais e psicológicos sofridos, problemas familiares e vínculos empobrecidos. Quando em situação de rua, precisam estar em grupo para sobreviver e, muitas vezes, o "rito de passagem" é o uso de drogas. Esses jovens vivenciam realidades de opressão e poucas perspectivas de mudança mesmo no antigo lar. Em resumo, não é a droga que leva a 
criança ou adolescente para a rua, é por estar na rua, e, pelos conflitos e sofrimentos que a levaram para lá, somado ao que vivenciam nesse ambiente que a criança ou adolescente usa a droga.

Outro fator de risco que não pode ser descartado é a mídia (Buchele, Coelho, \& Lindner, 2009; Costa et al., 2012). As propagandas despertam a curiosidade dos jovens e não mostram de fato a realidade do uso. Ou seja, as informações são ambíguas e pouco claras. De um lado, há propagandas que mostram o uso da cerveja como algo glorioso, que proporciona felicidade, amigos e relações afetivas. Por outro, apresenta nas novelas ou noticiários usuários de drogas que não estão de acordo com a realidade que vivenciam. Não mostrando de fato o porquê de aquela pessoa estar ali, se todas as pessoas que consomem drogas se tornam dependentes, e por que algumas se tornam dependentes e outras não. Os jovens estão em contato direto com usuários de drogas, mas nem sempre o que veem na mídia condiz com a realidade que vivenciam.

Por isso, também se faz tão importante considerar os fatores de proteção. Para o uso de drogas os fatores de proteção também podem ser divididos em três eixos: (1) habilidades pessoais (habilidades de vida), (2) família (estilos parentais e vínculos positivos) e (3) protagonismo juvenil. A compilação dos fatores de proteção encontrados nos textos analisados pode ser observada na Tabela 3. 
Tabela 3.

Fatores de proteção ao uso de drogas relacionados ao número de ocorrências nos textos analisados

\begin{tabular}{|c|c|c|c|c|c|}
\hline Individuais & Ocorrências & Familiares & Ocorrências & Comunitários & Ocorrências \\
\hline $\begin{array}{l}\text { Habilidades } \\
\text { interpessoais }\end{array}$ & 7 & $\begin{array}{l}\text { Suporte e apoio } \\
\text { familiar }\end{array}$ & 13 & $\begin{array}{l}\text { Informações claras } \\
\text { e crítica sobre } \\
\text { drogas }\end{array}$ & 4 \\
\hline $\begin{array}{l}\text { Autoeficácia/ Controle } \\
\text { emocional }\end{array}$ & 6 & $\begin{array}{l}\text { Bom relacionamento } \\
\text { com os pais }\end{array}$ & 11 & Práticas religiosas & 3 \\
\hline Habilidades sociais & 5 & $\begin{array}{l}\text { Suporte de pessoas } \\
\text { significativas/ } \\
\text { vinculos positivos }\end{array}$ & 10 & $\begin{array}{l}\text { Protagonismo } \\
\text { juvenil }\end{array}$ & 3 \\
\hline Sentido na vida & 4 & $\begin{array}{l}\text { Estilo Parental } \\
\text { autoritativo }\end{array}$ & 7 & $\begin{array}{l}\text { Programas } \\
\text { educativos }\end{array}$ & 3 \\
\hline Resiliência & 1 & & & $\begin{array}{l}\text { Trajetória } \\
\text { acadêmica } \\
\text { competente/ } \\
\text { sucesso acadêmico } \\
\text { Lugares de lazer }\end{array}$ & $\begin{array}{l}3 \\
2\end{array}$ \\
\hline
\end{tabular}

No quesito habilidades pessoais, os estudos apontam que quando o jovem apresenta autoeficácia, alta autoestima, resiliência e objetivo na vida, desenvolve em si um sentido mais forte de identidade própria alinhando-se assim a um desenvolvimento saudável. A identidade é um construto definido por três aspectos fundamentais: autoconceito, autoestima e autoeficácia (Rodriguez \& Damásio, 2014). O autoconceito refere-se aos elementos que a pessoa percebe como constituintes de sua individualidade. Ou seja, está relacionado a sobre como a pessoa se vê, se ela tem clareza e autoeficácia. Suas ações serão coerentes e suas decisões serão mais fáceis de serem tomadas quando seu autoconceito é coerente. A autoestima refere-se à avaliação do indivíduo sobre os elementos do autoconceito. Quando sua autoestima é alta, o adolescente não precisa validar constantemente seu comportamento. E, a autoeficácia é o grau de confiança, levando em conta os recursos, habilidades e crenças, que o indivíduo tem para alcançar suas metas. Quanto mais coesa for a sua identidade mais o adolescente se engajará em comportamentos coerentes com essa identidade (Erikson, 1976; Rodriguez \& Damásio, 2014). 
Tendo uma identidade coesa, o adolescente apresenta uma maior percepção de sentido na vida, buscando assim se comportar de forma a atingir seus objetivos. $\mathrm{O}$ abuso de drogas, então, se apresentaria como um empecilho aos seus projetos. Quando o adolescente tem objetivos e planos para o futuro, e atitudes positivas frente à vida, há uma menor probabilidade de se envolverem em problemas complexos (Costa et al., 2012; Ferreira, 2013). "Não precisa você usar droga pra você tá bem" afirmou um jovem na pesquisa de Costa et al. (2012, p. 806).

A família, como ambiente em que o desenvolvimento do adolescente ocorre, pode ser tanto um fator de risco como de proteção. Nela se observa um contexto favorável para que o diálogo sobre as drogas aconteça e tenha significado. É no ambiente familiar que as principais trocas afetivas acontecem. $\mathrm{O}$ apoio e o suporte percebido pelo adolescente advindo de seus familiares o protege contra fatores de risco, pois oferece oportunidade e espaço para trocas e a abertura a pedir ajuda. Além disso, diálogo e vínculos fortes são promotores de autonomia, autoafirmação e qualidade de vida, o que levam os adolescentes a evitarem comportamentos de risco (Benchava et al., 2011; Costa et al., 2012; Domingues, 2011; Freire \& Gomes, 2012; Loyola et al., 2009; Sanches, Oliveira, \& Nappo, 2005).

Os estilos parentais também afetam a probabilidade de o adolescente ter ou não problemas devido às drogas. $\mathrm{O}$ estilo parental autoritativo, que seria aquele em que os pais impõem limites ao filho com responsividade e amor, está associado a comportamentos mais saudáveis dos jovens (Baus et al., 2002; Benchava et al., 2011, Broecker \& de Jour, 2007, Freire \& Gomes, 2012). Esse estilo parental é caracterizado pela combinação de controle e responsividade. Como apresentado por Freire e Gomes (2012), corresponde ao estabelecimento de regras e limites claros, combinado a diálogo, 
monitoramento e supervisão, apoio e negociação. Esse estilo parental se correlaciona a uma relação de confiança e respeito entre pais e filhos.

As práticas religiosas são também tidas como fator de proteção do uso de drogas. Sanches e Nappo (2007), em sua revisão da literatura, apontam que pessoas que frequentam algum culto religioso e professam os princípios da religião apresentam menores índices de consumo de drogas. Corroborando esses dados, o estudo qualitativo de Sanches, Oliveira e Nappo (2005), com 62 participantes de 16 a 24 anos, de classe socioeconômica baixa, apresentam que a religião propõe aos fiéis reflexões sobre as consequências das drogas. A religião também é vista como algo que fortalece o indivíduo e auxilia na construção da identidade dos indivíduos que professam a sua fé. "O importante é que a religião ajuda a pessoa a desenvolver seu caráter, aprender coisas certas aí ela vai saber escolher melhor" relatou um dos participantes da pesquisa (p. 50).

Por fim, pode ser citado o protagonismo juvenil, que corresponde as oportunidades que os adolescentes apresentam em sua vida. Estão incluídas oportunidades de lazer, trabalho, participação em grêmios estudantis ou movimentos juvenis, grupos de dança ou música. Essas práticas inspiram os jovens a terem metas e sentido na vida (Costa et al., 2012; Loyola et al., 2009; Macedo et al., 2014).

Como apresentado anteriormente, o álcool e outras drogas estão inseridas no cotidiano dos jovens, seja pela experimentação, seja pelo uso abusivo. Porém, o uso da droga por si só nem sempre representa um risco. O risco, como definido por Schenker e Minayo (2005), é "uma consequência da livre e consciente decisão de se expor a uma situação na qual se busca a realização de um bem ou de um desejo, em cujo percurso se inclui a possibilidade de perda ou ferimento físico, material ou psicológico" (p. 708). O risco corresponde às consequências potenciais de uma situação real ou possível que poderão produzir efeitos adversos à saúde e desenvolvimento desse adolescente. 
Dessa forma, analisar os fatores de risco e de proteção corresponde a uma análise dos preditores de agravamento potencial de uma situação por esta estar associada ao uso de álcool e outras drogas que podem repercutir no desenvolvimento do indivíduo. Ou seja, não é o uso da droga em si que predispõe ao risco, mas como esse uso é feito (uso abusivo ou recreativo) e por que é feito (fuga de uma realidade estressante, problemas familiares, pressão por pares).

Por isso, também, a necessidade de analisar os fatores de proteção. Proteção como a oferta de condições de crescimento, de desenvolvimento e fortalecimento (Schenker \& Minayo, 2005). Ao dar ênfase nos fatores de proteção, busca-se compreender os fatores que são importantes para o desenvolvimento do bem-estar individual, familiar ou comunitário. Dessa forma, valorizando aspectos que auxiliam na autoeficácia, autoestima, e senso de bem estar (Mrazek \& Haggrty, 1994). Entender os fatores de proteção proporciona uma mudança do olhar, não partindo da doença, mas do que é saudável, e assim retira-se o foco do negativo, passando para o que é positivo.

\section{Desenvolvimento de inovação/ Estudos Piloto}

Dos estudos encontrados sobre essa fase do ciclo de pesquisa em prevenção dois corresponderam a descrição de oficinas de trabalho; quatro se utilizaram de pesquisaintervenção, um tratando de discussão de caso, outro sobre a utilização de um jogo, os outros dois apenas afirmaram se tratar de oficinas de trabalho, mas não discutiram qual metodologia utilizaram, descrevendo as dificuldades enfrentadas na execução das oficinas. São apresentados a seguir três exemplos de estudos analisados.

O estudo de Corradi-Webster, Esper e Pillon (2009) apresentou a oficina de trabalho com jovens de 15 a 17 anos em situação de vulnerabilidade social. As atividades eram realizadas durante um ano e correspondiam a discussões temáticas e ações que os jovens desenvolviam em sua comunidade. Porém, o estudo não apresentou nenhum dado 
sobre o resultado da oficina na vida dos jovens. A proposta trazida eram oficinas sobre drogas, em que objetivavam-se levantar informações sobre substâncias psicoativas, utilizando o jogo "Tipos de drogas", no qual os participantes deveriam falar o nome das drogas que conheciam. O segundo encontro explorava habilidades de enfrentamento, com a oficina "Por que os jovens usam drogas?". O terceiro encontro foi realizada a oficina "Mito e fato". O quarto encontro trabalhou o tema sexualidade. O quinto, oficina sobre propaganda, em que os adolescentes propuseram mudança das propagandas, para tirar as mulheres bonitas e colocar mulheres gordas e feias (não foi exposto como a facilitadora trabalhou os resultados que envolveu preconceito e conteúdo sexista). O sexto encontro trouxe o tema saúde. O sétimo, um júri simulado sobre violência. O oitavo e nono trabalharam projeto de vida. E os encontros finais foram para elaborar uma ação na comunidade.

Já o trabalho de Costa et al. (2013) trouxe um modelo de seis etapas que poderia ser utilizado para a prevenção do abuso de drogas. Essas etapas seriam (1) contato inicial e planejamento da intervenção; (2) diagnóstico e mapeamento; (3) sensibilização; (4) capacitação dos agentes comunitários; (5) acompanhamento e (6) devolutiva. No texto não fica claro como seria desenvolvido o programa, apenas explicita a necessidade de planejamento junto à comunidade. $\mathrm{O}$ texto apresenta como resultados os dificultadores e facilitadores de implementação de programas nas comunidades. Os pontos facilitadores são a participação dos agentes comunitários na aplicação, organização e planejamento das práticas, e a realização de práticas educacionais e preventivas nas escolas e comunidades. Os aspectos que dificultam a implementação de programas residem na falta/insuficiência de recursos, ausência de intersetorialidade, falta de mobilização comunitária.

O trabalho de Monteiro, Vargas e Rebello (2003) traz o relato de experiência advindo do Jogo da Onda. Esse jogo, projetado para ser jogado em dupla, apresentava 
diversos temas relacionados ao uso de drogas, como conceitos, efeitos, legislação, políticas preventivas, relacionamento familiar e amoroso, práticas sexuais, conflitos pessoais, Aids, pressão social, entre outros. As temáticas são abordadas por meio de perguntas e respostas, mensagens e situações cotidianas. A avaliação realizada pelos pesquisadores consistiu na observação do alcance das mensagens veiculadas ao material, das trocas de experiências proporcionadas pelo jogo, a aquisição de conhecimento e reflexão sobre os temas. Essa avaliação foi realizada por meio de grupo focal, observação direta e questionário. A pesquisa foi realizada com 62 adolescentes e 17 educadores.

Os artigos encontrados se apresentaram pouco descritivos em relação a sua metodologia e sobre como os temas foram trabalhados. Também há uma ausência na avaliação dos resultados das oficinas ou jogos. A avaliação é um mecanismo fundamental para se contextualizar se os objetivos da intervenção foram ou não alcançados.

\section{Testes de eficácia e efetividade}

O estudo encontrado sobre avaliação de efetividade de um programa foi realizado por De Michele, Firsberg e Formigoni (2004). O estudo quase-experimental contou com a participação de 99 adolescentes que buscaram atendimento médico em um serviço ambulatorial. Os adolescentes foram divididos em usuários no último mês (UM) e não usuários no último mês (NUM). Cada um desses grupos foi divido em grupo controle (COUM e CONUM) e grupo experimental. O grupo UM recebeu Intervenção Breve e o grupo NUM recebeu orientação preventiva. Após seis meses foi realizado um follow-up para verificar se os resultados se mantinham, constatando-se a efetividade da sessão única na prevenção ao abuso de substâncias.

\section{Difusão}

Nenhum estudo sobre difusão foi encontrado a partir da pesquisa realizada. Oldenburg et al. (1999) discutem essa questão a partir de uma revisão realizada sobre a 
difusão de programas de promoção em saúde e identificaram uma lacuna na literatura sobre o tema. Percebeu-se a necessidade de se desenvolver estruturas empíricas básicas para se discutir e monitorar o processo de difusão de programas. Eles afirmam que os benefícios das estratégias de intervenção em saúde pública são determinados não apenas por sua eficácia e efetividade, mas também pela forma como a intervenção é conduzida, se favorece ou não a sua adoção e implementação, além do fato de se ela gera um impacto na saúde dos indivíduos, grupos ou comunidade e até mesmo na população como um todo.

Esse resultado é coerente com o momento histórico nacional. A área da prevenção no Brasil ainda é recente e o modelo vigente brasileiro ainda é o biomédico. Mas, essa perspectiva está mudando timidamente. Por isso, faz-se necessário a construção de metodologias que suportem a difusão de programas. Como afirmado por Bartholomew et al. (2011), os pesquisadores devem pensar na difusão do programa desde o seu desenvolvimento.

\section{Conclusões}

Este estudo teve por objetivo examinar o estado da arte da pesquisa em prevenção do abuso de substâncias no Brasil, situando-os no ciclo de pesquisa em prevenção. Conclui-se com esse estudo, primeiramente que há um alto índice de consumo de substâncias entre adolescentes, motivados principalmente por fatores tais como problemas familiares, carência de habilidades sociais, ausência de oportunidade de lazer e trabalho para os adolescentes. Segundo, como já apontado por Abreu (2012), são poucas as iniciativas em prevenção no Brasil, com poucas publicações que descrevem o desenvolvimento de intervenções e avaliações de resultado dessas iniciativas. Somado a 
isso, ainda resta pouco conhecimento sobre prevenção ao uso de drogas, haja vista o conteúdo abordado nas intervenções avaliadas por este estudo.

O problema das drogas é complexo e multifacetado. Por isso, inexiste uma solução única e fácil. Porém, existem direções quanto à solução. Na década de 1970 alguns estudos foram realizados (Carroll \& Meisch, 1979; Khavari, Peters, \& Baity, 1975; Nichols, Headlee, \& Coppock, 1956, citado por Alexander, Beyrstein, Hadaway, \& Coambs, 1981) em que, sobre determinadas condições (de isolamento), animais de laboratório preferiam soluções a base de opióides à água, levando os animais à morte prematura. Na década de 1980 Bruce Alexander e colaboradores (1981) reformularam esse experimento, em que alguns ratos foram deixados isolados e outros em colônia com outros ratos. Nos locais em que os ratos ficaram era possível que consumissem água ou uma solução com morfina. Ao final do estudo, os ratos isolados consumiram mais a solução com morfina do que aqueles que estavam em colônias. O estudo foi replicado, e denominado "ratolândia". Concluiu-se com esse experimento que a grande questão não era a substância que levava à dependência e morte, mas a ausência de outros recursos disponíveis no contexto do sujeito que levava ao consumo excessivo. Por isso, reduzir o problema aos componentes da substância perde-se o contato com todo um contexto que agrava o problema. Sendo assim, a análise e estudos sobre prevenção às drogas devem compreender todo o fenômeno que cerca o indivíduo.

A literatura nacional, constado a partir desta pesquisa, tem apresentado diversos estudos que caracterizam o problema, seus fatores de risco e proteção. Demonstrando o que o experimento da ratolândia descreve, mas de uma forma mais complexa. Com a pesquisa realizada percebe-se que os fatores de risco ao uso de substâncias estão relacionados à ausência de oportunidades aos jovens, tanto de lazer como de ocupação. 
Também, percebe-se ausência de habilidades, como assertividade, resolução de problemas, autocontrole, e um grande problema relacionado à família.

Por isso, vale destacar a necessidade de construção de programas preventivos que tenham em consideração esses fatores de risco e proteção e as características da população-alvo das intervenções, tendo em vista as poucas publicações sobre a construção de metodologias de intervenção. Ações voltadas às famílias, com o ensino de habilidades parentais e habilidades de vida para os filhos são uma alternativa à prevenção do uso de drogas, por exemplo.

Os limites do estudo correspondem a ser uma pesquisa restrita a adolescentes e ausência de uma análise mais extensa da literatura, com análise exclusiva de artigos científicos. Sabe-se que o padrão de uso entre outros públicos, como universitários, adultos, moradores de rua, são diferentes, e para cada público há uma demanda específica. A depender do público, muda-se a forma de lidar com o problema, a partir das necessidades específicas da demanda. A pesquisa bibliográfica, também, restringiu-se a revistas de saúde e psicologia, e não contemplou a análise de livros ou capítulos de livros, teses e dissertações. Além do mais, podem existir diversas ações que tenham sido realizadas no Brasil, porém, não são avaliadas de forma sistemática ou publicadas em revistas científicas, mas com resultados positivos, como é o caso de iniciativas como os projetos desenvolvidos pelo Centro Escrava Anastácia, do Instituto Pe. Vilson Groh (http://avea.conselheiros7.nute.ufsc.br/conteudo/webteca/modulos/politicas-publicas-

drogas). Deste modo, é recomendável que futuras revisões integrativas de literatura incluam novas fontes de consulta e outras populações para além da adolescência. 


\section{Referências}

Andrade, T. M. R., \& Ramos, S. P. (2011) Fatores de proteção e de risco associados ao início do uso de cannabis: revisão sistemática. SMAD: Revista Eletrônica Saúde Mental Álcool e Drogas, 7(2), 98-106.

Andrade, Duarte e Oliveira (2010) I Levantamento Nacional sobre o uso de álcool, tabaco e outras drogas entre universitários das 27 capitais brasileiras. Brasília: SENAD.

Baus, J.; Kupek, E., \& Pires, M. (2002) Prevalência e fatores de risco relacionados ao uso de drogas entre escolares. Revista Saúde Pública, 36 (1), 40-46.

Benchaya, M. C., Bisch, N. K., Moreira, T. C., Ferigolo, M., \& Barros, H. M. T. (2011) Non-authoritative parents and impact on drug use: the perception of adolescent children. Jornal de pediatria, 87(3), 238-244.

Broecker, C. Z.; \& de Jou, G. I. (2007) Práticas educativas parentais: a percepção de adolescentes com e sem dependência química. Psico-USF, 12 (2), 269-279.

Buchele, F., Coelho, E. B. S., \& Lindner, S. R. (2009) A promoção da saúde enquanto estratégia de prevenção ao uso das drogas. Ciência \& Saúde Coletiva, 14(1), 267-273.

Canoleti, B., \& Soares, C. B. (2004) Programas de prevenção ao consumo de drogas no Brasil: uma análise da produção cientifica de 1991 a 2001. Interface - Comunicação, Saúde, Educação, 9(16), 115-129.

Carlini, E. L. A., Noto, A. R.; Sanches, Z., Carlini, C. M. A., Locatelli, D. P. ... Moura, Y. G. (2010) VI Levantamento nacional sobre o consumo de drogas psicotrópicas entre estudantes do ensino fundamental e médio das redes pública e privada de ensino nas 27 capitais brasileiras. SENAD, Brasília - DF. $1^{\text {a }}$ ed. 
Cavalcante, M. B. P. T., Alves, M. D., \& Barroso, M. G. T. (2008) Adolescência, Álcool e drogas: uma revisão na perspectiva da promoção da saúde. Escola Anna Nery Enfermagem, 12 (3), 555-559.

Cerqueira-Santos, E., Melo-Neto, O., \& Koller S. H. (2014) Adolescentes e Adolescências In L. F. Habigzang, Diniz, E., \& Koller, S. H. (Eds.), Trabalhando com adolescentes: teoria e intervenção psicológica (pp. 17- 29). Porto Alegre: Artmed.

Chagas, F. G. L., \& Ventura, C. A. A. (2010) Cooperação Internacional em prevenção ao uso abusivo de drogas no Brasil. SMAD Revista Eletrônica Saúde Mental Álcool e Drogas, 6 (1), 1 -20.

Claro, H. G., Oliveira, M. A. F., Ribeiro, A. R., Fernandes, C. C., Cruz, A. S., \& Santos, E. G. M. (2014) Perfil e Padrão de uso de crack de crianças e adolescentes em situação de rua: uma revisão integrativa. SMAD Revista Eletrônica Saúde Mental Álcool e Drogas, 10(1), 35-41.

Corradi-Webster, C. M., Esper, L.H., \& Pillon, S. C. (2009) A enfermagem e a prevenção do uso indevido de drogas entre adolescentes. Acta Paulista de Enfermagem, 22(3), $331-334$.

Costa, P. H. A., Mota, D. C., Cruvinel, E., Paiva, F. S., \& Ronzani, T. M. (2013) Metodologia de implementação de práticas preventivas ao uso de drogas na atenção primária latino-americana. Revista Panamericana de Salud Publica, 33(5), 325- 331.

Costa, A. G., Camurça, V. V., Braga, J. M., \& Tatmatsu, D. I. B. (2012) Drogas em áreas de risco: o que dizem os jovens. Physis: Revista de Saúde Coletiva, 22(2): 803-819.

De Michele, D., Firsberg, M., \& Formigoni, M. L. O. S. (2004) Estudo da Efetividade da intervenção breve para o uso de álcool e outras drogas em adolescentes atendidos num serviço de assistência primária à saúde. Revista da Associação Médica Brasileira, 50 (3), 305-313. 
Domingues, A. E. (2011) Uso de drogas e estilos parentais percebidos na adolescência (dissertação de mestrado não publicada). Universidade Federal do Rio Grande do Sul. Rio Grande do Sul.

Erickson, E. (1976) Identidade: juventude e crise. Rio de Janeiro: Zahar. $2^{\mathrm{a}}$ ed.

Ferreira, V. R. T. (2013) Relato de uma experiência com adolescentes sobre o uso de drogas. Psicologia Teoria e Prática, 5(2), 47-54.

Freire, I. A., \& Gomes, E. M. A. (2012) O Papel da família na prevenção ao uso de substâncias psicoativas. Revista Brasileira de Ciências da Saúde. 16(1), 99-104.

Garcia, M. L. T., Leal, F. X., \& Abreu, C. C. (2008) A Política antidrogas brasileira: velhos dilemas. Psicologia e Sociedade, 20(2), 267-276.

Kessler, F., Von Diemen, L., Seganfredo, A. C., Brandão, I., Saibro, P., Scheidt, B., Grillo, R., \& Ramos, S. P. (2009) A psicodinâmica do adolescente envolvido com drogas. Revista de Psiquiatria RS, 25 (suplemento 1), 33-41.

Laranjeira, R., \& Romano, M. (2004) Brazilian consensus on public policies on alcohol. Revista Brasileira de Psiquiatria, 26 (supl 1), 68-77.

Locatelli, D., Sanchez, Z., Opaleye, E., Carlini, C., \& Noto, A. (2011) Socioeconomic influences on alcohol use patters among private school students in São Paulo. Revista Brasileira de Psiquiatria, 34, 193-200.

Lopes, A. P., \& Rezende, M. M. (2013) Consumo de substâncias psicoativas em estudantes do ensino médio. Revista Psicologia: Teoria e Prática, 16(2), 29-40.

Lopes, A. P., \& Rezende, M. M. (2013) Ansiedade e consumo de substâncias psicoativas. Estudos de Psicologia (Campinas), 30(1), 49-56. https://dx.doi.org/10.1590/S0103$\underline{166 \times 2013000100006}$

Loyola, C. M. D., Brands, B., Giesbrecht, N., Simich, N., \& Wright, M. G. M. (2009) Uso de drogas ilícitas e perspectivas críticas de familiares e pessoas próximas na 
cidade do Rio de Janeiro - Zona Norte, Brasil. Revista Latino-americana de Enfermagem, 17 (esp.), 817-823.

Macedo, J. Q., Aygnes, D. C., Barbosa, S. P., \& Luis, M. V. (2014) Concepções e vivências de estudantes quanto ao envolvimento com substâncias psicoativas em uma escola pública de Ribeirão Preto, São Paulo, Brasil. Ciencia y Enfermaria, XX(3), 95107.

Malta, D. C., Mascarenhas, M. D. M., Porto, D. L., Duarte, E. A., Sardinha, L. M. V., Barreto, S. M., \& Morais-Neto, O. L. (2011) Prevalência do consumo de álcool e drogas entre adolescentes: Pesquisa Nacional de Saúde Escolar. Revista Brasileira de Eidemiologia, 14(1) Supl, 136-46.

Malta, D. C., Porto, D. L., Melo, F. C. M., Monteiro, R. A., Sardinha, L. M. V., \& Lessa, B. H. (2011) Família e proteção ao uso de tabaco, álcool e drogas em adolescentes, Pesquisa Nacional de Saúde dos Escolares. Revista Brasileira de Epidemiologia, 14(1) Supl, 166-77.

Medeiros, P. F. P., Bezerra, L. C. A., Santos, N. T. V., \& Melo, E. O. (2006) Um estudo sobre a avaliabilidade do Programa + Vida: política de redução de danos em álcool, fumo e outras drogas do município de Recife, Brasil. Revista Brasileira em Saúde Materna e Infantil, 10 (supl. 1), s209-s217.

Monteiro, S. S., Vargas, E. P., \& Rebello, S. M. (2003) Educação, prevenção e drogas: resultados e desdobramentos da avaliação de um jogo educativo. Educação e Sociedade, 24 (83), 659-678.

Moreira, M. R., Fernandes, F. M. B., Ribeiro, J. M., \& Neto, T. L. F. (2015) Uma revisão da produção científica brasileira sobre o crack - contribuições para a agenda política. Ciência \& Saúde Coletiva, 20(4): 1047-1062. 
Moreira, A., Vólvio, C. L., \& De Micheli, D. (2015) Prevenção ao consumo abusivo de drogas na escola: desafios e possibilidades para a atuação do educador. Educação $e$ Pesquisa, 41(1), 119-135.

Moretti-Pires, R. O., Carrieri, C. G., \& Carrieri, G. G. (2008) O Estado frente à temática das drogas lícitas e ilícitas: avanços da nova legislação e desafios ao sistema único de saúde. SMAD Revista Eletrônica Saúde Mental Álcool e Drogas, 4(2), 1-13.

Mota, D. B., \& Ronzani, T. M. (2015) Implementation of public policy on alcohol and other drugs in Brazilian municipalities: comparative studies. Health \& Social Care. doi: $10.1111 /$ hsc. 12240

Mrazek, P. J., \& Haggerty, R. J. (1994). Reducing risks for mental disorders: Frontiers for preventive intervention research. Washington, National Academy Press.

Muñoz, R. F., Mrazek, P. J., \& Haggerty, R. J. (1996) Institute of Medicine Report on Prevention of Mental Disorders. American Psychologist.

Murta, S. G., Conceição, M. I. G., Abreu, S., Miranda, A. A. V., \& Correa, A. (2015) Prevenção ao abuso de álcool e drogas entre adolescentes no Brasil. In A. P. Gómez, J. M. Trujillo, E. B. Iglesias, De la prevención y otras historias. Corporación Nuevuos Rumbos. Bogotá: California edit.

Nappo, S. A., Sanchez, Z. M., \& Ribeiro, L. A. (2012) Is there a crack epidemic among students in Brazil? Cadernos de Saúde Pública, 28 (9), 1643-1649.

Oliveira, E. B., Bitteencourt, L. P., \& Carmo, A. C. (2008) A importância da família na prevenção do uso de drogas entre crianças e adolescentes: papel materno. SMAD Revista Eletrônica Saúde Mental Álcool e Drogas, 4(2), 1-16.

Oldenburg, B. F., Sallis, J. F., Ffrench, M. L., \& Owen, N. (1999) Health promotion research and the diffusion and institutionalization of interventions. Health Education Research, 14(1), 121-130. 
Paiva, F. S., \& Rodrigues, M. C. (2008) Habilidades de Vida: Uma estratégia preventiva ao consumo de substâncias psicoativas no contexto educativo. Estudos e Pesquisa em Psicologia, 8 (3), 672-684.

Pedroso, R. T., Abreu, S., \& Kinoshita, R. T. (2015) Aprendizagens da intersetorialidade entre saúde e educação na prevenção do uso de álcool e outras drogas. Textura, 33, 924.

PNAD (2005) Resolução Nº3/GSIPR/CH/CONAD, de 27 de outubro de 2005.

Pratta, E. M. M., \& Santos, M. A. (2013) Fatores de risco para o uso na vida e no ano de álcool entre adolescentes do ensino médio. SMAD Revista Eletrônica Saúde Mental Álcool e Drogas, 9(1), 18-24.

Rodriguez, S. N., \& Damásio, B. F. (2014) Desenvolvimento da identidade e do sentido de vida na adolescência In L. F. Habigzang, E. Diniz, \& S. H. Koller (Eds.), Trabalhando com adolescentes: teoria e intervenção psicológica (pp. 17- 29). Porto Alegre: Artmed.

Sanchez, Z. M., Oliveira, L. G., Ribeiro, L. A., \& Nappo, S. A. (2011) The role of information as a preventive drug measure among youth at risk. Ciência e Saúde Coletiva, 16 (Supl. 1), 1257-1266.

Sanchez, Z. M., \& Nappo, S. A. (2007) A religiosidade, a espiritualidade e o consumo de drogas. Revista de Psiquiatria Clinica, 34 (supl 1), 73-81.

Sanchez, Z. M., Oliveira, L. G., \& Nappo, S. A. (2005) Fatores protetores de adolescentes contra o uso de drogas com ênfase na religiosidade. Ciência e Saúde Coletiva, 9 (1), 43-55.

Sanchez, Z. M., Oliveira, L. G., \& Nappo, S. A.(2005) Razões para o não-uso de drogas ilícitas entre jovens em situação de risco. Revista Saúde Pública, 39(4), 599-605. 
Schenker, M., \& Minayo, M. C. S. (2005) Fatores de risco e de proteção para o uso de drogas na adolescência. Ciência e Saúde Coletiva, 10 (3), 707-717.

Silva, L. V. E. R., Malbergier, A., Stempliuk, V. A., \& Andrade, A.G. (2013) Fatores de risco que podem induzir o uso de drogas por estudantes de uma universidade pública. Revista Saúde Pública, 40 (2), 280-288.

UNODC (2014) Diretrizes internacionais sobre a prevenção do uso de drogas.

Ventura, C. A. A. (2011) Drogas lícitas e ilícitas: do direito internacional à legislação brasileira. Revista Eletrônica de Enfermagem, 13 (3), 554-559.

Vieira, D. L, Ribeiro, M., \& Laranjeira, R. (2007) Evidence of association between early alcohol use and risk later problems. Revista Brasileira em Psiquiatria, 29(3), 222-227 WHO (2015) Adolescent Health Research Priorities: Report of a Technical Consultation $\begin{array}{llll}13 \text { th } & \text { and } & \text { October } & 2015\end{array}$ (http://apps.who.int/iris/bitstream/10665/203564/1/WHO_FWC_MCA_15_07_eng.pdf? $\mathrm{ua}=1)$ 


\section{MANUSCRITO 2}

Difusão de programas preventivos em saúde mental: da produção à transferência de conhecimento. 


\section{Resumo}

Transtornos mentais causam incapacidades e mortes prematuras, além de representarem um custo psicológico, social e econômico elevados. Embora programas de prevenção e promoção em saúde mental com evidências de efetividade estejam disponíveis, são pouco difundidos mundo afora e, em particular, no Brasil. Este artigo tem o propósito de discutir a difusão de programas de prevenção e promoção em saúde mental, segundo as lentes da Teoria da Difusão de Inovações e desdobramentos contemporâneos. Ênfase será dada às etapas de disseminação, adoção, implementação e sustentabilidade. Implicações para o ensino, a pesquisa e a gestão neste campo são discutidas.

Palavras chave: Programas de prevenção; saúde mental; difusão; práticas baseadas em evidência. 


\begin{abstract}
Mental disorders cause disability and premature death, as well as representing a psychological, social and economic high cost. Although prevention and promotion programs in mental health with effectiveness evidence is available, they are less known worldwide particularly in Brazil. This article aims to discuss the dissemination of prevention and promotion programs in mental health, according to the lens of the Theory of Diffusion of Innovation and contemporary developments. Emphasis will be given to the dissemination's steps, adoption, implementation and sustainability. Implications for teaching, research and management in this field are discussed.
\end{abstract}

Keywords: Prevention Program; Mental Health; Diffusion of innovations; Evidence-based Practice. 


\section{Difusão de programas preventivos em saúde mental: da produção à transferência de conhecimento.}

Transtornos mentais causam incapacidades e mortes prematuras, além de representarem um custo psicológico, social e econômico elevados (Andrade et al., 2009, Hosman, Jané-llopis, \& Saxena, 2004, Mihalopoulos, Vos, Pirkis, \& Carter, 2011, Oliveira, 2012). Estima-se que 450 milhões de pessoas sofram de algum transtorno mental em todo o mundo e que esse número irá aumentar em 15\% até 2020 (Hosman, Jané-llopis, \& Saxena, 2004). No Brasil, estima-se que transtornos mentais graves são a causa de 21,5\% dos anos potenciais de vida perdidos da população. A depressão e o abuso de substâncias estão entre as principais causas de perda dos anos potenciais de vida entre mulheres e homens, respectivamente, com índices elevados de DALY ${ }^{1}$ (índice de anos perdidos de vida saudável) entre a população brasileira. A depressão é a primeira colocada entre mulheres com 25,2 DALY-por mil habitantes e o uso de substâncias a terceira colocada entre os homens (10,1 DALY por mil habitantes) (Leite et al., 2008). Por outro lado, uma saúde mental preservada permite ao indivíduo desenvolver suas potencialidades, enfrentar estresses cotidianos, trabalhar de forma produtiva e contribuir para a comunidade (WHO, 2010).

Além dos serviços de tratamento em saúde mental serem insuficientes para assistir a toda a população que deles necessita, apresentam custos econômicos consideráveis (Albee, 1982). Na Austrália, em 2003, os gastos com tratamento de doenças mentais chegaram a 5 bilhões de dólares, tendo uma projeção de um aumento de 12 bilhões em 2033 (Gross, 2008). A maior parte desse orçamento se deve aos custos decorrentes das inabilidades causadas pelos transtornos. $\mathrm{O}$ impacto econômico também é afetado pela baixa produtividade, custos para familiares e cuidadores, gastos judiciais, entre outros

\footnotetext{
${ }^{1} \mathrm{O}$ índice DALY combina os anos de vida perdidos por morte prematura e anos de vida perdidos em decorrência de se viver com alguma incapacitação ou deficiência (Mihalopulos et al., 2011)
} 
(Mihalopoulos et al., 2011). No Brasil, cenário similar ocorre. Em 2014, foram investidos aproximadamente 1 bilhão de reais nos Centros de Atenção Psicossocial e mais de 25 milhões com gastos hospitalares com pacientes psiquiátricos (Ministério da Saúde, 2015). Apesar disso, a rede de serviços de tratamento encontra-se ainda aquém das necessidades da população (Pitta, 2011).

Em contrapartida, resultados de revisões sistemáticas de literatura vem mostrando que é possível reduzir a incidência de transtornos mentais e assim reduzir custos econômicos decorrentes de transtornos mentais, além de minimizar o impacto emocional para familiares, cuidadores e pessoas envolvidas (Mihalopoulos et al., 2011; Scott, Knapp, Henderson, \& Maughan, 2001). Mihaloupoulos et al. (2011), em uma revisão da literatura em avaliação econômica de programas preventivos, encontraram evidências favoráveis a uma boa relação custo-benefício em 11 programas com esse foco, sobretudo os voltados para intervenções precoces para psicoses e prevenção à depressão em crianças e adultos, à ansiedade em crianças e ao suicídio. Esses achados indicaram que investimentos em prevenção são compensadores, tanto do ponto de vista ético como econômico, dado que os ganhos resultantes da prevenção, além de representarem substancial acréscimo em qualidade de vida, compensam largamente seus custos e estes são menos dispendiosos do que os investidos em tratamento.

Nesse sentido, a promoção de saúde mental e a prevenção a agravos em saúde mental são alvos não apenas desejáveis como urgentes. Entende-se por promoção de saúde mental ações dirigidas ao incremento de condições facilitadoras de saúde, desde as relativas aos determinantes sociais quanto aos determinantes pessoais. Dentre os determinantes sociais, incluem-se as condições de segurança, moradia, lazer, alimentação, trabalho, educação, pertencimento à comunidade e direitos associados à igualdade de oportunidades, independente de raça, orientação sexual, gênero, idade, 
nacionalidade etc. (Comissão Nacional sobre Determinantes Sociais da Saúde, 2008; Dahlgren \& Whitehead, 1991). Dentre os determinantes individuais, incluem-se a capacidade de estabelecer vínculos seguros, ativar a rede de apoio social, regular as emoções, lidar com estressores, perceber-se capaz de afetar o curso da própria vida, dentre outros (Kessler \& Albee, 1975).

A prevenção em saúde mental, por sua vez, consiste em ações dirigidas a evitar ou reduzir fatores de risco para desfechos negativos à saúde mental e aumentar a capacidade de enfrentamento desses fatores por meio do fortalecimento de fatores protetivos (Kessler \& Albee, 1975) pessoais (ex.: habilidades sociais), familiares (ex.: práticas parentais autoritativas), comunitários (ex.: bibliotecas e parques) e sociais (políticas públicas de incentivo à profissionalização e enfrentamento à violência de gênero). Há, portanto, estreita relação entre promoção de saúde mental e prevenção de agravos à saúde mental; a primeira é a via pela qual a segunda opera. Ao se promover saúde antecipadamente, agravos à saúde mental são prevenidos. Não se pode prevenir sem promover (Abreu, 2012).

De fato, evidências de revisões sistemáticas de literatura e meta-análises indicam que programas preventivos, sob condições adequadas de implementação e com conteúdo embasado em mediadores de mudança, são efetivos na redução de problemas em saúde mental, tais como abuso de álcool e drogas (Foxcroft et al., 2003; Lemstra et al., 2010), depressão (Horowitz \& Garber, 2006) e transtornos alimentares (Stice \& Shaw, 2004), bem como na redução de fatores de risco, como preconceito (Beelman \& Heinemann, 2014), violência pelo parceiro íntimo (Murta, Santos, Martins, \& Oliveira, 2013) e abuso sexual (Wals, Zwi, Woolfenden, \& Shlonsky, 2015). Adicionalmente, evidências apontam, para além da redução em desfechos negativos em saúde, o fortalecimento de fatores protetivos e desfechos positivos em saúde mental (Organización Mundial de la Salud, 2004). O 
inverso também tem sido constatado, sugerindo que programas destinados a promover competências são exitosos na prevenção de agravos à saúde mental. Consistentemente com isto, achados de uma meta-análise (Durlak, Weissberg, Dymnicki, Taylor, \& Schellinger, 2011) revelaram que a promoção de competências socioemocionais reduziram problemas de conduta e problemas internalizantes em crianças e adolescentes.

Embora evidências de efetividade estejam disponíveis, programas de prevenção em saúde mental baseados em evidências são pouco implementados mundo afora e, em particular, no Brasil. Pode-se indagar se tais programas ocupam pouco espaço na agenda de pesquisa ou espaço restrito na agenda das políticas de saúde nacionais. Quanto ao primeiro aspecto, um estudo de Abreu (2012) indicou que poucos são os programas de prevenção a fatores de risco e agravos em saúde mental publicados no Brasil, até o ano de 2012. Foram encontrados apenas 11 artigos avaliados de forma sistemática, o que sugere ser esta uma área ainda embrionária no país. Quanto ao segundo aspecto, ainda que historicamente restrita e com embates e retrocessos, parece crescente a percepção de relevância da prevenção na agenda das políticas públicas em saúde e seus determinantes, como evidenciado nas políticas sobre drogas (Política Nacional sobre Drogas, 2011), homofobia (Programa Brasil sem Homofobia, 2004), violência contra a mulher (Lei Maria da Penha, Lei 11.340/2006), racismo (Lei 7.716/1989) e bullying (PL 6725/2010).

Corroborando essa perspectiva, o relatório da Política Nacional de Gestão de Tecnologias em Saúde (2010) discute que ainda há necessidades profundas no momento atual brasileiro por maiores articulações entre os setores envolvidos na produção, incorporação e na utilização de tecnologias nos sistemas de saúde. Faz-se necessário que os gestores entrem em contato com as novas tecnologias existentes e assim construam processos políticos que contribuam para melhorias na saúde como um todo. 
Se as políticas públicas demandam isso, a transferência do conhecimento acadêmico para o mundo real ganha urgência. Uma das teorias que discute isso é a Teoria da Difusão de Inovações, desenvolvida por Everett Rogers na década de 1950 no contexto da agricultura. Ainda que reconhecido como autor dessa teoria, deve-se notar que Rogers não foi o primeiro a usar o termo difusão. Gabriel Tarde, um dos pais da sociologia e psicologia social, utilizava o termo para se referir às "leis da imitação" em 1903 na França. Esse autor investigava o fenômeno do aprendizado gerado por centenas de inovações concebidas ao mesmo tempo. Quando Rogers desenvolveu sua teoria, havia 405 publicações sobre o tópico (Rogers, 1962/1995; Rogers, 2004). Nas décadas recentes, esta teoria permanece sendo amplamente usada e aprimorada por outros autores, notadamente no campo da promoção de saúde (Bartholomew, Parcel, Kok, Glottlieb, \& Fernández, 2011, Wiecha et al., 2004).

Tendo isso em vista, o presente artigo tem o propósito de discutir a pesquisa em difusão de programas de prevenção em saúde mental, segundo as lentes da Teoria da Difusão de Inovações, a partir de Rogers e teóricos contemporâneos. O texto apresenta as seguintes subseções: (1) Teoria da Difusão, em que são descritos os conceitos e as diferenciações entre modelos teóricos; (2) as etapas do processo de difusão, em que são definidos os pontos principais e estudos sobre cada etapa; e (3) considerações finais.

\section{Difusão}

Difusão é definida como um tipo especial de comunicação, pois a mensagem a ser comunicada envolve novas ideias que representarão certo grau de incerteza para o indivíduo e/ou organização (Rogers, 1962/1995). Antes que um programa de prevenção a fatores de risco ou agravos à saúde mental possa ser difundido, um longo caminho de pesquisa precisa ser percorrido. A pesquisa em programas preventivos envolve diversas 
etapas. A primeira consiste na descrição de dimensões do problema-alvo, tais como prevalência e severidade. Estudos epidemiológicos e estudos qualitativos voltados para a compreensão do fenômeno são comuns nesta etapa. A segunda etapa compreende a análise de fatores de risco e de proteção do problema-alvo, quando estudos longitudinais e correlacionais podem ser realizados. A terceira etapa refere-se ao desenvolvimento de programas de intervenção embasados em estudos das etapas prévias. Estudos piloto voltados para a avaliação da validade social das inovações desenvolvidas são então realizados. Após essa fase, passa-se à investigação das evidências de eficácia e efetividade, quando a ênfase recai sobre os efeitos dos programas preventivos sobre a saúde (meta distal), ou seus fatores de risco e protetivos (metas proximais). Por fim, ao apresentar um potencial impacto à saúde pública, esse programa poderá ser difundido para um elevado número de pessoas (Mrazek \& Haggerty, 1994).

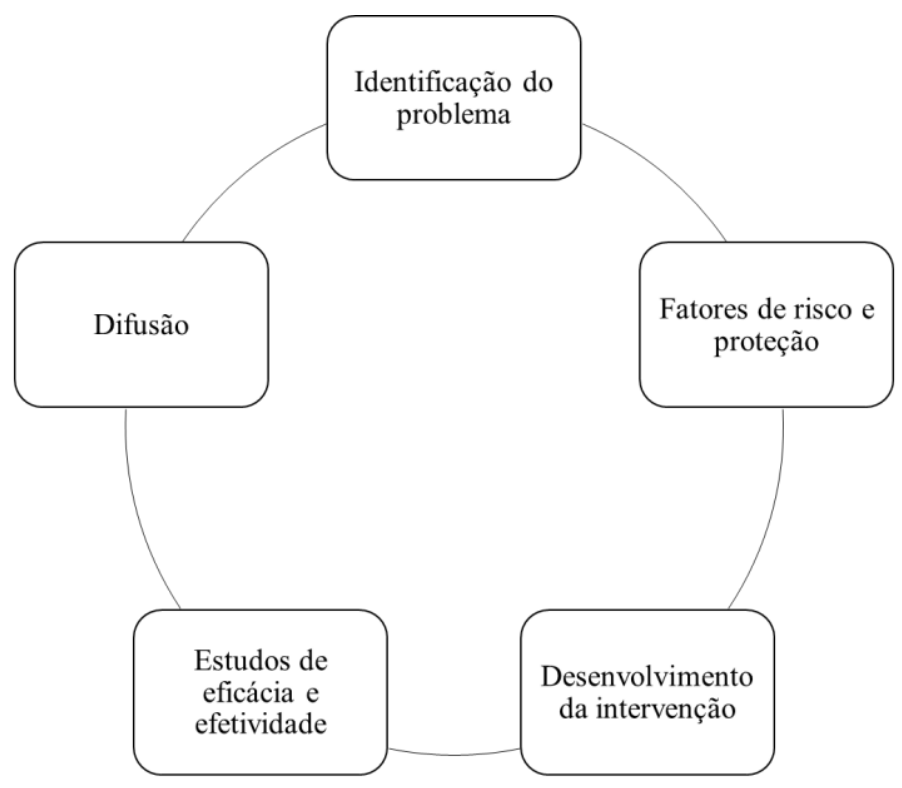

Figura 1. Ciclo da pesquisa em prevenção (baseado em Mrazek \& Haggerty, 1994).

Além das evidências de efetividade, outros requisitos são necessários para que um programa possa ser difundido para outros locais. Tais requisitos englobam componentes relacionados tanto ao programa em si, quanto a fatores econômicos (custo-benefício), 
sociais (quais problemas são percebidos pela sociedade como relevantes naquele momento) e políticos (ideologia do partido que está no poder, jogo de interesses entre os burocratas, soluções apresentadas, dentre outros). Pode-se prever que os programas percebidos como tendo melhor custo-benefício, estejam compatíveis com os interesses políticos vigentes e atendam aos problemas sociais vistos como prioritários seriam os melhores candidatos a serem difundidos. A título de exemplo, o governo dos Estados Unidos determinou o uso e difusão apenas de programas baseados em evidências nas escolas, argumentando a necessidade de confiabilidade dos resultados que se pretende atingir (Ozer, Wanis, \& Bazell, 2010). Ainda assim, deve-se notar que estudos voltados para verificação de evidências de efetividade são apenas uma das formas de se produzir conhecimento (Gottfredson et al., 2015), e tampouco devem ser considerados como a panaceia para as necessidades no campo da saúde mental.

A Teoria da Difusão de Inovações de Rogers prevê quatro elementos considerados essenciais para que a difusão aconteça: a inovação, os canais de comunicação, tempo e sistema social (Rogers, 1995). Esses elementos podem ser visualizados na Figura 2.

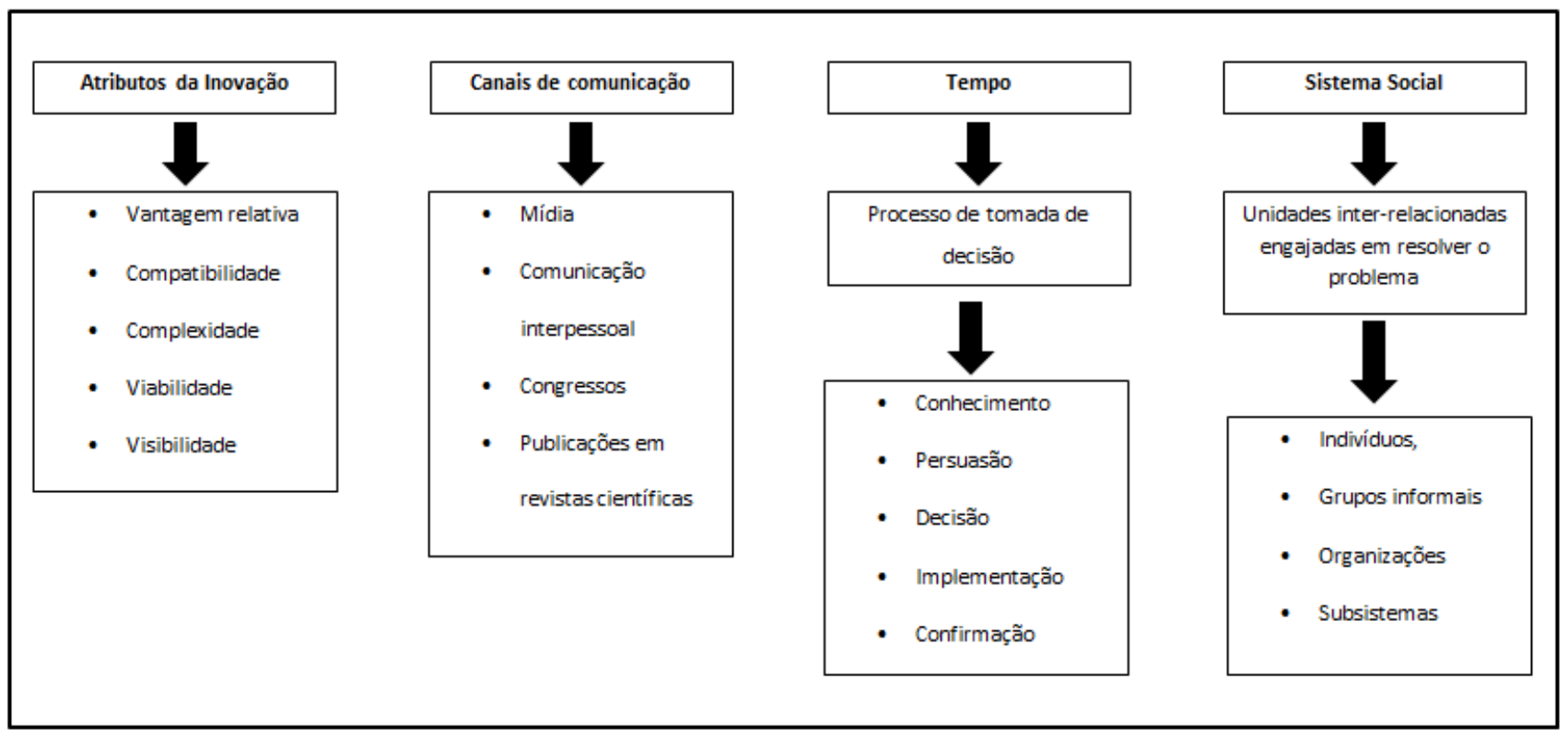

Figura 2. Elementos que caracterizam a difusão (baseado em Rogers, 1995/1962). 
O primeiro elemento, a inovação, pode ser definido como uma ideia, prática, programa, produto ou tecnologia que é percebida como nova pelo indivíduo, organização ou comunidade que a adota (Bartholomew et al., 2011; Meyers et al., 2012; Rogers, 1962/1995). Uma inovação, para ser adotada e implementada, deve incluir padrões bem definidos dos componentes críticos, ou elementos essenciais. Ao colocar uma inovação em prática deve haver monitoramento do processo e avaliação das atividades que serão realizadas. Quando transferida para outro local (como outra cidade, estado, país), a inovação deve ser adaptada àquela realidade (Meyers et al., 2012).

O segundo elemento, canal de comunicação, diz respeito ao processo pelo qual novas informações são compartilhadas (Rogers, 1962/1995). Para que a transferência de conhecimento seja efetiva é necessário que o conhecimento seja, primeiramente, transferido para os potenciais adotantes e seu uso encorajado. Também, é necessário motivar a institucionalização ou manutenção da inovação pelos adotantes (Stekler et al., 1991). Isso requer uma comunicação em que equipes competentes possam fazer a gestão, marketing, produtos (como guias e manuais do programa) e pesquisa avaliativa junto a diferentes atores envolvidos no processo (Bartholomew et al., 2011; Murta, 2011).

O terceiro elemento, tempo, envolve o percurso temporal em que ocorre a tomada de decisão, que vai desde o conhecimento da inovação à sua adoção ou rejeição. Conforme previsto na Teoria da Difusão de Inovações, essa decisão passa por cinco passos: conhecimento, persuasão, decisão, implementação e confirmação. $\mathrm{O}$ conhecimento ocorre quando o tomador de decisão é exposto ou entra em contato com a inovação. A persuasão se dá quando é formada opinião favorável (ou não) sobre a inovação. A decisão ocorre quando o tomador de decisão se engaja na atividade que leva a escolha ou rejeição pela inovação. A implementação tem lugar quando a inovação é utilizada. E, por fim, a confirmação ocorre quando há uma validação de aprovação ou 
rejeição do que já foi posto em prática, o que pode levar a sustentabilidade ou descontinuidade do uso (Rogers, 1983).

O programa \#Tamujunto/Unplugged, adotado no Brasil recentemente como estratégia embasada em evidências para prevenção do uso abusivo de drogas, pode servir como exemplo. Nesse programa, implementações prévias bem avaliadas já haviam ocorrido em diversos países europeus, africanos e asiáticos. Dessa forma, o UNODC levou ao conhecimento do Ministério da Saúde o programa, centrando-se em evidências de sua efetividade (conhecimento); uma visão favorável ao programa foi construída (persuasão) e o MS tomou então a decisão de implementá-lo no Brasil, haja vista os resultados positivos encontrados em realidades diferentes (decisão). A partir disso, deuse início em 2013 a adaptação cultural do programa, após implementação em três cidades diferentes no Brasil. E, em 2014 o programa foi expandido para mais oito novas cidades (implementação) (Pedroso, Abreu, \& Kinoshita, 2015; https://www.unodc.org/lpobrazil/pt/frontpage/2014/08/21-unodc-e-ministerio-da-saude-expandem-versaobrasileira-de-programa-de-prevencao-ao-uso-de-drogas-nas-escolas.html). O último elo, a confirmação (continuidade ou interrupção do programa), deverá esperar pela passagem do tempo para ser verificada.

E, por último, o sistema social, definido como o conjunto de esforços dirigidos a uma meta para se resolver um problema (Rogers, 1983). Os membros do sistema social podem ser formados por indivíduos, grupos informais, organizações ou subsistemas em que os membros cooperam para que um problema específico seja resolvido.

Dessa forma, o processo de difusão segue algumas etapas até seu resultado final: chegar a um maior número de pessoas, proporcionando mudanças sociais encorajadoras, ao longo do tempo. Estas etapas são didaticamente apresentadas por Rogers (1962/1995) como segue: adoção, implementação, disseminação e sustentabilidade. A adoção 
corresponde à fase de captação de parcerias, ou seja, quando a inovação é vista e escolhida pelo adotante, e há um compromisso firmado. A implementação incide em colocar a inovação em prática. A disseminação é definida como o processo de expansão do programa para os serviços dentro do mesmo sistema em que foi inserido. E, por fim, a sustentabilidade, refere-se à manutenção ou continuidade do programa, isto é, a inovação se transforma em rotina na instituição que a adotou.

Alguns autores contemporâneos na área da promoção de saúde apresentam uma inversão nessa ordem, a saber: disseminação, adoção, implementação e sustentabilidade (Bartholomew et al., 2011; Dearing, 2009; Durlak \& DuPre, 2008; Wiecha et al., 2004). A disseminação, segundo esses autores, é a fase em que há um planejamento sistemático para que o programa seja visto e disponibilizado para ser usado. As demais fases, adoção, implementação e sustentabilidade, são definidas tal como em Rogers (19662/1995). Neste artigo, optamos por adotar este modelo, já utilizado em pesquisas acerca do planejamento de programas de promoção de saúde (Bartholomew et al., 2011, Wiecha et al., 2004).

\section{Etapas do processo de difusão}

\subsection{Disseminação}

A disseminação pode ser conceitualizada como o estudo acerca de como as práticas, programas ou políticas baseadas em evidência podem ser divulgadas ou comunicadas para um setor social interorganizacional ou potenciais adotantes e implementadores para produzir resultados efetivos (Dearing, 2009). Os indivíduos ou organizações devem tomar consciência que um novo conhecimento, uma nova tecnologia exista e esteja disponível (Backer, David, \& Soucy, 1995). Essa etapa influencia o processo de difusão por meio de esforços calculados para a transferência ou compartilhamento de uma inovação de um lugar para outro (Stecker et al., 1992). 
Para se transferir conhecimentos é importante, primeiramente, conhecer, ser persuadido e tomar a decisão pela inovação. É necessário ainda apresentar as informações de forma a abarcar certas características do usuário em potencial (idade, sexo, raça, status socioeconômico) e de seu ambiente ou contexto (como as características da cultura local), de forma a demonstrar que a inovação será útil ao público. Ademais, é necessário prover assistência aos potenciais adotantes e fazer com que o novo conhecimento seja viável (Backer et al., 1995, Fox et al., 2004).

A maneira pela qual a intervenção ou programa é apresentado aos tomadores de decisão irá influenciar se os mesmos irão ou não adotar e implementar a intervenção. Por exemplo, Fox et al. (2004), em seu estudo sobre a disseminação do Strengthening Washington DC Families Program (SFP) nos EUA, apresentam a relevância social do programa para a comunidade, custo-benefício e formato das sessões como fatores pertinentes para a disseminação. Outros fatores apontados são referentes a como o programa se adapta ao contexto organizacional ou comunitário; experiências prévias por parte do contexto adotante na condução da implementação de outros programas; e como a intervenção é recebida pelos tomadores de decisão, isto é, se a nova tecnologia é vista como relevante para o local naquele momento (Fox et al., 2004).

Fatores adicionais apontados por Fox et al. (2004) incluem a necessidade de se fortalecer a estrutura organizacional dos locais que receberão o programa. Os autores afirmam que programas em prevenção são desafiantes em muitas áreas em que serão implementadas, pois o contexto adotante pode não estar familiarizado com esse tipo de inovação. Dessa forma, os pesquisadores devem estar preparados para conduzir trabalhos preliminares, como demonstrar a atratividade do programa para os destinatários em potencial. É igualmente recomendável um trabalho de convencimento, baseado em princípios éticos e técnicos, para que o programa seja percebido como gerador de 
benefícios-naquele local. Por isso, a tarefa da disseminação envolve empreendedorismo por parte do pesquisador, para fazer com que sua produção seja conhecida e julgada como útil e vantajosa.

Consistentemente com essas especificações, Sturza e Davidson (2006), em um estudo longitudinal para analisar o ciclo da pesquisa de um programa voltado para a prevenção de comportamentos antissociais em adolescentes, apontaram como fator relevante ser percebido como adequado, satisfatório pelo adotante e apresentar valor social. Esses fatores foram os que mais se destacaram como determinantes para o processo de disseminação do programa.

Logo, tomando-se esses achados em consideração, tenderá a ser mais persuasiva a disseminação de programas preventivos percebidos como socialmente relevantes, coerentes com as necessidades contextuais, adequadas à infraestrutura local, com menor complexidade, e menor custo e maior benefício. Antes disso, porém, caberá aos centros produtores de conhecimento dar visibilidade à inovação produzida e transpor a distância entre quem produz e quem consome o conhecimento, por meio da criação de canais de comunicação apropriados entre universidade e comunidade. Isso indica a necessidade de múltiplas formas de comunicação entre acadêmicos e sociedade, para além das formas tradicionais de comunicação aos pares.

\subsection{Adoção}

Programas preventivos, quando disseminados, podem ser ou não adotados. A adoção envolve uma escolha e, para tal, esse processo de decisão abarca diversos fatores, entre eles: se a inovação apresenta vantagem relativa (é melhor do que outras práticas usuais); se há compatibilidade de valores com a cultura local do adotante; se a inovação é difícil de ser compreendida ou usada, isto é, se é complexa; se os resultados são visíveis 
ou observáveis; e se ela é viável em sua implementação (Bartholomew et al., 2011; Rogers, 2002; Wiecha et al., 2004). A tecnologia também deve apresentar evidências de que ela será útil para a população-alvo e para aquele contexto em que será implementada (Backer et al., 1995).

Para compreender melhor esse processo, Backer et al. (1995) apresentam seis elementos-chave para a adoção, quais sejam: (1) Contato interpessoal: para que uma inovação seja usada em um novo contexto é necessário ser direto, com um contato pessoal entre aqueles que irão adotar a inovação e os desenvolvedores ou outros com conhecimento suficiente sobre a inovação. (2) Planejamento e previsão conceitual: uma estratégia bem desenvolvida sobre como a inovação será adotada no novo contexto, incluindo a possibilidade de problemas durante a implementação e como isso pode ser manejado. (3) Consultor externo no processo de mudança: um consultor pode proporcionar uma assistência conceitual e prática no delineamento da adoção ou adaptação, podendo oferecer objetividade sobre a probabilidade de sucesso, custo, possíveis efeitos colaterais entre outros. (4) Informação orientada para o usuário: o conhecimento sobre a inovação deve ser traduzido para uma linguagem acessível aos potenciais usuários em termos de benefícios esperados e como pode ser implementado. (5) Entusiasmo por parte das lideranças locais: a chance de sucesso da adoção de uma inovação é muito maior se potenciais adotantes influentes (líderes) expressam entusiasmo na adoção. (6) Envolvimento do usuário potencial: todos aqueles que irão conviver com os resultados da inovação devem estar envolvidos no planejamento da adoção do programa. Logo, estratégias participativas de envolvimento dos atores relevantes no contexto são preferenciais às unilaterais e impositivas.

É possível verificar dois fatores importantes no processo de adoção: um relativo à capacidade institucional e empreendedora do adotante, e outro relativo ao programa, se o 
mesmo apresenta evidências de efetividade. Tendo em vista que a efetividade pressupõe o custo-benefício do programa, percebe-se assim uma busca por soluções que também sejam estratégicas. Dessa forma, são considerados desde fatores orçamentários, práticas com melhor custo-benefício, até capacidade institucional de adoção, entre outros fatores.

A adoção de programas preventivos e de promoção de saúde pode ser prevista desde sua criação. Esta é a recomendação de Bartholomew et al. (2011), que defendem a posição de que desde o planejamento da intervenção os potenciais adotantes sejam incluídos na equipe responsável pelo desenvolvimento do programa. Nesta perspectiva, as equipes de pesquisadores que se ocupam do desenvolvimento de programas preventivos e de promoção de saúde devem se abrir para incluir também gestores ou profissionais "da ponta", potenciais implementadores do programa em desenvolvimento. A experiência no contexto e o conhecimento acumulado por gestores e profissionais da ponta podem indicar em que medida se alinham as características do programa, do contexto, dos adotantes e do público-alvo. Assim, a motivação, o interesse e a habilidade para adotar, implementar e manter a nova tecnologia já se fazem conhecidas desde a fase de desenvolvimento do programa. Barreiras à adoção podem ser antecipadas e resolvidas, minimizando as chances de que a inovação fique restrita aos laboratórios e bibliotecas das universidades ou centros de pesquisa. Em síntese, quanto mais os potenciais adotantes entenderem a intervenção e auxiliarem em sua construção, mais provável será a sua adoção posterior.

\subsection{Implementação}

Programas preventivos e de promoção de saúde adotados são, em seguida, implementados. A implementação é "a ciência de colocar ideias em ação” (Meyers, et al., 2012, p. 481). Essa fase acontece quando o programa é colocado em prática chegando aos 
usuários almejados. A implementação é, possivelmente, a etapa de maior complexidade, responsável pela efetividade e sobrevivência da inovação no novo contexto. Por isto, é desejável que a avaliação da qualidade da implementação seja conduzida sistematicamente a fim de informar a continuidade ou não do programa e, caso continue, seu ajustamento à realidade local (Dusenbury et al., 2005; Fagan, Hanson, Hawkins, \& Arthur, 2008). Avaliar a implementação é conhecer os aspectos da intervenção que foram entregues e quão bem eles foram conduzidos (Durlak \& DuPre, 2008). Dada a relevância da qualidade da implementação para os resultados do programa, alguns autores têm se empenhado em desenvolver medidas para avaliar a qualidade da implementação (Dusenbury et al., 2005; Fagan et al., 2008, Meyers; Katz et al., 2012).

A qualidade da implementação pode ser definida como o processo pelo qual uma inovação é colocada em prática de forma a manter os padrões necessários para se encontrar os resultados desejados ou esperados (Gerstner, \& Finney, 2013; Meyers, et al., 2012). A qualidade da implementação é caracterizada por oito fatores: fidelidade, dosagem, qualidade, responsividade, diferenciação, monitoramento, alcance e adaptação (Durlak \& DuPre, 2008). Esses componentes estão apresentados na Tabela 1.

A fidelidade é caracterizada por quão bem uma intervenção é implementada em comparação com o desenho original do programa (Kershner et al., 2014; O’Donnel, 2008), isto é, o que foi planejado foi executado? O que estava previsto no programa original foi colocado em prática? Se o que foi planejado não foi executado não é coerente esperar os resultados de eficácia e efetividade propostos pelo programa (Gerstner, \& Finney, 2013). Além do mais, só é possível uma análise de efetividade se há integridade (aqui posto como sinônimo de fidelidade) na implementação do programa. 
Tabela 1

Características da Implementação

\begin{tabular}{|c|c|c|}
\hline Dimensão & Definição & Outros rótulos \\
\hline Fidelidade & $\begin{array}{l}\text { Corresponde a se os componentes centrais do programa são } \\
\text { entregues como o indicado no protocolo do programa original }\end{array}$ & $\begin{array}{l}\text { Confiabilidade } \\
\text { Integridade } \\
\text { Replicação fiel }\end{array}$ \\
\hline Dosagem & $\begin{array}{l}\text { Refere-se ao número de sessões do programa que foram } \\
\text { disponibilizadas }\end{array}$ & $\begin{array}{l}\text { Quantidade } \\
\text { Força da intervenção }\end{array}$ \\
\hline Qualidade & $\begin{array}{l}\text { Refere-se a quão bem os componentes do programa foram } \\
\text { conduzidos }\end{array}$ & Competência \\
\hline Responsividade & $\begin{array}{l}\text { Refere-se ao grau em que o programa estimula o interesse ou prende } \\
\text { a atenção dos participantes. Refere-se a envolvimento e interesse } \\
\text { pelo programa }\end{array}$ & $\begin{array}{l}\text { Engajamento } \\
\text { Acompanhamento } \\
\text { Satisfação }\end{array}$ \\
\hline Diferenciação & $\begin{array}{l}\text { Refere-se ao que diferencia o novo programa, em sua teoria e } \\
\text { prática, dos programas já existentes }\end{array}$ & Singularidade do \\
\hline Monitoramento & $\begin{array}{l}\text { Refere-se a descrição da natureza e quantidade dos serviços que os } \\
\text { participantes da intervenção e o grupo controle receberam } \\
\text { (monitoramento de serviços adicionais que podem ter sido recebido) }\end{array}$ & $\begin{array}{l}\text { Escopo do programa } \\
\text { Contaminação } \\
\text { Serviços alternativos }\end{array}$ \\
\hline Alcance & $\begin{array}{l}\text { A extensão pela qual os participantes atendidos pelo programa são } \\
\text { representativos da população alvo }\end{array}$ & Taxa de participação \\
\hline Adaptação & $\begin{array}{l}\text { Adições ou modificações feitas no programa durante a } \\
\text { implementação }\end{array}$ & Modificação \\
\hline
\end{tabular}
Nota. Adaptado de Durlak e DuPre (2008) e Berkel, Maurício, Schoenfelder e Sandler (2011).

A dosagem é caracterizada pela exposição suficiente ao programa, em outras palavras, o quanto do programa original foi entregue aos participantes (Durlak \& DuPre, 2008, Dusenbury et al., 2005). Dos 59 estudos analisados por Durlak e DuPre, que identificavam aspectos especificamente relativos à implementação, 29 eram relativos à dosagem. Isso pode caracterizar uma correlação elevada entre dosagem e qualidade na implementação. Além disso, 76\% (45) apresentaram correlação positiva entre o nível da implementação e os resultados. Observa-se que a variabilidade no nível da implementação levava a resultados mais fracos ( 8 de 14 estudos).

A qualidade de processo está relacionada a como o programa é executado. E, pode ser medida pelo engajamento dos participantes ao programa e pela observação de como os seus componentes são executados e recebidos (Dusenbury et al., 2005). Para alguns autores, a qualidade é equivalente à aderência. E, ambas relacionam-se ao resultado de 
participação (Fagan et al., 2008). A qualidade pode ser medida pelo conhecimento e conforto em relação ao material, entusiasmo e estabilidade do programa (Kershner et al., 2013). Estão também relacionados ao apoio percebido pelos implementadores, pelos desenvolvedores, agência implementadora e comunidade. Fatores relacionados ao programa como baixa complexidade, alta flexibilidade, apoio institucional para aplicação, facilidade de implementação também se relacionam positivamente à qualidade. Por isso, o sucesso da implementação pode ser medido pelo treino fornecido, assistência técnica e supervisão do projeto (Fagan et al., 2008).

A responsividade pode ser definida como o nível de participação e entusiasmo demonstrado pelos participantes. Uma forma de ser medida é pela frequência dos participantes nas sessões, participação ativa nas atividades propostas, satisfação, e a prática das habilidades desenvolvidas nos contextos externos ao do programa (Berkel et al., 2011).

A diferenciação do programa está relacionada ao detalhamento das características específicas do programa que o distingue de outras intervenções usuais. Já o monitoramento é referente ao acompanhamento do programa, se os resultados que serão obtidos de fato são devido ao programa ou a outros fatores ou outras intervenções. O alcance direciona a se o programa está atingindo de fato o público-alvo; em outras palavras, qual o êxito do programa em chegar até os seus destinatários (Berkel et al., 2011; Durlak \& DuPre, 2008; Dusenbury et al., 2005; Fagan et al., 2008).

Por fim, a adaptação corresponde às mudanças realizadas no programa para ser responsivo às necessidades locais que receberão a intervenção. Essas modificações não afetam os elementos centrais do programa, apenas o tornam mais compatível com as características e valores da cultura local. Dessa forma, essas adaptações não podem prejudicar a efetividade do programa. Pelo contrário, as adaptações culturais devem 
favorecer a validade social do programa e, por consequência, contribuir para sua efetividade (Berkel et al., 2011; Durlak \& DuPre, 2008; Dusenbury et al., 2005; Fagan et al., 2008).

Corroborando a teoria, uma revisão sistemática de Durlak e DuPre (2008) com 500 estudos acerca da implementação de programas de prevenção e promoção em saúde mental demonstrou que a forma como a implementação é conduzida reverbera nos resultados finais do programa. No estudo, foram encontrados 23 fatores contextuais que influenciam a implementação, divididos nas categorias: capacidade organizacional (do local que recebe a inovação), características da inovação, a comunidade que o recebe, e o suporte oferecido pela organização ou sistema de suporte na execução do programa. Além disso, fidelidade, dosagem e aderência foram encontrados como fatores determinantes para se atingir os resultados esperados. Os achados desta revisão ainda demonstraram que, quando há monitoramento da implementação do programa, os efeitos são três vezes maiores em relação a programas sem monitoramento. Além do mais, implementação bem conduzida não apenas aumenta a chance de sucesso do programa como também fortalece os benefícios para os participantes e as possiblidades para a sua sustentabilidade. Este é, portanto, um importante foco de investimento entre gestores.

\subsection{Sustentabilidade}

A sustentabilidade está relacionada à manutenção da inovação no contex to em que foi adotada, mesmo após a retirada dos recursos iniciais (Murta, 2011; Rogers, 1962/1995). É o estágio final do processo de difusão, quando o uso do programa é mantido e institucionalizado; é um processo de incorporação da inovação à organização ou à comunidade. Programas sustentáveis não apenas continuam existindo, mas mantêm seus resultados positivos (Bartholomew et al., 2011). 
O planejamento para a sustentabilidade requer diversos componentes. Primeiro, é necessário estar claro quais os indicadores que podem ser utilizados no monitoramento do programa. Algumas categorias importantes incluem: manutenção dos benefícios em saúde encontrados no início do projeto; nível de institucionalização do programa dentro da organização ou comunidade; e desenvolvimento de medidas de capacitação da comunidade. O segundo componente requer o uso de estratégias que facilitem a manutenção da inovação em longo prazo. Por fim, também são fatores determinantes o desenho do programa, fatores referentes à implementação, elementos relativos à organização e ao contexto em que o programa está inserido (Shediac-Rizkallah, \& Bone, 1998).

Por isso, o processo de sustentabilidade deve estar previsto em todas as outras fases da difusão, e até mesmo no planejamento da criação do programa em si. Isso pode ser feito quando do desenho da inovação, quando os possíveis adotantes do programa poderiam ser convidados para discutir as reais necessidades relativas à proposta. Ademais, programas mais atrativos, de fácil implementação e com baixo custo são facilitadores da continuidade da intervenção. É também importante ter avaliações constantes de processo e uma estrutura organizacional que comporte e apoie a institucionalização do programa. Outro ponto que merece destaque é se a intervenção permanece relevante ao longo do tempo. Alguns programas podem perder sua validade social com o passar do tempo ou não ser mais interessante para o contexto (Bartholomew et al, 2011).

Shediac-Rizkallah e Bone (1998) apresentam um guia para o planejamento da sustentabilidade, apresentada na Tabela 2. Esse modelo é composto por três categorias subdivididas em 11 fatores. A primeira categoria, desenho do programa, compreende os recursos disponíveis ao projeto; a adoção do programa; planejamento (como foi realizado, 
com quem e quais metas) e se o mesmo foi discutido com a comunidade. Também se considera para essa categoria se a intervenção mostrava efetividade, resultados visíveis, complexidade, se de longa duração, de alto ou baixo custo, e treinamento adequado e suficiente. A segunda categoria, contexto organizacional, corresponde aos fatores subjacentes referentes à força institucional, a integração com projetos e serviços existentes, e lideranças locais. Esses fatores se referem às habilidades organizacionais para manter o programa, experiências prévias de implementação de programas, se há lideranças e quais seus atributos, se essa liderança advoga em favor da sustentação do programa, e se é possível integrá-lo aos projetos existentes na instituição, isto é, não é algo divergente aos princípios do local, da comunidade e da organização. A terceira categoria, ambiente comunitário, inclui os fatores mais amplos do ambiente comunitário. Estes incluem as considerações políticas e socioeconômicas e a participação comunitária. Esses fatores estão ligados à receptividade econômica e política do local, se o programa é aceito pela comunidade, se a comunidade se sente engajada a participar da intervenção, e como é o envolvimento no processo (Shediac-Rizkallah \& Bone, 1998).

Porém, ainda é pouco usual escutar as necessidades locais. Ao invés disso, oferece-se um serviço à comunidade sem antes consultá-la sobre o que é percebido como necessário naquele momento. Tal prática constitui um processo contrário ao empoderamento comunitário e ao que é posto por Shediac-Rizkallah e Bone (1998) e Bartholomew et al. (2011) que recomendam que a comunidade esteja engajada no processo decisório do programa. A exclusão da comunidade desse processo não favorece a sustentabilidade dos programas, pois, mesmo que o programa seja adotado e implementado, sem que haja uma escuta daquela comunidade quanto à suas necessidades e preferências, as chances de manutenção da inovação serão baixas. 
Tabela 2

Guia para o planejamento da sustentabilidade (adaptado de Shediac-Rizkallah \& Bone, 1998).

Desenho do programa

\begin{tabular}{|c|c|}
\hline $\begin{array}{l}\text { Processo de } \\
\text { negociação do } \\
\text { projeto }\end{array}$ & $\begin{array}{l}\text { A abordagem do projeto foi discutida com os membros da comunidade como iguais? As } \\
\text { necessidades da comunidade foram consideradas? Houve uma negociação para a } \\
\text { implementação ou um processo de construção consensual? }\end{array}$ \\
\hline Efetividade & $\begin{array}{l}\text { O programa é percebido como efetivo? É viável? Os resultados são visíveis? Quais são os } \\
\text { efeitos desejáveis e indesejáveis do programa? }\end{array}$ \\
\hline Duração & Qual a duração do programa? É um programa novo ou a reformulação de um já existente? \\
\hline Financiamento & $\begin{array}{l}\text { Quais os recursos existentes na comunidade? A comunidade é capaz de manter o programa } \\
\text { sozinha? Quanto a comunidade dispõe para manter o programa? Quais estratégias podem ser } \\
\text { conseguidas para que a comunidade seja autossuficiente? }\end{array}$ \\
\hline Tipo & Qual o tipo do programa (ex. prevenção ou tratamento)? \\
\hline Treinamento & O programa tem um componente de treinamento? \\
\hline
\end{tabular}

\begin{tabular}{|c|c|}
\hline Força institucional & $\begin{array}{l}\text { Qual organização irá implementar o programa? Quão amadurecida (recursos disponíveis, } \\
\text { desenvolvimento, estabilidade) é a organização? É provável que a organização ofereça } \\
\text { uma base forte para o programa? }\end{array}$ \\
\hline $\begin{array}{ll}\text { Integração } & \text { com os } \\
\text { serviços e } & \text { programas } \\
\text { existentes } & \end{array}$ & $\begin{array}{l}\text { O programa é vertical ou horizontal? As metas, objetivos e abordagens são pré- } \\
\text { estabelecidas ou adaptadas à população local e/ou ao contexto? O programa será } \\
\text { integrado às práticas existentes? }\end{array}$ \\
\hline a do programa & $\begin{array}{l}\text { O programa tem um líder? Quais são os atributos necessários para esse líder? Se não, } \\
\text { existe alguém que defenda/ advoga pelo programa? Ou o programa é uma decisão vinda } \\
\text { de cima? }\end{array}$ \\
\hline \multicolumn{2}{|r|}{ Ambiente comunitário } \\
\hline $\begin{array}{l}\text { Considerações } \\
\text { socioeconômicas e } \\
\text { políticas }\end{array}$ & $\begin{array}{l}\text { Quão favorável é o contexto socioeconômico e político para a sustentabilidade do } \\
\text { programa? }\end{array}$ \\
\hline $\begin{array}{l}\text { Participação da } \\
\text { comunidade }\end{array}$ & $\begin{array}{l}\text { Qual o nível de participação da comunidade? Quão profundo é o seu envolvimento? } \\
\text { Como é esse envolvimento? }\end{array}$ \\
\hline
\end{tabular}

Segundo nosso conhecimento, estudos nacionais acerca da sustentabilidade de programas preventivos em saúde mental são ainda inexistentes. Mesmo os estudos internacionais são ainda em menor número, quando comparados aos estudos sobre as fases anteriores da difusão (Stirman et al., 2012). Um estudo com este foco foi relatado por Hunter et al. (2015), o qual examinou o processo de sustentabilidade de um programa de prevenção do uso de substâncias entre adolescentes, o A-CRA (Adolescent community reinforcement aproach). Os resultados encontrados corroboram a literatura na área, em 
que as práticas baseadas em evidência para se sustentarem nos locais, fora do contexto de pesquisa, ou sem o apoio financeiro das agências de disseminação, dependem do contexto em que estão inseridos, da qualidade da implementação durante o período de avaliação e das características da inovação. No estudo realizado, os autores encontraram que a maioria dos locais não continuaram o programa em seus locais três ou quatro anos após a retiradas dos recursos iniciais. Os autores discutem isso à luz da dificuldade organizacional em dar continuidade ao programa. Segundo os seus achados, quando o local apresenta algum tipo de programa similar anterior à chegada da inovação, ou seja, com experiência prévia ou estrutura que suporte o programa, a inovação continua a ser implementada por mais tempo. Também foram encontradas associações entre qualidade da implementação, recursos disponíveis e a percepção sobre os resultados e a continuidade da intervenção. Assim, a sustentabilidade do programa em questão parecia depender da estabilidade de recursos e benefícios gerados pela intervenção.

\section{Considerações Finais}

Almejou-se neste artigo discutir aspectos conceituais norteadores da pesquisa em difusão de programas de prevenção a riscos e agravos à saúde mental com base na Teoria da Difusão de Inovações de Rogers e autores contemporâneos. É sabido que grande parte das intervenções psicossociais desenvolvidas, usualmente descritas em teses, dissertações e artigos, raramente ultrapassam o teste de eficácia e tampouco chegam a alcançar a comunidade. A literatura abordada instiga indagações acerca da utilidade de intervenções psicossociais, se sua comunicação ficar restrita aos pares da academia. Restringir as boas práticas ao banco de teses é engavetar oportunidades de crescimento e colocar potenciais

soluções para os problemas sociais identificadas em pesquisas à mercê da casualidade. É também privar a sociedade de usufruir do conhecimento que ela própria patrocinou a produção. Em oposição a esta prática endógena, em que os produtores de conhecimento 
são seus únicos consumidores, a Teoria da Difusão de Inovações oferece diretrizes para que inovações sejam disseminadas, adotadas e implementadas, com vida longa, fora dos muros das universidades.

Embora promissora, a tarefa de difundir programas de prevenção e promoção de saúde mental inovadores é árdua. Dentre os diversos fatores que a limitam, tem-se a interlocução restrita entre universidade e poder público, o descaso de boa parte da sociedade frente às injustiças sociais como determinantes sociais da saúde mental, recursos escassos para a pesquisa em prevenção e promoção, fraca interlocução entre áreas de conhecimento nas ciências da saúde e afins, e formação profissional centrada no tratamento. Somam-se a isto os poucos incentivos ao desenvolvimento sistemático de programas preventivos, baixa divulgação de materiais produzidos e ausência de tecnologias de difusão em larga escala de programas desenvolvidos. De fato, percebe-se poucos mecanismos de tornar público os achados dos pesquisadores, além de uma lacuna entre pesquisa e prática, que sejam sensíveis às necessidades das comunidades locais (Melo \& Izbicki, 2015).

A análise da Teoria da Difusão de Inovações indica diversas implicações para a pesquisa, a gestão e o ensino em prevenção e promoção em saúde mental. No primeiro aspecto, sugere-se a ampliação de estudos e publicações sobre o processo de difusão de programas e políticas, seja na área de saúde mental ou âmbitos relacionados. Faz-se necessário investigar como tais programas e políticas têm sido disseminados, adotados, implementados e sustentados, que barreiras e sucessos caracterizam cada uma dessas etapas e que lições para a prática profissional e o ensino podem ser daí extraídas. Ainda que a área de saúde mental tenha ainda poucos programas preventivos brasileiros baseados em evidência (Abreu, 2012), estudos voltados para áreas afins podem trazer dados iluminadores. 
No segundo aspecto, a Teoria da Difusão oferece critérios para o monitoramento da qualidade da implementação e indica quais condições são necessárias para a sustentabilidade de programas em prevenção e promoção de saúde mental. Tais critérios e condições podem ser de utilidade para o cotidiano profissional de gestores que lidam neste campo. Alguns exemplos incluem conhecer os elementos centrais do programa e as características do local de implementação, principalmente durante a adaptação do programa. A identificação dos elementos centrais do programa e as características contextuais permitem adaptar o programa à realidade mais próxima do cotidiano do serviço, pois conhece-se as vulnerabilidades e constrói-se conjuntamente soluções para aquelas demandas.

É também recomendável que os gestores trabalhem de modo sensível, aberto e colaborativo com a comunidade adotante; examinem a prontidão da comunidade para receber o programa; adotem programas potencialmente efetivos e condizentes com as necessidades da comunidade; busquem meios de integrar o programa aos serviços já existentes; monitorem e apoiem a qualidade da implementação; e sejam sensíveis ao contexto econômico e político ao longo do processo de difusão.

Como recomendação aos desenvolvedores de programas de prevenção, indica-se conhecer todas essas peculiaridades da difusão e considerá-las precocemente, quando do planejamento da intervenção. Sugere-se conhecer a realidade dos possíveis locais de implementação do programa, desenvolver treinamento coerente com a possível formação dos profissionais e convidar o público-alvo para discutir sobre suas principais necessidades. Além do mais, é necessário desenvolver um programa que possibilite flexibilidade na implementação. Programas que se apresentam mais flexíveis são mais facilmente adaptáveis e apresentam mais chances de serem adotados. 
No terceiro e último aspecto, a formação profissional em ciências da saúde e áreas afins deve prever, já na etapa de desenvolvimento de programas, sua difusão. Assim, o ensino de graduação e pós-graduação pode fomentar conhecimentos e habilidades de comunicação, em que se atinja a sociedade em geral à pesquisa científica, encorajar o desenvolvimento de programas mais facilmente adotáveis, estimular a avaliação da qualidade da implementação em larga escala de programas e facilitar a discussão de sua sustentabilidade. Adicionalmente, o ensino por meio do trabalho em equipes mistas, com pesquisadores de áreas distintas do conhecimento, usuários em potencial, gestores e profissionais da ponta deve ser encorajado. Estas são algumas das vias possíveis para construção de pontes que liguem a academia e a prática, em que o conhecimento científico, embasado em estudos empíricos validados, alcance a sociedade. 


\section{Referências}

Abreu, S. (2012). Prevenção em saúde mental no brasil na perspectiva da literatura e de especialistas da área (Dissertação de Mestrado não publicada). Universidade de Brasília, Brasília-DF.

Albee, G. W. (1982). Preventing psychopathology and promoting human potential. American Psychologist, 37(9), 1043-1050.

Andrade, F. B., Bezerra, A. I. C., Pontes, A. L. F., Ferreira-Filha, M. O., Vianna, R. P. T., Dias, M. D., \& Silva, A. O. (2009) Saúde mental na atenção básica: um estudo epidemiológico baseado no enfoque de risco. Revista Brasileira de enfermagem, 62(5), $675-680$

Backer, T. E., David, S. L., \& Soucy, G. (1995) Introduction. In T. E. Backer, S. L. David, \& G. Soucy, NIDA 155: Reviewing the behavioral science knowledge base on technology transfer. Rockville, MD: National Institute on Drug Abuse.

Bartholomew, L. K., Parcel, G. S., Kok, G., \& Gottlieb, N. H. (2011). Planning Health Promotion Programs: An Intervention Mapping Approach. Third edition. San Francisco, CA: Jossy-Bass.

Beerman, A. \& Heinemann, K. S. (2014). Preventing prejudice and improving intergroup attitudes: A meta-analysis of child and adolescent training programs. Journal of Applied Developmental Psychology, 35, 10-24.

Comissão Nacional sobre Determinantes Sociais da Saúde (2008). As causas sociais das iniqüidades em saúde no brasil. Relatório final da Comissão Nacional sobre Determinantes Sociais da Saúde (CNDSS). Rio de Janeiro: Fiocruz.

Dahlgren, G. \& Whitehead, M. (1991). Policies and strategies to promote social equity in health. Stockholm: Institute for Future Studies. 
Dearing, J. W. (2009) Applying diffusion of innovation theory to intervention development. Research on Social Work Practice, 19(5), 503-518.

Durlak, J. A., \& DuPree, E. P. (2008). Implementation matters: A review of research on the influence of implementation on program outcomes and the factors affecting implementation. American Journal Community Psychology, 41, 327-350.

Durlak, J. A.; Weissberg, R. P., Dymnicki, A. B., Taylor, R. D., \& Schellinger, K. B. (2011) The impact of enhancing students' social and emotional learning: a metaanalysis of school-based universal interventions. Child Development, 82(1), 405-432.

Dusenbury, L., Brannigan, R., Hansen, W. B., Walsh, J., \& Falco, M. (2005) Quality of implementation: developing measures crucial to understanding the diffusion of preventive interventions. Health Education Research. 20 (3), 308-313.

EU-Dap Study Group (2002) Unplugged: An effective school-based program for the prevention of substance use among adolescents. Eudap Final Technical Report $n .1$

Fagan, A. A., Hanson, K., Hawkins, J. D., \& Arthur, M. W. (2008) Bridging science to practice: achieving prevention program implementation fidelity in the community youth development study. American Journal of Community Psychology, 41, 235-249.

Fox, D. P., Gottfredson, D. C., Kumpfer, K. K, \& Beatty, P. D. (2004) Challenges in Disseminating Model Programs: a qualitative analysis of the Strengthening Washington DC Families Program. Clinical Child and Family Psychological Review, 7(3), 165-176.

Foxcroft, D. R., Ireland, D., Lister-Sharp, D. J., Lowe, G., \& Breen, R. (2003). Long-term primary prevention for alcohol misuse in young people: a systematic review. Addiction, 93, 397-411. 
Gerstner, J. J., \& Finney, S. J. (2013) Measuring the implementation fidelity of student affairs programs: a critical component of the outcomes assessment cycle. Research \& Practice in Assessment, 8, 15-28.

Gottfredson, D. C., Cook, T. D., Gardner, F. E. M., Gorman-Smith, D., Howe, G. W., Sandler, I. N., \& Zafft, K. M. (2015). Standards of evidence for efficacy, effectiveness, and scale-up research in prevention science: next generation. Prevention Science, 16, 893-926.

Horowitz, J. L. \& Garber, J. (2006). The prevention of depressive symptoms in children and adolescents: a meta-analytic review. Journal of Consulting and Clinical Psychology, 74(3), 401-415.

Hunter, S. B., Han, B., Slaughter, M. E., Godley, S. H., \& Garner, B. R. (2015). Associations between implementation characteristics and evidence-based practice sustainment: a study of the Adolescent Community Reinforcement Approach. Implementation Science, 10, 173.

Kershner, S., Flynn, S., Prince, M., Potter, S. C., Craft, L., \& Alton, F. (2014) Using data to improve fidelity when implementing evidence-based programs. Journal of Adolescent Health. 54, 29-36.

Kessler, M., \& Albee, G. W. (1975) Primary Prevention. Annual Review of Psychology. 26 (1) 557-591.

Lemstra, M., Bennett, N., Nannapaneni, U., Neudorf, C., Warren, L., Kershaw, T., \& Scott, C. (2010). A systematic review of school-based marijuana and alcohol prevention programs targeting adolescentes aged 10-15. Addiction Research and Theory, 18(1), 84-96.

Melo, M. H. S. (2006). Programa de treinamento para promover competência social em crianças e seus professores no ambiente escolar. Pós-Doutorado, 
Departamento de Psicologia Clínica, Universidade de São Paulo. Relatório apresentado à Fundação de Amparo à Pesquisa do Estado de São Paulo (FAPESP).

Melo, M. H. S., \& Izbicki, S. (2015) Adoção, disseminação e sustentabilidade de programas preventivos e de promoção em saúde mental. In S. G. Murta, C., LeandroFrança, K. B. Santos \& L. Polejack (Eds.) Prevenção e Promoção em Saúde Mental: Fundamentos, Planejamento e Estratégias de Intervenção (pp. 230-248). Novo Hamburgo: Sinopsys.

Meyers, D. C., Katz, J., Chien, V., Wandersman, A., Scaccia, J. P., \& Wright, A. (2012). Practical implementation science: Developing and piloting the quality implementation tool. American Journal of Community Psychology, 50, 481-496.

Minto, E. C., Pedro, C. P., Netto, J. R. C, Bugliani, M. A. P., \& Gorayeb, R. (2006). Ensino de habilidades de vida na escola: uma experiência com adolescentes. Psicologia em Estudo, 11(3), 561-568.

Mitchell, P. F. (2011) Evidence-based practice in real-world services for young people with complex needs: new opportunities suggested by recent implementation Science. Children and Youth Service Review, 33, 207-216.

Mrazek, P. J., \& Haggerty, R. J. (1994). Reducing risk for mental disorders: frontiers for preventive intervention research. National Academy Press: Washington DC.

Murta, S. G. \& Barletta, J. B. (2015). Promoção de saúde mental e prevenção aos transtornos mentais em terapia cognitivo-comportamental. In B. Neufeld, E. Falcone, \& B. Rangé, (Eds.). PROCOGNITIVA, Programa de Atualização em Terapia CognitivoComportamental (pp. 9-62). Porto Alegre: Artmed

Murta, S. G. (2011). Aproximando ciência e comunidade: difusão de programas de habilidades sociais baseados em evidências. In A. Del Prette \& Z. A. P. Del Prette 
(Eds.) Habilidades sociais: intervenções efetivas em grupo (pp. 83-114). São Paulo: Casa do Psicólogo.

Murta, S. G.; Santos, B. R. P, Martins, C. P. S., \& Oliveira, B. (2013) Prevenção primária à violência no namoro: uma revisão de literatura. Contextos Clínicos, 6 (2), 117 131.

O’Donnell. (2008). Defining, Conceptualizing, and Measuring Fidelity of Implementation and Published on behalf of Its Relationship to Outcomes in K-12 Curriculum Intervention Research. Review of Educational Research, 78(1), 33-84.

Olderburg, B. F., Sallis, J. F., Ffrench, M. L., \& Owen, N. (1999) Health promotion research and the diffusion and institutionalization of interventions. Health Education Research. 14 (1), 121-130.

Organización Mundial de la Salud (2004). Prevención de los trastornos mentales: intervenciones efectivas y opciones de política. Ginebra: Organización Mundial de la Salud, Dept.de Salud Mental y Abuso de Sustancias y Centro de Investigación de Prevención de las Universidades de Nijmegen y Maastricht.

Organização das Nações Unidas para a Educação, a Ciência e a Cultura (2006). Marco estratégico para a UNESCO no Brasil. Brasília. Retirado de http://unesdoc.unesco.org/images/0014/001475/147544por.pdf

Ozer, E. J., Wanis, M. G., \& Bazell, N. (2010) Diffusion of School-Based Prevention Programs in Two Urban Districts: Adaptations, Rationales, and Suggestions for Change. Prevention Science, 11(1) 42-55

Pedroso, R. T., Abreu, S., \& Kinoshita, R. T. (2015) Aprendizagens da intersetorialidade entre saúde e educação na prevenção do uso de álcool e outras drogas. Textura, 17 (33), 9-24.

Rogers, E. (1995) Diffusion of innovations. New York: Free Press. 
Rohrbach, L. A., Graham, J. W., \& Hansen, W. B. (1993). Diffusion of a schoolbased substance abuse prevention program: predictors of program implementation. Preventive Medicine. 22, 237-260.

Scott, S., Knapp M., Henderson J., \& Maughan, B. (2001). Financial cost of social exclusion: follow up study of antisocial children into adulthood. British Medical Journal, 323, 191-194.

Shapiro, V. B., Oesterle, S., \& Hawkins, J. D. (2015) Relating coalition capacity to the adoption of science-based prevention in communities: evidence from a randomized trial of communities that care. American Journal of Community Psychology, 55, 1-12.

Shediac-Rizkallah, M. C. \& Bone, L. R. (1998). Planning for the sustainability of community-based health programs: conceptual framework a future directions for research, practice and policy. Health Education Research, 13, 87-108.

Stecker, A., Goodman, R. M., McLeroy, K. R., Davis, S., \& Koch, G. (1992). Measuring the diffusion of innovative health promotion programs. American Journal of Health Promotion. 6(3), 214-225.

Stice, E., \& Shaw, H. (2004). Eating disorder prevention programs: a metaanalytic review. Psychological bulletin, 130(2), 206.

Sturza, M. L., \& Davidson II, W. S. (2006) Issues facing the dissemination of prevention program: three decades of research on the Adolescent Diversion Project. Community Action Research, 32 (1), 5-24.

Wals K., Zwi K., Woolfenden, S., \& Shlonsky A. (2015) School-based education programmes for the prevention of child sexual abuse. Cochrane Database of Systematic Reviews. In: The Cochrane Library, Issue 5. 
Word Health Organization (2010) Financiamento dos sistemas de saúde: o caminho para a cobertura universal. Relatório Mundial da Saúde. Retirado de: http://www.who.int/whr/2010/whr10_pt.pdf

Wiecha, J. L., Ayadi, A. M., Fuemmeler, B. F., Carter, J. E., Handler, S., Johnson, S., Strunk, N., Korzec-Ramirez, D., \& Gortmaker, S. L. (2004) Diffusion of an integrated health education program in an urban school system: planet health. Journal of Pediatric Psychology. 29(6) 467-474. 


\section{MANUSCRITO 3}

A Difusão do Programa Famílias Fortes: um estudo baseado em teoria Fundamentada 


\section{Resumo}

O Programa Famílias Fortes (PFF) é um programa de prevenção do abuso de drogas desenvolvido internacionalmente e adotado pelo Ministério da Saúde em 2013 a fim de fortalecer práticas preventivas baseadas em evidências. O presente estudo analisou características do Programa Famílias Fortes que afetaram sua difusão no Brasil. Realizouse um estudo qualitativo baseado em teoria fundamentada. Entrevistas semiestruturadas foram realizadas com seis participantes responsáveis pela gestão, supervisão e monitoramento do programa. Análise documental e observação de reuniões de equipe foram também realizadas. O PFF tem sido percebido como vantajoso, compatível com as necessidades locais e com resultados iniciais positivos. Por outro lado, sua implementação tem sido percebida como complexa e pouco viável.

Palavras-chave: programas de prevenção; Teoria Fundamentada; difusão de inovação; abuso de substâncias; Programa Famílias Fortes. 


\begin{abstract}
The Strengthening Families Program (SFP 10-14) is a drug abuse preventive program developed abroad and adopted for the Ministry of Health in Brazil in 2013 to enhance evidence-based preventive practices. The current study examined characteristics of the Strengthening Families Program that has influenced its diffusion process in Brazil. A qualitative study was performed based on Grounded Theory methodology. Semistructured interviews were done with six participants in charge of program's administration, supervision and monitoring. Analysis of documents and observations of team meetings were also conducted. The SFP 10-14 has been perceived as advantageous, compatible with local needs and with initial positive results. On the other hand, its implementation has been faced problems related to its complexity and feasibility.
\end{abstract}

Keywords: Prevention Programs; Grounded Theory; Diffusion of Innovations; drug abuse; Strengthening Families Program. 


\section{A Difusão do Programa Famílias Fortes: um estudo Baseado em Teoria Fundamentada}

O consumo abusivo de álcool e outras drogas tem sido apontado como um grave problema de saúde entre adolescentes. Ele está relacionado à violência, tráfico de drogas, gravidez precoce, doenças como HIV/AIDS e hepatite (Moreira, Vóvio, \& De Micheli, 2015; Pratta \& Santos, 2007; Schenker \& Minayo, 2005), entre outros. Estudos nacionais (Baus, Kupek, \& Pires, 2002, Benchava et al. 2011, Broecker \& de Jou, 2007, Claro et al., 2014; Domingues, 2011, Ferreira, 2013, Freire \& Gomes, 2012; Loyola et al., 2009; Schenker \& Minayo, 2005), corroborados por dados internacionais (Foxcroft, Ireland, Lister-Sharp, Lowe, \& Breen, 2013; Yo \& Stiffman, 2010;), têm apontado que problemas familiares situam-se entre o leque de fatores de risco relevantes para o início precoce e uso indevido de substâncias. Baixa coesão familiar e estilo parental autoritário, negligente ou indulgente são alguns dos principais preditores familiares de uso abusivo de álcool e outras drogas.

Intervir precocemente nesses fatores de risco aumentaria as chances de se retardar o início do uso de substâncias entre adolescentes. Adicionalmente, a promoção de vínculos familiares e de estilo parental autoritativo, associado a níveis adequados de sincronia e exigência, fortaleceria o desenvolvimento saudável e seguro de adolescentes, protegendo-os de diversos desfechos negativos em saúde, para além do uso de drogas, como comportamento sexual de risco e comportamento antissocial. Isso ganha relevo ao se considerar a família a primeira e principal fonte de socialização da criança, cujo funcionamento interfere em outras esferas da vida do indivíduo (UNODC, 2011).

Ademais, deve-se notar que os custos associados ao tratamento de doenças mentais causadas por abuso de substâncias são elevados. A prevenção é uma das formas mais efetivas de se reduzir esses custos, uma vez que intervenções preventivas e de 
promoção em saúde mental podem influenciar os fatores de risco e proteção e reduzir assim a incidência e a prevalência de diversas doenças mentais causadas por abuso de substâncias (Hosman, Jané-Llopis, \& Saxena, 2004).

Ao encontro dessa premissa, encontra-se o Strengthening Families Program. Esse programa foi desenvolvido em 1983 por um grupo de pesquisa da Universidade de Utah, Estados Unidos (Allen, Foxcroft, \& Coombes, 2006). Em sua origem, era um programa de prevenção seletiva, para crianças de 6 a 12 anos, advindas de famílias com problemas relacionados ao uso de drogas, com duração de 14 sessões semanais. Na década de 1990, foi reformulado pelo grupo de pesquisa da Universidade de Iowa, tornando-se um programa de prevenção universal (Molgard \& Kumpfer, 1993). O programa passou por nova reformulação com a versão atual desenvolvida pela School of Health and Social Care da Oxford Brookes University, Reino Unido, passando a focar adolescentes de 10 a 14 anos.

Esse programa foi difundido para diversos países da União Europeia, como Suécia (Skärstrand, Sundell, \& Andréasson, 2013), Polônia (Okulicz-Kozaryn \& Foxcroft, 2012), Itália (Ortega et al., 2012), Alemanha (Stole et al., 2011) e Irlanda (Kumpfer, Xie, \& O'Driscoll, 2012). Na América Latina, ele foi difundido para o Chile (Correa et al., 2012), Colômbia, Honduras (http://www.paho.org/) e Brasil (Murta, Nobre-Sandoval, Ramos, Pedralho, \& Tavares, 2014). Em todos esses países, foram realizadas adaptações culturais, verificando-se a aceitabilidade dos usuários ao programa e, em vários deles, avaliados os resultados para a prevenção de comportamentos de risco entre adolescentes e qualidade das relações parentais. No Brasil, foi intitulado inicialmente de Programa Fortalecendo Famílias e, atualmente, de Programa Famílias Fortes (PFF). Um estudo de avaliação de necessidades para subsidiar a adaptação cultural do PFF foi realizado por Murta et al. (2014) e apontou resultados favoráveis à atratividade, relevância e clareza 
das atividades do programa, bem como procedimentos que careciam de ajustes. Desde então, sucessivas adaptações foram realizadas pelo Ministério da Saúde e o programa vem sendo expandido para novas cidades brasileiras. Avaliações de efetividade do PFF no Brasil ainda não foram conduzidas.

\subsection{Referencial teórico}

A transferência de conhecimentos de centros de pesquisa para a sociedade é uma alternativa para se solucionar problemas complexos. Programas preventivos que buscam a melhoria da qualidade de vida da população construídos a partir de intervenções com embasamento teórico, planejados de forma sistemática, implementados com rigor e avaliados gerando evidências de efetividade são bons modelos para serem implementados em larga escala (Gottfredson et al., 2015; Murta, 2011; Oldenbury et al., 1999). Porém, o conhecimento não é transferido de forma natural e espontânea (Rogers, 1962/1995). Diversos fatores políticos, econômicos e sociais estão envolvidos no processo de difusão de programas preventivos baseados em evidências.

Por difusão compreende-se o processo em que uma inovação é comunicada por certos canais de comunicação, através do tempo, entre os membros de um sistema social. É um tipo especial de comunicação na qual a mensagem está interessada em novas ideias. Difusão é um tipo de mudança social, definida como um processo pelo qual uma alteração ocorre na estrutura em função de um sistema social. Esta é a definição de Everett Rogers, autor de uma das principais teorias no campo, a Teoria da Difusão de Inovações. Quando novas ideias são inventadas, difundidas e adotadas (ou rejeitadas), mudanças sociais podem ocorrer como consequência dessa cadeia (Rogers, 1962/1995).

Para que uma inovação seja difundida, deve apresentar certos atributos que chamem a atenção dos potenciais adotantes. Essas características interferem e explicam 
a taxa de adoção. Esses atributos são: (1) vantagem relativa: o grau em que uma inovação é percebida como melhor que outras ideias; (2) compatibilidade: em que medida a inovação é congruente com os valores e as normas sociais vigentes no local em que será adotado; (3) complexidade: o grau em que uma inovação é percebida como difícil de ser entendida ou colocada em prática; (4) viabilidade: a quantidade de recursos necessários para que a inovação seja implementada, sendo mais viáveis aquelas que podem ser executadas com recursos limitados; (5) resultados observáveis: em que medida os resultados são visíveis para os outros (Rogers, 1962/1995). Aumenta-se a chance de adoção quando se tem inovações mais vantajosas, mais compatíveis, menos complexas, mais viáveis e com resultados mais visíveis (Rogers, 2002).

O processo de difusão também requer que alguns passos aconteçam. Primeiro, é necessário que a informação sobre a intervenção seja transmitida e viabilizada (disseminação). Segundo, um local ou uma organização deve decidir testar ou iniciar o novo programa (adoção). Terceiro, o programa deve ser implementado mantendo os elementos centrais que o constitui como eficaz (implementação). E, por fim, o programa deve se sustentar no local, mesmo depois que os recursos iniciais não estejam mais disponíveis, ou seja, ser institucionalizado (sustentabilidade) (Bartholomew et al., 2011; Durlak \& DuPre, 2008). Essas quatro fases são de grande importância para a compreensão do processo de difusão de um programa.

O principal objetivo da disseminação é transferir conhecimento. Essa transferência envolve facilitar a comunicação para que uma inovação seja implementada e demonstre sua eficiência em promover resultados. Por isso, envolve persuasão, comunicação entre agências, organizações e indivíduos (Turner \& Sanders, 2006; Wiecha et al., 2004). A disseminação, muitas vezes é tida como sinônimo da difusão, porém, 
corresponde ao primeiro passo de transmissão da prática. Essencialmente, consiste em divulgar a inovação e encorajar sua adoção.

A adoção, por outro lado, envolve a escolha ou tomada de decisão pela inovação (Turner \& Sanders, 2006). É quando o programa é inserido em uma agenda para então ser implementado. A adoção corresponde à seleção do programa e ao compromisso de se iniciá-lo. Está relacionada à capacidade de suporte e apoio aos implementadores ou funcionários-chave da organização que irão implementar a inovação. Requer, portanto, capacidade organizacional e treinamento de pessoal para conduzir o programa (Fagan \& Mihalic, 2003). É nessa fase que são realizadas a formação dos profissionais para colocar em prática a intervenção e auxiliar a organização adotante para que a implementação ocorra de forma efetiva.

A implementação se refere a colocar o programa ou a inovação em prática, é quando se alcança a população por meio da intervenção (Meyers et al., 2012). A forma como o programa chega ou é entregue à população interfere nos resultados. A qualidade da implementação, fidelidade, dosagem, aderência e qualidade de processo interferem nos resultados que serão obtidos após o término do programa (Durlak \& DuPre, 2008, Dusenbury et al., 2005, Meyers et al., 2012, Santos \& Murta, 2015). A Figura 1 apresenta alguns elementos que podem influenciar a implementação do programa, os quais levam em consideração aspectos do contexto externo, do contexto interno, dos facilitadores e características da inovação para os resultados da inovação no local de aplicação (Santos \& Murta, 2015). 


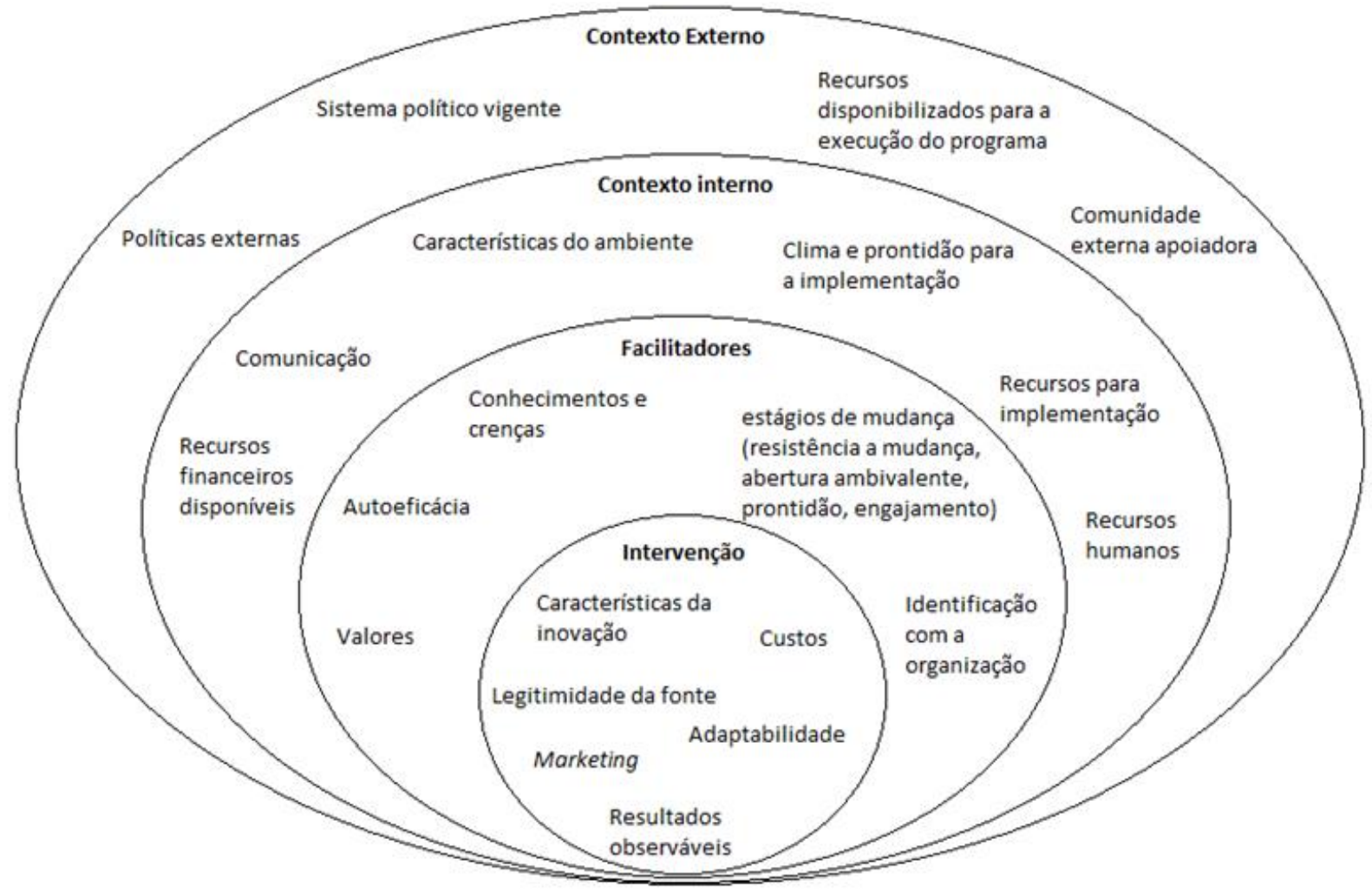

Figura 1. Fatores influentes na implementação (adaptado de Santos \& Murta, 2015).

A sustentabilidade de um programa no local de aplicação é a meta final de muitos projetos, de forma a manter os resultados benéficos na comunidade (Shediac-Rizkallah \& Bone, 1998). A sustentabilidade, então, é a capacidade de manutenção ou institucionalização do programa na comunidade, quando o programa começa a fazer parte da rotina de trabalho dos profissionais, mesmo quando os recursos iniciais de disseminação já se esgotaram (Bartholomew et al., 2011; Shediac-Rizkallah \& Bone, 1998). Planejar a sustentabilidade de um programa requer fortalecer as fases anteriores da difusão.

Desde o processo de negociação pela intervenção à forma como o programa é implementado interfere na sustentabilidade do programa (Bartholomew et al., 2011; Melo \& Izbicki, 2015; Shediac-Rizkallah \& Bone, 1998). Alguns outros fatores que influenciam na sustentabilidade do programa estão relacionados às características da 
inovação, o contexto que o adotou, a capacidade institucional e organizacional, as adaptações realizadas no programa, treinamento da equipe, suporte técnico, participação da comunidade e liderança de atores locais que advogam pelo programa (Melo \& Izbicki, 2015; Shediac-Rizkallah \& Bone, 1998). Todos esses fatores interferem não apenas na sustentabilidade, mas também nos resultados do programa.

A transposição do conhecimento para a prática é demasiadamente complexa. Poucos estudos, mesmo internacionais, focalizam nessa fase da pesquisa em prevenção (Gottfredson et al., 2015; Spoth et al., 2013). No Brasil, apenas Melo (2006, citado por Melo \& Izbicki, 2015) apresentou um estudo sobre a disseminação de uma intervenção preventiva baseado em habilidades sociais em contexto escolar para crianças da $2^{\mathrm{a}}$ série do ensino fundamental. O estudo contou com a participação de psicólogas e professores da rede pública de ensino na testagem de material para treinamento dos profissionais, além de orientação e acompanhamento da implementação da intervenção.

Dessa forma, percebe-se uma lacuna na literatura nacional sobre a difusão de programas de prevenção a riscos e agravos à saúde mental. Além disso, pouco se sabe sobre o processo de difusão do Programa Famílias Fortes no Brasil, tendo em vista sua recente adoção no contexto nacional. Assim, o propósito deste estudo foi investigar o processo de difusão do Programa Famílias Fortes no Brasil por meio de uma abordagem qualitativa baseada em teoria fundamentada. Especificamente, (a) buscou-se descrever a história do programa no Brasil, (b) examinar como os atributos do PFF, vantagem relativa, compatibilidade, complexidade, viabilidade e resultados observáveis, influenciaram em sua adoção e (c) investigar os desafios e facilitadores dos processos de disseminação, adoção, implementação e sustentabilidade do programa. 


\section{Método}

\subsection{Descrição do Programa}

O Programa Famílias Fortes busca em suas atividades prevenir o uso de álcool e outras drogas. É direcionado a famílias com adolescentes de 10 a 14 anos, que não estejam já em situação de risco, ou seja, é um programa de caráter universal. O programa utilizase de vídeos com conteúdo relativo a interações familiares para disparar as discussões em grupo. As suas metas principais são a redução do abuso de substância e de comportamentos de risco à saúde entre adolescentes. Os seus objetivos intermediários são: melhorar as relações pais e filhos, desenvolver as habilidades de estabelecimento de limites dos pais, aperfeiçoar as habilidades de comunicação entre pais e filhos e aprimorar as habilidades pró-sociais entre os adolescentes (Allen, Foxcroft, \& Combes, 2006). Essas metas podem ser visualizadas pelo Modelo Lógico do Programa apresentado na Figura 2.

Programa Fortalecendo Famílias: Para Pais e Adolescentes de 10-14 anos
A versão original desse programa foi desenvolvida pelo Projeto Familia pelo Centro de Pesquisa Social e Comportametal para a Saúde Rural da Iowa Statte University.

\begin{tabular}{|c|c|c|c|}
\hline $\begin{array}{l}\text { Componentes do } \\
\text { Programa }\end{array}$ & $\begin{array}{c}\text { Alvo: } \\
\text { Causadores de } \\
\text { problemas de }\end{array}$ & $\begin{array}{c}\text { Metas Proximais } \\
\text { Participantes }\end{array}$ & $\begin{array}{l}\text { Metas Distais } \\
\text { para a Saúde } \\
\text { Pública }\end{array}$ \\
\hline $\begin{array}{l}\text { Sessões Parentais } \\
\text { Meta: Aprimorar as } \\
\text { habilidades parentais e } \\
\text { promover estilos } \\
\text { parentais efetivos. }\end{array}$ & comportamentc & $\begin{array}{c}\text { Aprimorar } \\
\text { habilidades/ estilos } \\
\text { parentais }\end{array}$ & $\begin{array}{l}\text { Reduzir o uso de } \\
\text { substância nos } \\
\text { adolescentes }\end{array}$ \\
\hline $\begin{array}{l}\text { Sessão com os } \\
\text { Adolescentes } \\
\text { Meta: Construir } \\
\text { habilidades de vida e } \\
\text { promover atitudes } \\
\text { positivas }\end{array}$ & $\begin{array}{c}\text { Diminuir Fato } \\
\text { de Risco }\end{array}$ & $\begin{array}{c}\text { Aprimorar as } \\
\text { atitudes/ habilidades } \\
\text { dos adolescentes }\end{array}$ & $\begin{array}{l}\text { Reduzir } \\
\text { comportamentos } \\
\text { de risco nos } \\
\text { adolescentes }\end{array}$ \\
\hline \begin{tabular}{|l|} 
Sessões Familiares \\
Metas: Fortalecer \\
Vinculos familiares, \\
promover comunicação \\
posițva, melhorar a \\
resolução conjunta de \\
problemas.
\end{tabular} & $\begin{array}{l}\text { Aumentar } \\
\text { fatores de } \\
\text { Proteção }\end{array}$ & $\begin{array}{l}\text { Melhorar as } \\
\text { relações } \\
\text { familiares }\end{array}$ & $\begin{array}{l}\text { Aprimorar o } \\
\text { desempenho e } \\
\text { engajamento } \\
\text { acadêmico }\end{array}$ \\
\hline
\end{tabular}

Figura 2. Modelo lógico do Programa Famílias Fortes. 
As sessões buscam desenvolver habilidades de vida, as quais proporcionem um melhor convívio familiar, desenvolvendo relações positivas entre os membros da família. Isso vem ao encontro do pressuposto de que relações positivas entre pais e filhos criam condições adequadas para o desenvolvimento saudável das crianças e adolescentes, prevenindo situações de risco. Todo o procedimento do programa está descrito em um manual detalhado com todas as atividades descritas (Allen, Foxcroft, \& Combes, 2006). O Programa Famílias Fortes (PFF) foi adaptado à realidade cultural brasileira após estudo inicial (Murta et al., 2014) sofrendo algumas alterações de seu plano original desenvolvido no Reino Unido. A adaptação do material foi realizada pelo Mistério da Saúde (MS), primeiro com uma tradução literal e, em seguida, com reformulações após as primeiras aplicações do programa.

O PFF tem o formato de sete encontros semanais com duração de aproximadamente duas horas. As sessões são divididas em duas partes. Em um primeiro momento são realizadas sessões separadas e concomitantes entre pais/responsáveis e adolescentes, com duração de uma hora cada, e uma sessão familiar com mesma duração. Os recursos utilizados são: audiovisuais, com apresentação de vídeo com o tema da sessão; discussão em grupo; atividades lúdicas e interativas. O tema de cada sessão é apresentado na Figura 3, que representa as sessões para pais e cuidadores, as sessões para adolescentes e sessão familiar. Ademais, alguns procedimentos também fazem parte do programa como sorteio de brindes, oferta de lanche ao início das sessões, e também deve ser oferecido transporte para que os participantes cheguem ao local de implementação. 


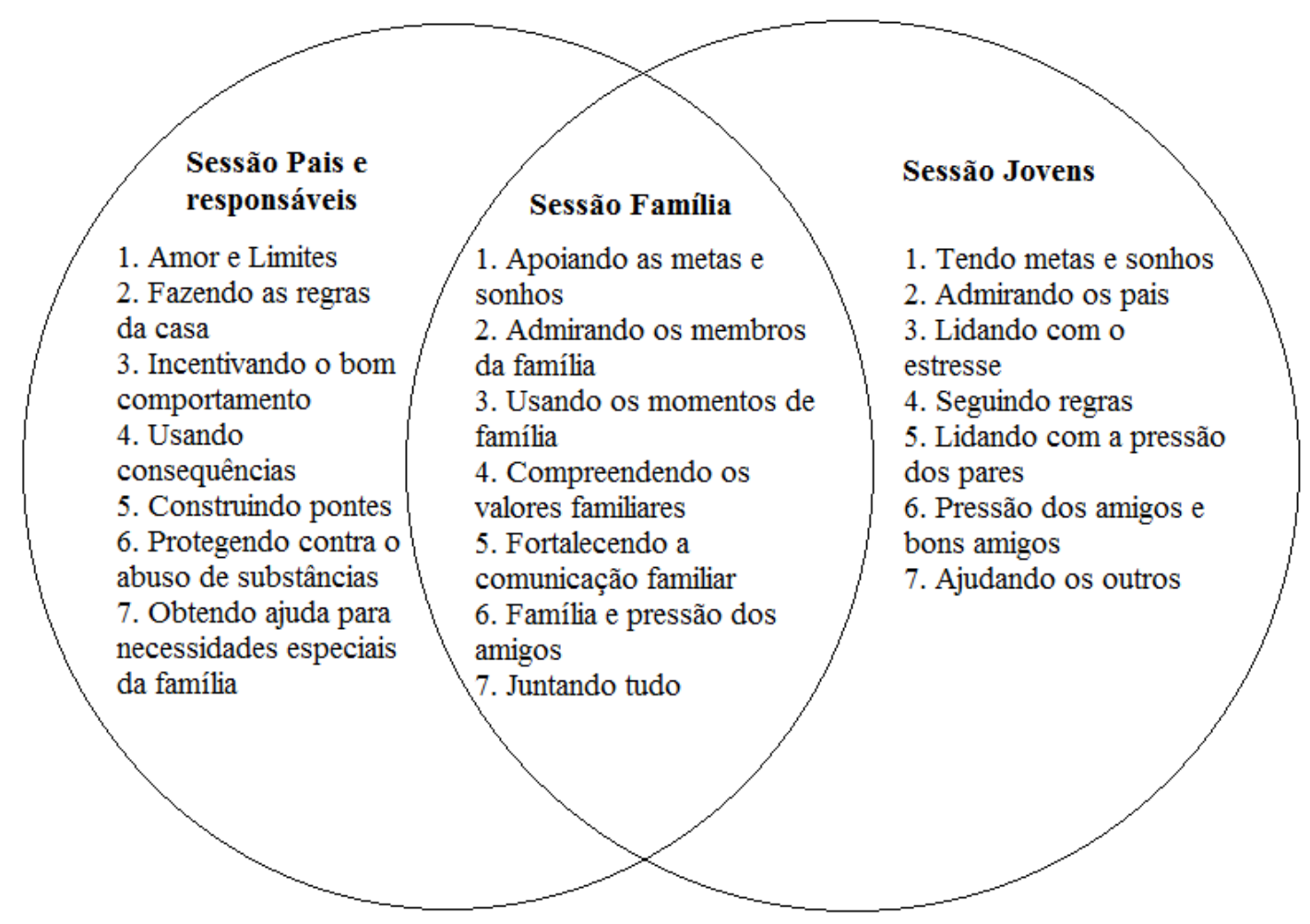

Figura 3. Temas das sessões do Programa Famílias Fortes.

\subsubsection{Estrutura organizacional do programa}

O Programa Famílias Fortes é um programa de prevenção universal direcionado a famílias com filhos de idades entre 10 a 14 anos, e que não estejam em situação de rompimento de vínculos familiares, ou seja, abandono ou abrigamento dessas crianças. Sua missão é fortalecer vínculos familiares e, por conseguinte, postergar o uso de drogas entre adolescentes.

Este programa é um de três programas selecionados pelo Governo Federal para reduzir os fatores de risco relacionados ao uso de substâncias e promover ou fortalecer vínculos familiares e habilidades sociais, considerados fatores de proteção ao uso de álcool e outras drogas. Os outros dois programas, escolares, são: Unplugged ou \#Tamujunto, para crianças de 10 a 14 anos; e, Good Behavior Game ou Jogo Elos, para crianças de 6 a 10 anos, tem sido implementado em serviços de assistência social e 
atenção básica em saúde. Os principais serviços que têm recebido o programa são os Centros de Convivência/ Orientação Sócio-Educativo (COSEs), Centros de Referência da Assistência Social (CRAS) e Unidades Básicas de Saúde (UBS).

A estrutura básica do programa é delimitada por:

1. Ministério da Saúde: órgão máximo em que responde pela implementação inicial do programa.

2. Diretoria de Atenção Básica e Vigilância em Saúde: que responde pela:

3. Coordenação de Saúde Mental, Álcool e outras Drogas: na qual se firmam parcerias entre órgãos executores e estabelecem as diretrizes do programa;

4. Supervisor/ Formador Federal: formados por funcionários que executam a formação dos multiplicadores locais, supervisionam a atuação desses multiplicadores, atuam em atividades de monitoramento e supervisão.

5. Multiplicador Federal: formam e supervisionam os facilitadores locais. Atuam em atividades de monitoramento e pactuação dos serviços.

6. Facilitadores: aplicam o programa, sendo dois facilitadores para o grupo de pais e dois para o grupo de adolescentes.

\subsection{Delineamento de pesquisa}

O estudo tem por delineamento de pesquisa a teoria fundamentada (Glaser \& Strauss, 1967; Strauss \& Corbin, 2008). Esse delineamento de pesquisa busca ir além da descrição de um fenômeno e gerar ou criar uma teoria, um esquema abstrato de um processo. O investigador gera uma explicação geral de um processo, uma ação, ou interação compartilhadas pela visão de um grande número de participantes (Strauss \& Corbin, 2008). 


\subsection{Participantes}

Participaram como informantes neste estudo dois gestores responsáveis pela adoção do Programa Famílias Fortes, dois supervisores e dois multiplicadores do programa. Todos estavam vinculados ao Ministério da Saúde (MS), Coordenação de Saúde Mental, Álcool e Outras Drogas, no período de 2012 a 2015.

Também participaram deste estudo, mas não sendo entrevistados diretamente, nove facilitadores de grupo, uma funcionária do Escritório das Nações Unidas sobre Drogas e Crime-UNODC, uma do antigo Ministério do Desenvolvimento Social - MDS, quatro multiplicadoras do programa. Essas pessoas participaram de reuniões de adaptação do material (duas reuniões), na reunião do grupo de estudos sobre o programa, e em duas reuniões com chefes de serviço dos COSEs (Centro de Orientação Socioeducativo) do DF (cuja finalidade era falar sobre o programa). Essas reuniões ocorreram em 2015.

Conjuntamente, foram analisados os seguintes documentos: o relatório de pesquisa do estudo de avaliação de processo e levantamento de necessidades para adaptação cultural (Murta et al., 2014), três relatórios produzidos por formadoras federais, 25 diários cartográficos produzidos pelas multiplicadoras e três apresentações confeccionadas pelos servidores do MS dirigidas aos municípios.

\subsection{Instrumentos}

Foram utilizados roteiros de entrevistas semiestruturadas que abarcaram o processo de difusão do PFF para o Brasil. Os temas das perguntas foram: percurso histórico do Programa no Brasil; características determinantes do programa que culminaram em sua escolha; barreiras na adoção e implementação; vantagens relativas encontradas no programa; características dos locais de adoção e implementação; quais as 
principais barreiras e facilitadores para a disseminação, adoção e implementação do PFF, e quais barreiras e facilitadores estão sendo encontradas no processo de planejamento da sustentabilidade. Esses critérios também foram utilizados para guiar a leitura das fontes documentais e as observações de reuniões. Novas perguntas foram formuladas a partir da análise de documentos e entrevistas que já tinham sido analisadas. A coleta e dados foi finalizada apenas quando se alcançou a saturação dos dados. Considerou-se haver saturação quando as ideias apresentadas pelos participantes eram consistentes com os dados já coletados e não adicionavam informações novas.

O protocolo de entrevista (Apêndice A) foi desenvolvido pela pesquisadora responsável por este estudo baseado em publicações já existentes sobre o tema da difusão. Alguns exemplos de perguntas foram: "Quais critérios foram cruciais para a escolha do programa?"; "Como é realizado o marketing do programa?”; "Quais as vantagens relativas oferecidas pelo programa para o país?”; "Há apoio local/ apoio das lideranças locais para a adoção do programa?"; "Há estrutura institucional para a implementação do programa?"; "Quais barreiras ou facilitadores que indicam uma boa qualidade da implementação (relativas ao programa, aos facilitadores, e aos contextos internos e externos)?”; “Como está sendo planejada a sustentabilidade do programa?”.

\subsection{Procedimentos}

A pesquisadora, primeiramente, solicitou à Coordenação de Saúde Mental do MS acesso à documentação relativa ao programa. Após aceite, deu-se início a análise de conteúdo dos arquivos. Concomitante a isso, a pesquisadora foi convidada a participar de uma reunião para debater alguns aspectos do programa. Após a autorização dos participantes, a reunião foi gravada em áudio e transcrita posteriormente. A posteriori, a pesquisadora teve a oportunidade de participar das duas reuniões (de dois dias inteiros) 
em que se realizou discussão sobre a mudança do material. Todos os aspectos analisados desse momento subsidiaram os temas das perguntas que seriam realizadas com os gestores, supervisoras e multiplicadoras do programa.

Então, foram realizadas quatro entrevistas com os participantes, sendo duas entrevistas individuais com os gestores responsáveis pela adoção e duas entrevistas em duplas: uma entrevista em dupla com supervisores do programa e outra entrevista em dupla com as multiplicadoras do programa, com duração total de 3 horas e 41 minutos. As entrevistas foram finalizadas após a saturação dos dados. As entrevistas foram transcritas na íntegra e analisadas por meio do software NVIVO 11.

Todos os dados (transcrição de entrevistas e reuniões, e documentos) foram analisados primeiramente por meio de análise microscópica, como sugerido por Straus e Corbin (2008). Essa análise, também chamada linha a linha, é um processo flexível e criativo em que se faz um exame detalhado dos dados, interpretando-os constantemente. Os dados, então, foram isolados e se criaram categorias para posteriormente realizar a codificação aberta e axial. Esse primeiro passo, de codificação aberta, correspondeu a um processo analítico de maneira a identificar os conceitos, propriedades e dimensões advindas dos dados. A codificação aberta expressou os dados e fenômenos em forma de conceitos. Nessa fase, os dados foram segmentados em unidades de significado. Posteriormente, passou-se à categorização dos códigos advindos dessas unidades de análise. Agrupou-se então novamente esses códigos, mas de forma mais abstrata. O resultado da codificação aberta consistiu em diversas categorias associadas ao texto. A terceira etapa de análise consistiu na codificação axial, que correspondeu ao processo de relacionar categorias comparando-as. Por fim, foi realizada a codificação seletiva, em que há a integração da codificação na história do caso, de forma a gerar um fenômeno central 
(Flick, 2009; Straus \& Corbin, 2008). Todos os dados, entrevistas, documentos e memorandos advindos da observação ao campo, passaram por essa análise.

A validação dos dados (Cresswell, 2007) foi realizada por meio de três estratégias. A primeira estratégia foi a verificação pelos participantes, em que a pesquisadora solicitou aos seis entrevistados, após o término da pesquisa, que verificassem se o texto descritivo dos resultados representava (ou não) de modo acurado seus relatos e experiências e indicassem, caso encontrassem, alvos para correção. Dos seis participantes, três responderam à solicitação. Estes afirmaram que seus relatos e vivências com o PFF estavam adequadamente representados no texto. A segunda estratégia foi a revisão pelos pares, a qual consistiu na apresentação e discussão dos dados com outros pesquisadores atuantes em prevenção e promoção em saúde mental. Por fim, realizou-se a estratégia de triangulação dos dados, em que foram consultadas fontes diversas e complementares de dados, a saber, entrevistas, documentos, atas de reunião e observação de reuniões para análise sobre a implementação do programa.

\subsection{Considerações Éticas}

Este estudo segue as diretrizes e normas regulamentadoras de pesquisas envolvendo seres humanos como determina o Conselho Nacional de Saúde na Resolução 510/16. A pesquisa foi aprovada pelo Conselho de Ética em Pesquisa do Instituto de Ciências Humanas, com parecer CAAE 52760815.7.0000.5540 (Apêndice B). Os participantes foram informados sobre a confidencialidade dos dados e assinaram o termo de consentimento livre e esclarecido (Apêndice B).

\section{Resultados e discussão}

As grandes categorias de análise podem ser divididas em: origem e histórico do PFF no Brasil, características da inovação que influenciaram na sua adoção, 
características da disseminação e adoção em nível nacional, e desafios e facilitadores da disseminação, adoção, implementação e sustentabilidade do PFF em nível local.

\subsection{Origem e Histórico do Programa no Brasil}

O Programa Famílias Fortes chegou ao Brasil em 2013 a partir de uma demanda surgida da Política Nacional sobre Drogas (PNAD), em 2012, mais especificamente do Programa Crack é Possível Vencer. A Figura 2 apresenta o percurso histórico do PFF desde o contexto que antecedeu sua adoção (2012), passando por sua adoção e testagem inicial (2013), chegando às adaptações culturais sucessivas e implementação em diversas cidades brasileiras (2014 e 2015). A adoção do PFF foi sucedida por uma implementação no Distrito Federal, em 2013, junto a oito grupos em COSES, serviços de fortalecimento de vínculos situados na política de assistência social. A escolha dos COSEs partiu da Assistência Social que considerou o programa uma solução ao Programa de Atenção Integral à Família (PAIF), diretrizes as quais a assistência deve seguir. Essa experiência inicial foi alvo de um estudo solicitado pelo MS para análise de sua viabilidade e levantamento de necessidades para adaptação cultural (Murta et al., 2014). Os dados deste estudo subsidiaram a primeira onda de adaptação cultural dos procedimentos do PFF, realizada em 2014. Ainda nesse ano, deu-se início à expansão do PFF para cidades da região norte, nordeste, sudeste e sul do Brasil (ver Figura 4). Ao longo desses anos, foram atendidas 563 famílias, das quais 64 em 2013, 133 em 2014 e 366 em 2015.

Ainda em 2013, foi feita uma parceria com a Assistência Social, representada pelo MDS, que apresentou os COSEs, como possível local de implementação para o programa. Buscou-se na época parceria com esse Ministério, que alegava interesse em entrar no projeto também. Porém, não se conseguiu firmar uma parceria consolidada entre MS e MDS. A tentativa de parceira formal continuou até 2015. Porém, essa parceria não foi formalizada, e muitas dificuldades foram sentidas por essa ausência, como por exemplo 
a dificuldade em institucionalizar o programa. Em 2015, o programa começou então a ser aplicado também nas Unidades Básicas de Saúde (UBS), com resultados positivos. E, mais recentemente, 2014/2015, a Secretaria Nacional de Políticas sobre Drogas-SENAD (Ministério da Justiça) realizou parceria com o MS para também implementar o programa. A implementação feita pela SENAD não será objeto de análise neste estudo.

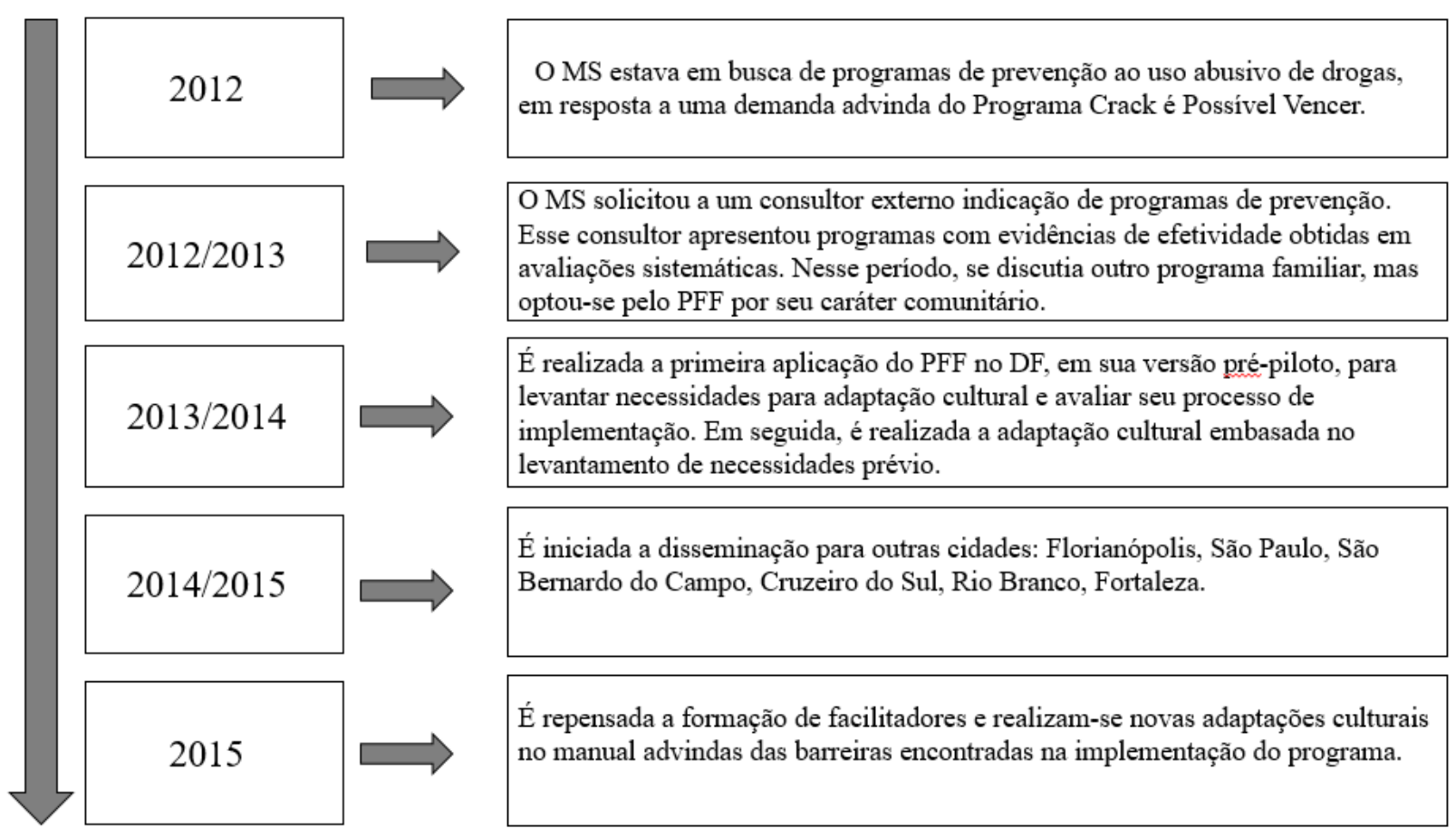

Figura 4. Marcadores da História do Programa Famílias Fortes no Brasil (2012-2015).

Conforme evidenciado nos dados das entrevistas, o Programa Crack é Possível Vencer conferiu ao uso de drogas um status relevante na agenda política e, assim, ofereceu o contexto que motivou a entrada do PFF no país. O crack chegou à mídia brasileira como um problema estarrecedor de grande magnitude. Porém, pouco se sabia sobre essa droga, suas consequências, quem ela afetava. Somado a isso havia um alarme de que o problema das drogas estava aumentando entre os adolescentes. Porém, os estudos do VI Levantamento Nacional sobre o consumo de Drogas Psicotrópicas entre estudantes de escolas públicas e particulares (Carlini et al., 2010) com jovens de 10 a 19 anos, de 
escolas públicas e privadas, demonstraram que a taxa de uso havia diminuído nos últimos anos. No entanto, demonstrava um outro problema: a evasão escolar. Como relata o Participante 3:

"O fato de ter uma tendência de redução (de drogas) no ambiente escolar não necessariamente indica que é uma redução geral do consumo de substâncias na população jovem, de 10 a 19 anos, pelo menos, porque como eu disse, 1/6 das crianças estavam fora da escola. (...) O que é paradoxal (...) porque as crianças saem da escola num período que tem uma política de sustentação das famílias que mantém as crianças na escola e, ainda assim, tem muitas que saem da escola" (Participante 3).

Então a tese que se discutia na época, segundo o Participante 3, era a de que o problema que se enfrentava era maior do que simplesmente o uso da substância. Estava relacionada à dinâmica familiar, entre outros fatores contextuais. A tese era a de que o crescimento econômico que o Brasil estava vivenciando não atingia uma certa camada da população, denominada "ralé". Essa ralé correspondia aos marginalizados da sociedade brasileira, que mesmo tendo acesso a recursos não conseguiam sair de uma situação de vulnerabilidade. A desigualdade brasileira vai muito além do que é apresentado nas estatísticas. A violência e a desigualdade dirigida a essa população é antiga, e se renova de diversas formas. Uma forma de violência é acreditar que essa população têm a mesma disposição de comportamento e as mesmas capacidades de disciplina, autocontrole e autorresponsabilidade que as pessoas que cresceram em lares com recursos ilimitados disponíveis (Souza, 2009). Como apresentado pelo participante 3, "um pai pode até falar para o filho pensar no futuro, mas como ele fará isso se nem ele sabe o que é futuro?" A herança imaterial é o que gera capital cultural, e permite ao indivíduo crescer e se desenvolver na cultura atual. Porém, usa-se dessa argumentação, de que todo homem tem 
as mesmas condições para evoluir, basta um pequeno estímulo (financeiro) para que essa população tenha as mesmas condições para sair de uma situação de miséria. Legitima-se com isso o privilégio de alguns (Souza, 2009). Como corroborado pelo Participante 3:

"A gente começa a perceber que as pessoas que tinham algum recurso na sua formação, as oportunidades que o crescimento econômico gera, permite a elas se incorporarem no mercado, aumenta a renda, consumir mais coisas, sair de fato de uma situação de carência direta. Agora, aquelas pessoas que não tinham recursos, não se desenvolviam, é o que ele (J. Souza) chama de ralé, as pessoas da ralé, como não desenvolveram seus requisitos básicos, os hábitos da sociedade complexa, a criação de oportunidade econômicas, de produção do mercado capital não é uma oportunidade real, porque as pessoas não se adequam a esse tipo de exigência. Então, o que nós começamos a perceber é isso... Há um movimento, 30 milhões de pessoas saindo da linha da pobreza, saindo de carências imediatas, deixa pra trás um monte de gente que não consegue entrar nesse barco do desenvolvimento. Pra essa população, vai ficando mais claro e a gente vai repetir a partir disso, os reflexos que traria para os jovens e para as crianças". (Participante 3)

Com isso, despreza-se todo um contexto imaterial para se justificar injustiças e culpabilizar as vítimas, colocando no sujeito toda a responsabilidade sobre os seus problemas. Porém, todo indivíduo é um ser cultural, que se transforma e é transformado por suas relações mais próximas. A família se constitui num dos ambientes mais favoráveis para essa socialização, pela reprodução de conhecimentos. Como afirmado por Souza (2009) em seu livro sobre a ralé brasileira:

“Apesar de 'invisível', esse processo de identificação emocional e afetiva já envolve uma extraordinária vantagem na competição social seja na escola, seja no 
mercado de trabalho em relação às classes desfavorecidas. Afinal, tanto a escola quanto o mercado de trabalho irão pressupor a 'in-corporação' (tornar 'corpo', ou seja, natural e automático) das mesmas disposições para o aprendizado e para a concentração e disciplina que são 'aprendidas', pelos filhos dessas classes privilegiadas, sem esforço e por mera identificação afetiva com os pais e seu círculo social.” (Souza, 2009, p. 20)

Dessa forma, ao se apresentar um programa para a realidade brasileira que venha de alguma forma fortalecer essa família como um todo, a expectativa do participante 3 é que faz-se mais do que prevenir o uso de drogas. Permite-se um desenvolvimento social dessa família. O PFF foi escolhido justamente por esse caráter comunitário, pois isolando o indivíduo do seu contexto, da sua realidade, não é possível compreender o fenômeno das drogas.

Além disso, ao se perceber essa realidade de desigualdade imaterial que constitui a ralé, o fenômeno das drogas toma outros rumos. Não é a droga como um produto isolado que causa o problema, por isso informações isoladas ou intervenções testemunhos (aquela em que se apresenta alguém que vivenciou a situação para contar sua história) não são eficazes para reduzir o uso. É o contexto desfavorável, de problemas familiares, comunidades vulneráveis, ausência de habilidades para viver nessa sociedade complexa, que perpetua a violência. Nesse cenário, as drogas entram como uma rota de fuga ou refúgio para problemas em que o indivíduo não tem, muitas vezes, habilidades para enfrentar.

Com isso, o MS buscou alternativas na prevenção para solucionar o problema levantado na Política Nacional sobre Drogas (em que um dos eixos da política é a prevenção), e em virtude do apelo social para se solucionar um problema emergente. Com isso, em parceria com a UNODC, foi em busca de programas preventivos. Antes de 
conhecer o PFF, estudava-se outro programa para ser implementado em larga-escala no país. O PFF foi escolhido por suas características metodológicas e comunitárias.

Dessa forma, pensa-se em outro paradigma para se compreender o fenômeno das drogas, qual seja, focar no indivíduo (e nas suas relações) ao invés de focar na droga (como substância). Assim, muda-se o paradigma de "guerra às drogas" para um paradigma de proteção ao indivíduo das consequências de problemas outros que levam ao uso das drogas, como exclusão social, problemas familiares, ausência de oportunidades (de lazer, trabalho e cuidado), pois, como apresentado pelo I Levantamento Nacional sobre o Uso de Crack no Brasil (Bastos \& Bertoni, 2014) as pessoas que mais sofrem com os problemas decorrentes do uso de drogas são aquelas que apresentam uma trajetória de vulnerabilidade social precedente ao uso da substância. E, a essa vulnerabilidade deve ser acrescida não apenas a pobreza, pois problemas decorrentes ao uso de drogas não são exclusivos de uma classe social, por mais que a pobreza agrave o problema (Bastos, \& Bertoni, 2014; SENAD, 2016).

\subsection{Características da Inovação}

Nesta seção serão apresentadas as principais características do PFF que impulsionaram a sua adoção no Brasil, de acordo com os componentes vantagem relativa, compatibilidade, complexidade, viabilidade e visibilidade.

\subsubsection{Vantagem Relativa: "A inovação é melhor que o status quo" (Wiecha,}

\section{4, p. 468)}

O PFF é uma proposta que foca na redução de problemas comportamentais entre adolescentes por meio de uma intervenção familiar e pela construção de fatores protetivos como habilidades parentais de disciplina consistente e suporte familiar ao jovem, além de desenvolver habilidades sociais, como assertividade nos adolescentes participantes. 
“(...) nós achamos que cabia naquilo que estávamos querendo... Uma proposta de prevenção às drogas, mas que fosse uma abordagem que levasse em conta o sujeito e não diretamente as drogas. Então, que atuasse nas habilidades sociais, habilidades de vida e, principalmente, porque esse, diferente dos outros, envolvia a família.” (Participante 1)

Esse programa apresenta um diferencial na proposta em comparação aos outros programas difundidos no Brasil. O PFF foi escolhido, como apresentado anteriormente, por apresentar um enfoque voltado às habilidades sociais do indivíduo e por não ser um programa como os outros, que fazem "guerra às drogas". Como afirmado pelo participante 2:

"Então é algo que o filho não pode dizer que o pai está fazendo um curso sobre drogas para aprender a cuidar deles e nem que o filho está fazendo e o pai joga a responsabilidade nele porque já aprendeu alguma coisa na escola. É ao mesmo tempo e no mesmo ambiente. É uma interação muito forte.” (Participante 2)

Outra característica notável no programa, como demonstra os dados, são seus procedimentos interativos e ludicidade, envolvendo objetos intermediários (advindos do psicodrama). Não é uma palestra sobre drogas, mas uma construção de vivências envolvendo os adolescentes e seus cuidadores que gera mudança de atitude frente às drogas. Como citado pelo Participante 1:

“Todas as atividades são mediadas por algum recurso físico, seja o DVD, uma cartolina, um papel, um jogo. Sempre tem um motivo para gerar um lúdico ali e daí sim passar. Eu não consigo me lembrar de nenhuma atividade que parte do abstrato, parte sempre do concreto. Acho que isso é bom porque gera uma sensação de proteção nos participantes. É como se eles não estivessem falando 
deles mesmos; eles estão falando do jogo, daquele personagem, falando daquele desenho, então solta um pouco mais, eles se sentem mais protegidos até criar um vínculo maior de confiança.” (Participante 1)

Por fim, uma vantagem adicional do PFF consiste na sistematização das sessões. O programa apresenta uma proposta de sete sessões semanais, em que uma sessão tem ligação com as outras, como afirmado pela Participante 1: “(...) o programa tem um diferencial e, na nossa opinião, esse diferencial é exatamente a sistematização das atividades, do espaço pra criação, mas não do espaço para se perder."

Deste modo, percebe-se que o programa demonstrou ser vantajoso para o contexto brasileiro. Isto correspondia às necessidades e demandas do MS.

\subsubsection{Compatibilidade: "A inovação é consistente com os valores vigentes"}

(Wiecha, 2004, p. 468)

No ano de 2013, quando o programa chegou ao Brasil, teve início sua adaptação cultural, na qual pretendia-se verificar a compatibilidade do programa com os valores sociais e a cultura vigente. Como constatado pelo participante 3:

"[O estudo piloto] foi muito importante porque mostrou que as pessoas não se sentiam, não tinham o temido choque cultural do conteúdo do programa que era algo estereotipado. Era mais essa questão das imagens no DVD, mas o conteúdo em si, que são conflitos familiares, estabelecimento de regras, tarefas, elas pareceram comuns às pessoas que participaram, inicialmente" (Participante 3).

A origem estrangeira do PFF gerou certa desconfiança e resistência nos aplicadores da inovação. Porém, à medida em que os profissionais se tornaram mais familiarizados com o PFF durante sua implementação, percebiam sua utilidade para as 
famílias e adolescentes participantes.

Mesmo tendo sido desenvolvido em outro contexto, a realidade apresentada no DVD, nos procedimentos do programa e nas atividades eram congruentes com as necessidades da população. As afirmações dos participantes constatam essa afirmação:

“(...) a nossa vulnerabilidade social, ela é muito grosseira, ela é muito violenta no sentido de não ter casa, entendeu? De não ter alimentos, então isso ia impactar. (...) Mas, as famílias falavam assim: 'olha, tudo bem, a casa deles é arrumadinha, mas está tratando de coisas que eu passo em casa"” (Participante 6)

"A hipótese dele (Souza, J.) era que o Brasil tem uma estrutura social que reproduz nessa dinâmica, uma parcela grande da população que, historicamente se reproduz aquém das exigências da sociedade (...) Seria uma reprodução contínua de uma marginalidade, uma população marginalizada que está abstraída da possibilidade de desenvolver os recursos necessários pra participar de uma sociedade complexa. Traduzindo em palavras mais simples, existem gerações que não conseguem educar seus filhos, (...) mais especificamente, a educação numa sociedade complexa demanda controle de impulsos, controle corporal, controle de elementos muito básicos que só se adquire na infância ou, não só, mas que adquirir isso na fase mais adulta é bem mais difícil” (Participante 3).

Dessa forma, o programa vem sanar uma necessidade muito grande dessa população como um todo, em adquirir comportamentos complexos. Nesse cenário, o PFF apresenta essa oportunidade de construção de habilidades parentais nas famílias e habilidades interpessoais nos jovens.

No entanto, o PFF, ao requerer cuidados com planejamento das sessões, entrou 
em conflito com uma característica da cultura brasileira que é a do improviso.

\begin{abstract}
"Posso estar sendo generalista demais, mas eu acho que, é quase senso comum, que não se fazem as coisas com muito planejamento aqui no Brasil. Pedir aos profissionais, as pessoas que estavam envolvidas que antes da sessão durante 3 horas, uma sessão que duraria 1 hora, 1 hora dos pais, 1 hora dos filhos e depois junto, eu achei que isso esbarrou na característica cultural. A gente gosta muito daquilo que conseguimos fazer no improviso" (Participante 1).
\end{abstract}

Deste modo, nota-se que o PFF mostrou-se parcialmente compatível com a cultura local. Por um lado, atende às necessidades das famílias e adolescentes participantes, mas por outro requer alto engajamento de equipes para planejamento.

\title{
3.2.3 Complexidade: $O$ grau de dificuldade da inovação ser compreendida e
} utilizada (Rogers, 1962/1995; Wiecha, 2004)

No Brasil, o PFF se apresentou como complexo em sua aplicação pela ausência de recursos materiais e pela interação dos profissionais responsáveis pela execução com os procedimentos manualizados. No primeiro aspecto, sua execução depende de salas para atendimento simultâneo ao adolescentes e pais e aparelho de TV e DVD, nem sempre disponíveis como parte da infraestrutura rotineira dos equipamentos de proteção social básica, contexto onde o programa foi inicialmente implementado no Brasil.

“Sala, cadeira, carteira, mesa, televisão, DVD, isso também foi bastante difícil. Não é que foi difícil porque não tinha como. Era difícil as pessoas entenderam na pactuação que o programa ia exigir isso." (Participante 5)

No segundo aspecto, o PFF prevê o uso de procedimentos manualizados. A ênfase na estrutura dos procedimentos, incluindo o tempo restrito destinado a cada atividade ao 
invés da livre discussão entre os participantes, parece trazer dificuldades de adesão entre os facilitadores.

"Tenho a desconfiança que as pessoas estão muito acostumadas a participar de capacitações e pegam alguma coisa daquela capacitação que pode ser útil e inclui naquilo que você faz no dia-a-dia. O PFF não é isso. Ele não é uma teoria pra embasar o restante do seu trabalho. Ele pode funcionar dessa forma, como a gente tem relatos, mas a proposta não é essa. A capacitação do PFF é para realizar o PFF inteiro." (Participante 1)

Logo, a conciliação entre a fidelidade na implementação do programa e uma adaptação sensível ao contexto parece ser um desafio.

\subsubsection{Viabilidade: "A inovação pode ser utilizada em bases parciais ou} temporárias" (Wiecha, 2004, p. 468)

No quesito viabilidade, as barreiras encontradas foram as de recursos humanos e financeiros relativos aos serviços de assistência social nos quais o PFF foi implementado.

"Recursos humanos porque os serviços todos parecem trabalhar no limite da sobrecarga. Recurso financeiro porque o programa prevê alguns elementos que não estão na carta comum de aquisição do serviço. Se você tem uma rubrica e pode comprar alguma coisa, adquirir algum serviço, um jogo, tudo bem, mas se você não tem esbarrava nisso.” (Participante 1) "Em alguns grupos isso funciona bem, eles conseguem encaixar o PFF na carga horária, agora em outros, ou eles fazem tudo ao mesmo tempo, o que gera uma sobrecarga, ou eles abrem mão de alguns, fazem o PFF e depois correm atrás dos que eles deixaram de fazer” (Participante 5). 
Estes relatos apontam que a viabilidade do PFF está, portanto, relacionada a fatores contextuais, tais como as condições de trabalho e a infraestrutura dos serviços que o executam.

\subsubsection{Resultados Observáveis: "Os resultados de uma inovação são visíveis à} população" (Wiecha, 2004, p. 468)

Os resultados do programa no Brasil, mesmo com adoção e implementação recentes, apresentam indícios evidentes de benefício para os participantes. Dados apresentados no relatório sobre o levantamento de necessidades para adaptação cultural do programa e avaliação de processo da implementação de um piloto no DF (Murta et al., 2014), obtidos em entrevista com 34 participantes via telefone aos dois meses após o término do programa, indicaram transferência de conhecimentos para as interações familiares. Os relatos foram agrupados em relatos de práticas de habilidades e conhecimentos adquiridos no programa (43 relatos) e ausência de prática ou de compreensão do que fora discutido no programa (4 relatos). Dentre os relatos de mudança, a maior parte deles (34 relatos) evidenciou mudança na interação familiar, especialmente aumento em comunicação assertiva (10 relatos), engajamento dos filhos em tarefas de casa e ajuda aos pais (oito relatos), definição de limites (sete relatos) e tempo na interação com os filhos (cinco relatos). Este relatório indicou ainda uma apreciação positiva por parte de facilitadores (Murta et al., 2014), como revela este relato de um deles: "Esse programa é a estratégia mais eficaz para trabalhar o fortalecimento de família que eu conheci até agora (...) A proposta desse trabalho realmente trabalha a família como um todo (...) o programa estimula e encoraja a mudança de comportamento.”

Estes dados também estão consoantes com os dados coletados por esta pesquisa. Conforme o relato do Participante 5: 
“(...) ele induz a autonomia dessas famílias: que ele induz que essas famílias se libertem do bolsa família, no sentido de eu vou ser o protagonista da minha vida, né, quer dizer, eu vou acessar outros serviços, eu vou me tornar um cidadão”.

Nesse sentido, muito além de uma perspectiva de combate às drogas, o programa proporciona o empoderamento familiar e o fortalecimento de vínculos, como observado nessa outra afirmação:

“(...) no sentido de acessar o direito mesmo, de chegar, eu acho lindo quando a família fala: "tá, que outra coisa tem no CRAS que a gente possa participar?", delas se libertarem dessa escravidão que a gente vive até hoje. Delas se libertarem desse oceano que separa as pessoas por classe social.” (Participante 5)

Sobre esses aspectos, o participante 2 apresenta uma clara discussão sobre a realidade brasileira que impactou o processo de escolha do programa para o Brasil:

"Souza fala que esse estado de sobrevivência contínua, um eterno presente, as pessoas não desenvolvem noção de futuro. Elas conseguem conceber futuro racionalmente, mas não tem a emoção de ter um futuro, porque a emoção deles está sempre no presente, na necessidade imediata. Então, um pai nessas condições não consegue transmitir ao filho o sentido de um esforço pra construção de um futuro, porque o tempo todo, na prática, está batalhando para conseguir sobreviver no presente. O pai pode até falar pro filho: "Vai estudar que isso é pro seu bem, pro seu futuro", mas esse pai não sabe o que é futuro, então como ele fala isso? A única coisa que a criança entende é a agressão. Isso não traz um sentido de fato. Tomando essas coisas que a gente entendeu que um programa como o PFF, como assim você vai ensinar os outros a cuidarem dos seus filhos, a educar seus filhos, a se relacionar. Parece pretencioso e ao mesmo tempo tolo. Parece. Na hora que a 
gente começa a observar e ver como isso funciona, quais as etapas de interação e, fundamentalmente, a resposta que os pais dão, a gente fala assim, isso não é tolo, ao contrário. Eles saem muito agradecidos, satisfeitos, alguém está me ajudando a cuidar dos meus filhos e isso traz uma satisfação muito grande. O PFF tem um sentido estratégico, político, tem uma questão de tentar trabalhar aspectos decorrentes da desigualdade estrutural do país e, no fundo, tentar ver se a gente consegue encurtar o caminho de uma geração pra poder sair dessa situação de ralé.” (Participante 2).

O programa dessa forma constrói recursos e habilidades nos indivíduos que os auxiliam na luta constante de sair desse estado de ralé, como diz Jessé Souza (2011), e se constitui como um mecanismo de defesa às adversidades cotidianas. E a construção desse empoderamento pessoal provoca mudanças que não se constituem num combate às drogas, mas faz com que o indivíduo não precise mais dela para se "sentir feliz", ou para ter que fugir de uma realidade que o esmaga, pois agora ele tem ferramentas para enfrentar os problemas de frente e, além disso, esse indivíduo se permite ter esperança num futuro que ele não conhecia. Com o PFF, mudam-se as relações anteriormente enrijecidas pela não habilidade de mudá-las.

“(...) muito bom ouvir depoimento das famílias, de como tem mudado a vida deles, e eles falam mesmo: 'ah, minha mãe só falava comigo gritando, agora ela sempre se acalma e conversa comigo'; E as mães falando: 'ah, eu tô menos estressada, meu filho tá obedecendo mais, agora todo mundo tem suas tarefas de casa e eles nem questionam mais por que que tem que fazer, eles já sabem que faz parte da rotina da família. Ah, agora todo final de semana a gente bota a mesa no quintal e faz um jantar, são os nossos momentos de família e tal.' É gostoso demais ouvir depoimentos assim.” (Participante 3) 


\subsection{Características do processo de difusão}

Nesta seção são analisados os aspectos facilitadores e dificultadores das várias etapas do processo de difusão do PFF para o Brasil, quais sejam, disseminação, adoção, implementação e sustentabilidade. Os resultados apontaram certas características que merecem destaque. A primeira, corresponde ao fato de que o processo de difusão não é linear, mas cíclico. A Teoria aponta uma ordem, primeiro vem a disseminação, depois a adoção, em terceiro a implementação e, quarto, a sustentabilidade. Na prática, porém, o processo se mostra mais complexo e não linear. Percebeu-se que houve um processo de disseminação por parte dos pesquisadores desenvolvedores do programa: primeiro, desenvolveram a intervenção; segundo comunicaram para a comunidade acadêmica que aquele programa existia, através de publicações, avaliações de eficácia e efetividade, avaliações com diversos grupos. E, terceiro, em revisão sistemática (Foxcroft, Ireland, Lister-Sharped, Lowe, \& Breen, 2003), em comparação com outros programas de prevenção, se mostrou o mais efetivo. Esse foi o primeiro passo em direção à disseminação e difusão do programa. Os funcionários do Ministério da Saúde buscavam uma solução para resolver um problema complexo. Ao buscar uma parceria com o UNODC, conheceu o PFF. Sendo assim, foi persuadido a adotá-lo (devido suas características metodológicas e por seus resultados). Esse foi o segundo passo no ciclo. A partir dessa escolha, colocou-o em prática, por meio do pré-piloto, em que foi realizada adaptação cultural desse programa à realidade brasileira. Após esse momento, começouse um novo ciclo. O MS disseminou esse programa para outras regiões do Brasil (DF, AC, SP, SC, CE). Esses locais tomaram conhecimento da inovação, foram persuadidos a adotá-la e implementaram-na. A partir das características em que envolveu os passos anteriores, a inovação poderá ou não se sustentar nos estados e municípios, e caso se sustente e novas ondas de disseminação e adoção aconteçam, o programa se manterá 
como uma possível política de prevenção das drogas (sustentabilidade no país).

Em segundo lugar, essa análise computou desafios/barreiras e facilitadores para o processo de difusão do programa no Brasil. Essa análise pode ser verificada de forma resumida na Tabela 1. A partir disso, as subseções seguintes tratarão dessas ondas apresentadas e os desafios e facilitadores da disseminação, adoção, implementação e sustentabilidade do programa.

\subsubsection{Disseminação e adoção em nível nacional}

A disseminação do Programa Famílias Fortes para o Brasil ocorreu a partir da orientação de um consultor da UNODC (Escritório das Nações Unidas sobre Drogas e Crime). A escolha se deu pelo fato do SFP ter demonstrado resultados de efetividade em outros países, o que foi um importante fator indutor da adoção, como se nota no relato do Participante 2.

"Foi uma sugestão que a gente pediu para um consultor, um oficial da UNODC, que fez um trabalho de seleção, de todos os programas de prevenção. Eles categorizaram os programas existentes, e avaliaram o que tem efeito e o que não tem, a partir de evidências fortes, médias e fracas. A nossa decisão foi adotar um programa que tenha efetividade demonstrada. (...) Então, nós temos esse contexto, o problema do crack; a partir de 2006, 2007 o crack começa a surgir como uma questão muito forte na mídia; 2008, 2009 já se tornou bastante difundido; 2010 entrou em pauta da agenda política, de campanha política. Então, em torno ao crack se criaram muitas fantasias, muito medo, muita insegurança e, ao mesmo tempo, emerge na questão do consumo de drogas por jovens." (Participante 2) 
Adotado o programa pelo MS, passou-se então a conhecer os procedimentos do programa, seus materiais e sua forma de aplicação. Porém, como afirmado pela Participante 1: "Teve uma certa dificuldade de conseguir o material de ter acesso ao material. O UNODC foi crucial nesse intercâmbio de fazer contato com os desenvolvedores do programa". 
Tabela 1.

Barreiras e facilitadores do processo de Difusão do PFF no Brasil

\begin{tabular}{|c|c|c|c|c|c|c|c|c|}
\hline & \multicolumn{2}{|c|}{ Contexto externo } & \multicolumn{2}{|c|}{ Contexto interno } & \multicolumn{2}{|c|}{ Facilitadores } & \multicolumn{2}{|c|}{ Programa } \\
\hline & Barreiras & Facilitadores & Barreiras & Facilitadores & Barreiras & Facilitadores & Barreiras & Facilitadores \\
\hline Disseminação & & $\begin{array}{l}\text { O programa } \\
\text { está de } \\
\text { acordo com } \\
\text { a PNAD }\end{array}$ & $\begin{array}{l}\text { Comunicação/ } \\
\text { Pactuação }\end{array}$ & $\begin{array}{l}\text { Relevância } \\
\text { social do } \\
\text { programa }\end{array}$ & Comunicação & $\begin{array}{c}\text { Interesse pelo } \\
\text { programa }\end{array}$ & Manual & $\begin{array}{l}\text { Resultados de } \\
\text { efetividade } \\
\text { demonstrado } \\
\text { em outros } \\
\text { países } \\
\end{array}$ \\
\hline Adoção & $\begin{array}{c}\text { Conjuntura } \\
\text { política local, } \\
\text { greves de } \\
\text { servidores, } \\
\text { constrangimentos } \\
\text { salariais } \\
\end{array}$ & $\begin{array}{l}\text { Relevância } \\
\text { social }\end{array}$ & $\begin{array}{l}\text { Recursos } \\
\text { humanos, } \\
\text { financeiros e } \\
\text { materiais }\end{array}$ & $\begin{array}{c}\text { Relevância } \\
\text { social do } \\
\text { programa/ } \\
\text { Está de } \\
\text { acordo com } \\
\text { PAIF } \\
\end{array}$ & Comunicação & $\begin{array}{l}\text { Interesse pelo } \\
\text { programa/ } \\
\text { resultados } \\
\text { observáveis }\end{array}$ & $\begin{array}{l}\text { Tempo de } \\
\text { aplicação e } \\
\text { planejamento } \\
\text { do programa }\end{array}$ & $\begin{array}{l}\text { Caráter lúdico } \\
\text { do programa }\end{array}$ \\
\hline Implementação & $\begin{array}{c}\text { Conjuntura } \\
\text { política local, } \\
\text { greves de } \\
\text { servidores, } \\
\text { constrangimentos } \\
\text { salariais } \\
\end{array}$ & $\begin{array}{c}\text { Apelo } \\
\text { comunitário }\end{array}$ & $\begin{array}{l}\text { Recursos } \\
\text { humanos, } \\
\text { financeiros e } \\
\text { materiais }\end{array}$ & $\begin{array}{l}\text { Relevância } \\
\text { social do } \\
\text { programa/ } \\
\text { Está de } \\
\text { acordo com } \\
\text { PAIF } \\
\end{array}$ & $\begin{array}{l}\text { Conhecimentos } \\
\text { e crenças sobre } \\
\text { prevenção ao } \\
\text { uso de drogas }\end{array}$ & $\begin{array}{c}\text { Engajamento ao } \\
\text { programa e às } \\
\text { famílias/Cuidado } \\
\text { com os } \\
\text { participantes }\end{array}$ & $\begin{array}{c}\text { Tempo para } \\
\text { planejamento }\end{array}$ & $\begin{array}{c}\text { Adaptação } \\
\text { recente do } \\
\text { material/ } \\
\text { Atividades } \\
\text { sistematizadas }\end{array}$ \\
\hline Sustentabilidade & $\begin{array}{c}\text { Comunicação } \\
\text { com MDSA }\end{array}$ & $\begin{array}{l}\text { Relevância } \\
\text { social/ } \\
\text { Apelo } \\
\text { comunitário/ } \\
\text { O programa } \\
\text { está de } \\
\text { acordo com } \\
\text { a PNAD }\end{array}$ & $\begin{array}{c}\text { Não foi } \\
\text { institucionalizado }\end{array}$ & $\begin{array}{c}\text { Está de } \\
\text { acordo com } \\
\text { as } \\
\text { necessidades } \\
\text { locais }\end{array}$ & $\begin{array}{c}\text { Constrangimento } \\
\text { salarial, carga de } \\
\text { trabalho }\end{array}$ & $\begin{array}{c}\text { O programa } \\
\text { atende uma } \\
\text { necessidade de } \\
\text { ferramentas para } \\
\text { o trabalho }\end{array}$ & $\begin{array}{l}\text { Características } \\
\text { metodológicas }\end{array}$ & $\begin{array}{l}\text { Atende aos } \\
\text { princípios do } \\
\text { PAIF, atende } \\
\text { às } \\
\text { necessidades } \\
\text { locais }\end{array}$ \\
\hline
\end{tabular}


Percebe-se que nessa primeira fase da difusão, o contato com os desenvolvedores do programa e alguém que advogasse pelo programa (UNODC, neste caso) constituiu-se em fator fundamental para a entrada do programa na realidade brasileira. Esse intercâmbio entre pesquisador/desenvolvedor da intervenção e realidade, a forma em que se apresenta a inovação aos seus futuros implementadores faz toda a diferença para que a inovação seja adotada e se mantenha no local. Essas fases iniciais constituem a base para a difusão. Além do mais, percebe-se que a escolha pelo PFF foi também uma decisão política, econômica e social (Berry \& Berry, 2007).

É uma decisão política, pois acompanha uma estratégia internacional, em que a emulação do programa acompanha uma resposta que tem sido empregada em outros países. Outrossim, é uma decisão política, pois segue as diretrizes da PNAD, e acompanhou a estratégia política de desenvolvimento social e humano do Governo Federal. Como observado no relato do participante 2:

“O PFF tem um sentido estratégico, político, tem uma questão de tentar trabalhar aspectos decorrentes da desigualdade estrutural do país e, no fundo, tentar ver se a gente consegue encurtar o caminho de uma geração pra poder sair dessa situação de ralé." (Participante 2).

"E, também, pensando em política pública, uma coisa que, é feio falar, mas que os governantes nas instâncias que eles tiverem podem usar como uma boa campanha política. Na periferia... Nas famílias, causa um bum, todo mundo tá falando nisso... tem o seu lugar, sabe?! Então é isso, tem apelo na família, na comunidade, não sei que... tem um apelo assim... Eu acho que tem outro ponto, (...) tem o cenário que a gente tá hoje, não tem programas tão sistematizados quanto esses" (Participante 5) 
É também uma decisão econômica, pois a prevenção apresenta um caráter mais vantajoso economicamente do que o tratamento. Uma vez que ao prevenir o retardo no início do uso de substância entre adolescentes, diversos gastos com saúde são evitados futuramente. Além do fato de que ao se fortalecer vínculos familiares, outros transtornos são prevenidos. Como apresenta a fala dos participantes a seguir:

“(...) a cada grupo que você faz de prevenção, você tá evitando que, daqui a cinco, sete anos, dez famílias apareçam pra você procurando os seus serviços. Acho que o tempo é até menor, né? É, se você fortalece aqui, você evita várias coisas, porque você está falando de um médio prazo e eu vejo muito um curto prazo" (Participante 6)

“(...) é mais barato você prevenir a doença do que agir nela” (Participante 5)

“Outro aspecto importante é que, quando se fala de prevenção, para além da questão da efetividade, que é muito importante também, os estudos mostram o quanto o retardo na iniciação, no consumo de qualquer substância, porque em tese, o sujeito mais maduro, mais vivido, mais responsável, fica menos vulnerável ao uso abusivo; existe uma correlação entre o início de consumo e probabilidade de uso abusivo.” (Participante 2).

Ademais, é uma decisão social, pois vem como resposta ao Programa Crack é Possível Vencer e a uma demanda da Política Nacional sobre drogas. E, também, responde a um apelo da população para se solucionar um problema complexo. Como apresentado na fala do participante 2 , os usuários do programa respondem de forma positiva ao programa.

“Tomando essas coisas que a gente entendeu que um programa como o PFF, como assim você vai ensinar os outros a cuidarem dos seus filhos, a educar seus 
filhos, a se relacionar. Parece pretencioso e ao mesmo tempo tolo. Parece. Na hora que a gente começa a observar e ver como isso funciona, quais as etapas de interação e, fundamentalmente, a resposta que os pais dão, a gente fala assim, isso não é tolo, ao contrário. Eles saem muito agradecidos, satisfeitos, alguém está me ajudando a cuidar dos meus filhos e isso traz uma satisfação muito grande.” (Participante 2).

Porém, a difusão não envolveu apenas obter conhecimento sobre a inovação, ser persuadido a usá-la, decidir colocar em prática (Rogers, 1995), mas também implementar de forma rigorosa e confirmar a decisão, quando o programa se mantém com seus resultados positivos (Fox, Gottfredson, Kumpfer, \& Beatty, 2004). Para se alcançar esses objetivos, o programa deve ser, e tem sido, expandido em larga escala para o interior do Brasil. Sendo assim, novo processo de disseminação, adoção, implementação tem ocorrido. Ou seja, o MS adaptou o programa à realidade brasileira, comunicou sobre o programa aos estados e municípios brasileiros, que devem ser persuadidos para implementarem a inovação, para então colocarem em prática e ao longo do tempo, a depender de como se consolidaram as etapas anteriores, manter em sua rotina a inovação. Uma etapa muito importante nesse momento correspondeu à adaptação cultural. Essa adaptação requer conhecer os elementos centrais do programa, conhecer a realidade do local de implementação, e realizar testes de eficácia e efetividade do programa com o novo formato. E, assim expandir o programa para outras localidades (scale up) (Gottfredson et al., 2015).

Com relação a essa configuração da difusão para os estados e municípios brasileiros, diversas barreiras ou desafios podem surgir. O processo de disseminação em larga escala de um programa não é algo simples de ser realizado, pois envolve diversas estratégias de uma metodologia ainda não completamente consolidada na literatura 
(Gottfredson et al., 2015; Spoth et al., 2013; Turner \& Sanders, 2006). As seções seguintes descrevem os desafios, barreiras e facilitadores para o processo de difusão do PFF no interior do Brasil.

\subsubsection{Disseminação em nível local}

No Brasil, a disseminação do PFF, como os dados apontam, tem acontecido da seguinte forma: o programa é apresentado aos tomadores de decisão, sejam eles prefeito, gestor da assistência social ou outro articulador local responsável pelos serviços como um todo dos municípios. Muitas vezes são os próprios gestores que procuram o MS solicitando o programa. Dessa forma, é realizada uma sensibilização quanto aos princípios do programa, e as contrapartidas que serão necessárias para se implementar o programa, como por exemplo, salas, aparelho de DVD, quatro funcionários aptos a colocar o programa em prática. Porém, algumas vezes, essa informação, das contrapartidas e informações sobre os princípios do programa não são apresentadas de forma clara aos facilitadores, por conseguinte os profissionais chegam na formação sem saber o que foram fazer lá. Porém, se a informação é relatada de forma adequada, o processo se torna mais tranquilo e não ocorrem problemas na formação. Como relata a Participante 5:

"É feita uma pactuação: a coordenadora do ministério vai lá no território, ou a gestora, vai lá no local, tem uma reunião com a gestão, com o articulador local e esse articulador vai entrar em contato com os serviços. Na maioria dos municípios tem uma pessoa representando um município - esse articulador local é representante do município: ele já chega na secretaria que cabe fazer a pactuação, entra em contato com a secretaria e, não sei, alguém manda os profissionais. (...) Só que como é muito distante a coordenação do ministério da saúde e esse facilitador, a informação se perde. A impressão que eu tenho é que 
a (coordenadora, nome omitido), por exemplo, passa as informações pro articulador local, ele compreende super bem, geralmente eles que procuram o ministério, então eles já sabem do que se trata. Quando eles passam pra gestão local, talvez essa informação já esteja alterada, quando esse gestor local for falar com os profissionais dele, ele vai dizer, olha a secretaria do estado está com três programas e o prefeito topou, então a gente tem que mandar três profissionais vai você, você e você. Aí as pessoas ficam... Mas sobre o que que é? Ah, prevenção ao uso de drogas.” (Participante 5).

Como se nota nesse relato, a maneira como uma intervenção é apresentada aos tomadores de decisão tem exercido influência sobre sua adoção, implementação e sustentabilidade no território (Fox et al., 2004). Esses dados indicam que o marketing envolvido na disseminação se mostra crucial para a adesão, compreensão e implementação do programa, como observado na literatura (Bartholomew et al., 2011).

Além do mais, muitas vezes o secretário ou o gestor local nem sempre conhecem a fundo a realidade daquele serviço em que o programa será implementado. Isso tem gerado uma barreira quanto à viabilidade para se adotar o programa, como expresso pela Participante 3.

"Essa foi uma barreira muito grande, porque, quando eles gostavam do programa, aceitavam o monitoramento, ainda tinha essa questão de como a gente vai fazer. Recurso financeiro porque o programa prevê alguns elementos que não estão na carta comum de aquisição do serviço. Se você tem uma rubrica e pode comprar alguma coisa, adquirir algum serviço, um jogo, tudo bem, mas se você não tem esbarrava nisso. E os recursos materiais no que se refere à estrutura mais permanente do programa. Sala, cadeira, carteira, mesa, televisão, DVD, isso também foi bastante difícil. Não é que foi difícil porque não tinha como. Era 
difícil as pessoas entenderam na pactuação, que o programa ia exigir isso. Não era pra ser feito de qualquer forma, em qualquer lugar, hoje numa sala, amanhã em outra." (Participante 3)

Dessa forma, percebe-se que há um desafio no início da disseminação que afeta tanto a adesão, quanto a implementação e a manutenção da inovação no local. Também fica clara a necessidade de uma pactuação que, em um segundo momento, envolva a sensibilização dos profissionais que irão implementar o programa. Esse passo seria preparar o local para receber a inovação (Bartholomew et al 2011, Fagan \& Mihalic, 2003). Assim, constituindo uma ação de mobilização dos profissionais e empoderamento dos principais atores envolvidos com a implementação.

Em contrapartida, o programa apresenta diversos pontos que facilitam sua disseminação, como por exemplo os resultados visíveis, o modelo proposto de intervenção e característica do lúdico do programa.

"Nós achamos que cabia naquilo que estávamos querendo. Uma proposta de prevenção às drogas, mas que fosse uma abordagem que levasse em conta o sujeito e não diretamente as drogas. Então, que atuasse nas habilidades sociais, habilidades de vida e, principalmente, porque esse, diferente dos outros, envolvia a família." (Participante 3).

Além do mais, recentemente o manual do programa foi reformulado para facilitar a adesão dos facilitadores. Essa reformulação aconteceu após reunião com profissionais que já haviam facilitado grupos do PFF. Porém, ainda se faz necessário uma melhor compreensão dos elementos centrais do programa para aprimorar a sua disseminação.

\subsubsection{Adoção em nível local}


A análise dos dados revelou duas barreiras para a adoção em nível local: viabilidade do programa para a realidade local e a configuração do local. Quanto à primeira, o programa se apresentou complexo em sua estrutura, necessitando de diversos recursos humanos, financeiros e materiais, que muitas vezes o local de adoção não apresenta, ou não está na carta comum de aquisição. O material de aplicação (manual do facilitador, caderno de atividades para pais e jovens, material de apoio, jogos, sessões booster) corresponde a um "calhamaço", com diversas atividades a serem planejadas antes da intervenção que requer muitas horas de planejamento, o que torna o programa muito dispendioso e caro. Porém, em 2015/2016, veio uma iniciativa para sanar essa barreira e adaptar o material.

"A sugestão de deixar tudo pronto veio de diminuir a complexidade do programa que se dava pela confecção dos materiais (demorar quatro horas para poder planejar uma sessão de duas horas, picotando papel), de forma que dê mais gosto ao facilitador para ele poder aplicar o programa. O que não acontecia anteriormente, pois ele achava muito complexo e difícil o antes da aplicação, que seria o de separar os materiais, confeccioná-los, e etc., o que demandava bastante tempo. A intenção era a de fazer um box, em que todos os materiais estivessem guardados e pudessem ser entregues ao facilitador.” (Participante 4)

A segunda barreira corresponde à configuração institucional do local em que o programa está sendo adotado, os serviços da assistência social, pois conhecia-se melhor o contexto da saúde e da escola, pois dois outros programas foram adotados para esses contextos, com um processo de disseminação avançado. "Boa parte de nós, inclusive (nome omitido) não tinha muita clareza dos limites e desafios, a gente conhecia mais a escola e a saúde do que a assistência, não tinha muita clareza de qual equipamento era mais adequado" (Participante 3). O serviço apresentou-se adequado, devido às 
características do serviço, e em decorrência do PAIF, mas por dificuldades institucionais tem-se apresentado ora como barreira para a difusão do programa ora como facilitador. Como apresentado pela Participante 4:

"O funcionalismo tem um sistema que é muito maior do que o programa em si... Até mesmo uma questão política, em que momento a assistência social está hoje para receber o programa, por que na teoria é isso, tipo, o programa é para fortalecimento de vínculo... Nossa! Um dos princípios do SUAS é isso: fortalecimento de vínculos familiares, né?!” (Participante 4).

Por conseguinte, essa barreira se apresenta mais como um desafio. A assistência social se mostra interessada pelo programa, pois, é algo em que deveria fazer parte de sua estrutura: fortalecer vínculos familiares. Também, no relatório de Murta et al. (2014) quanto à adaptação cultural, o equipamento se mostrou adequado para receber o programa. Ou seja, o desafio é conseguir inserir o programa na estrutura básica dos serviços de proteção básica (COSEs, CRAS, Centros POP etc.).

Já os facilitadores para a adoção se encontram na coerência da proposta do programa, a abordagem adotada (que é focada na família e não nas drogas), a compatibilidade da proposta com a realidade nacional, além de o programa apresentar um sentido político estratégico. Como mostram as Participantes 3 e 4:

"Todas as atividades são mediadas por algum recurso físico. Seja o DVD, uma cartolina, um papel, um jogo. Sempre tem um motivo pra gerar um lúdico ali e daí sim passar. Acho que isso é bom porque gera uma sensação de proteção nos participantes. É como se eles não estivessem falando deles mesmos; eles estão falando do jogo, daquele personagem, falando daquele desenho, então solta um 
pouco mais, eles se sentem mais protegidos até criar um vínculo maior de confiança." (Participante 3).

"Foi quando a gente teve a oportunidade de fazer um piloto, compartilhado com a UnB, pra gente verificar a viabilidade desse programa. E foram muitas boas surpresas. Primeiro, pra mim, a melhor de todas era a coerência do programa, do que ele se propunha e das estratégias que a gente utilizava. Você consegue identificar que tem um caminho. E a coerência também com o que a gente queria. Foi uma surpresa, não uma surpresa, mas uma constatação muito satisfatória que a gente viu que realmente o programa tinha uma mensagem que a gente queria." (Participante 4).

\subsubsection{Implementação}

Diversos fatores podem interferir na qualidade da implementação, e com isso alterar os resultados da intervenção e também sua sustentabilidade nos locais de adoção. Alguns desses fatores são relacionados às características da intervenção, aos facilitadores, aos aspectos do contexto interno e contexto externo ao programa, e por fim aspectos do processo de implementação. Esses fatores também podem se mostrar como barreiras ou facilitadores da implementação.

O PFF demonstrou apresentar características que facilitaram sua implementação no Brasil. O programa se apresentou compatível com a realidade brasileira, com resultados observáveis e vantajosos à comunidade. Porém, esbarrou em alguns problemas como resistência por ser um programa estrangeiro e devido aos custos para sua implementação. Como afirmado pelo participante 6: "o que se repete muito é a questão de preparação do material, que eles gastam muito tempo preparando o material”. Esses problemas, no entanto, têm sido trabalhados, com a adaptação dos materiais e com os 
resultados demonstrados. Apesar de ser um programa estrangeiro, apresenta diversos pontos vantajosos para a realidade brasileira.

Um ponto a ser destacado corresponde à teoria do programa. Diversos facilitadores demonstraram resistência ao programa por considerá-lo embasado em teoria behaviorista. A assistência social não aceita o uso de brindes como "reforço positivo", pois pode parecer assistencialismo, com isso houve muita resistência na implementação do programa. Uma das multiplicadoras afirmou que os facilitadores falavam nas formações: "mas isso é behaviorismo, treinar comportamento não existe". Por isso, as multiplicadoras tiveram que mudar o posicionamento e mudar a formação apresentando a teoria que embasa o programa. Porém, esse posicionamento não é consenso. Em alguns lugares o uso de "incentivos" é uma prática recorrente anterior ao PFF.

O segundo ponto sobre a qualidade da implementação é referente aos facilitadores. Conhecimentos, crenças, autoeficácia para aplicar o programa, identificação com a organização e valores pessoais interferem na condução da intervenção (Santos \& Murta, 2015). O programa, por apresentar uma abordagem voltada à prevenção ao invés de tratamento, tem gerado certa resistência nos facilitadores, como a resistência quanto à escolha das famílias para participar do programa. Como afirmado pela participante 6:

“É essa questão da visão da prevenção é um obstáculo que a gente enfrenta durante o monitoramento. Que é esse questionamento que surge na formação, mas se perpetua 'eu tô deixando de atender as famílias que chegam lá no CRAS para poder fazer o grupo do PFF, eu tô tendo que deixar de fazer atendimento para ter que preparar material', mas a cada grupo que você faz prevenção, você tá evitando que daqui cinco, sete anos, dez famílias apareçam pra você procurando os seus serviços" (Participante 6). 
Ademais, há questões de vinculação com a organização, muitos profissionais apresentam contrato temporário ou são transferidos de uma localidade à outra, o que torna o serviço descontínuo. Também há problemas com a sobrecarga de trabalho e diversas demandas concorrentes à implementação do PFF. Porém, muitos facilitadores, quando percebem a relevância do programa para o serviço, se mostram defensores do programa, como apresentado pela fala de uma participante em uma das reuniões: “Gente, esse é o nosso trabalho. A gestão federal não tá pedindo pra vocês fazerem coisas a mais. O PFF tem que entrar dentro da sua carga de trabalho, não é pra ser feito depois do expediente ou na hora do almoço". Outra participante relatou: "o PFF tem que estar aqui mesmo (nos serviços de assistência social- COSE), aqui é o local para fortalecer vínculos”. Esses dados revelam que quando o profissional adquire conhecimento e experiência quanto ao programa, quanto ao que significa o trabalho preventivo, a resistência ao programa e à sua implementação diminuem. E, ao contrário de se oporem, esses profissionais advogam pelo programa.

Relativo ao contexto interno, diversos desafios à implementação do PFF foram relatados pelos participantes. Há escassez de recursos financeiros e materiais nos locais, poucos recursos humanos disponíveis e, em decorrência disso, baixa prontidão para a implementação. Muitos recursos necessários à implementação do programa não estão na carta comum de aquisição de produto dos serviços da assistência em que o programa foi previsto, o que gera constrangimentos para a implementação. Por não ter um intercâmbio formalizado com o MDS (Ministério do Desenvolvimento Social), que é o órgão ao qual a assistência social responde, o processo se torna oneroso: “Agora, como não tem parceria com o MDS, que é que dita as regras para eles, eles não conseguem encaixar na rotina de trabalho". Esse fato também repercute na institucionalização do programa, que pode passar por dificuldades ainda maiores com a recente fusão desse ministério no novo 
MDSA (Ministério do Desenvolvimento Social e Agrário). Com as crises política e econômica, os entraves burocráticos complicam-se de forma exponencial devido à alteração de agenda política e na alocação de recursos.

No quesito contexto externo, os dados apontaram que os principais desafios à implementação são concernentes às políticas externas, sistema político, comunidade externa e recursos disponibilizados. Greves de servidores, constrangimentos salariais, instabilidade política são alguns dos problemas que têm afetado a implementação do programa. Já os elementos facilitadores relativos ao contexto externo referem-se ao fato de que o programa gera um apelo da comunidade que carece de programas de fortalecimento de vínculos e prevenção do uso de drogas. Além do mais, as diretrizes da Política Nacional sobre Drogas (2005) prevêem ações de cunho comunitário e de prevenção. Deste modo, esse programa configura-se como uma resposta a essa necessidade.

\subsubsection{Sustentabilidade}

A sustentabilidade da inovação no local de implementação está relacionada aos resultados da disseminação, da adoção e da qualidade da implementação do programa. O Programa Famílias Fortes ainda não foi institucionalizado nos locais de implementação, e por ser uma iniciativa recente, não é possível avaliar a sua manutenção nos locais. Porém, é possível, a partir da análise das fases anteriores, avaliar as perspectivas e planejamento para a sustentabilidade do PFF no Brasil. A Figura 5 apresenta uma síntese de fatores potencialmente impactantes na sustentabilidade do PFF. 


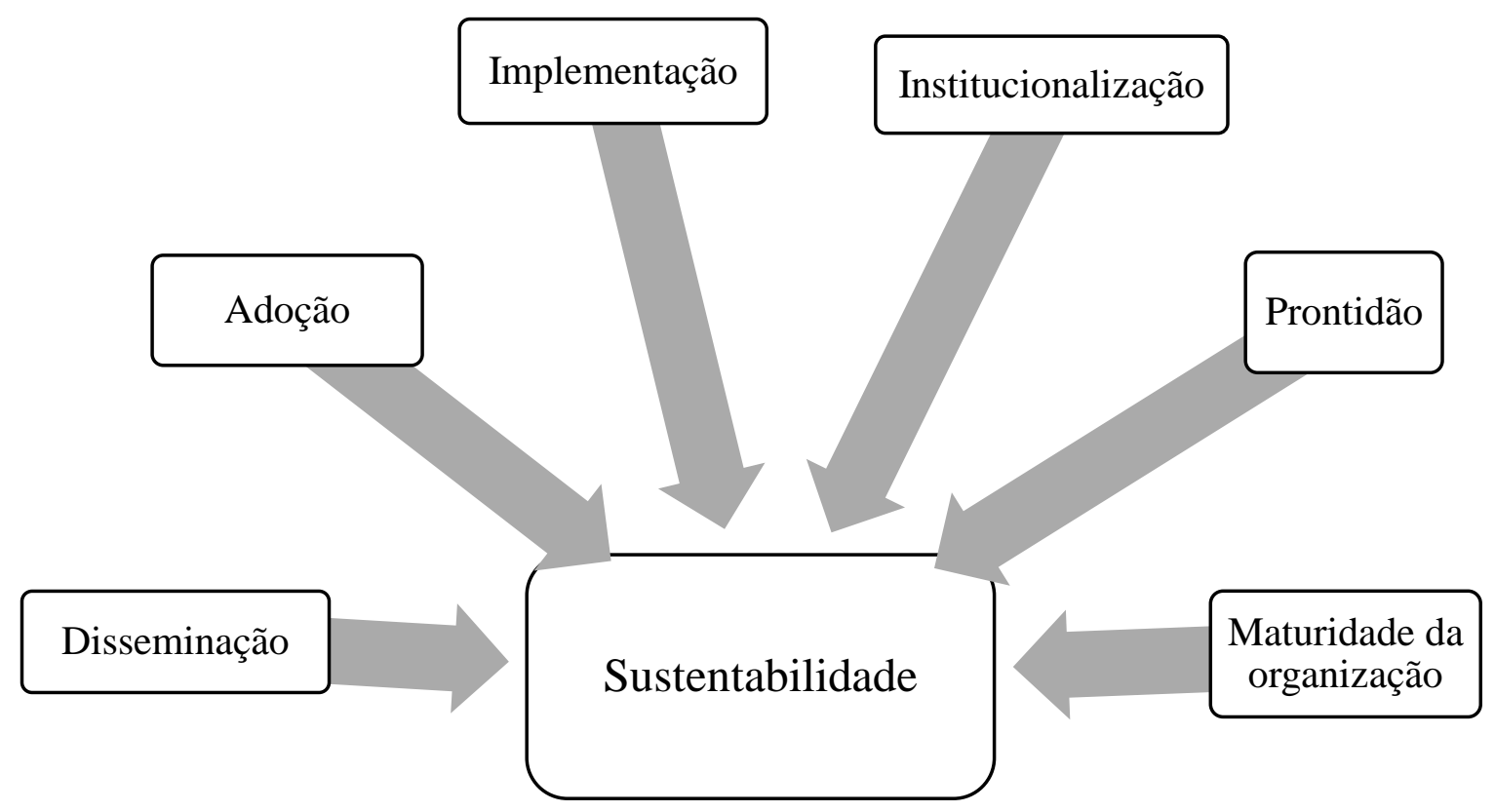

Figura 5. Aspectos influentes na sustentabilidade.

Um dos indicativos de sustentabilidade do programa é se a intervenção está de acordo com as necessidades da instituição. O PFF tem se mostrado relevante e de acordo com as diretrizes do Programa de Atenção Integral à Família (PAIF). A assistência social deve cumprir com os objetivos do PAIF, que dentre eles está o fortalecimento de vínculos familiares. O PFF atende essa demanda e vai além, como demonstra a Participante 5:

"Ele (PFF) é a resposta de uma demanda que a assistência tinha que é a de trabalhar fortalecimento de vínculos. E tudo o que eles (Assistência Social) tinham encontrado até o momento, ou não conseguiam segurar a família, ou não conseguiam perceber aquilo como de fato uma tarefa da assistência social" (Participante 5).

Além do mais, alguns profissionais, presentes nas reuniões observadas, relataram que há uma demanda muito grande por parte dos educadores por ferramentas que 
subsidiem o trabalho deles. O PFF é uma ferramenta que atende essa necessidade. Porém, a carga horária e a demanda de trabalho se apresentam concorrentes com o PFF.

"O grande entrave foi recursos humanos (...), eles (profissionais da assistência) não conseguiam colocar o PFF no horário normal da rotina de trabalho, não conseguem fazer um banco de horas (...) não ganhavam hora extra, não ganhava, pontuação, não ganhava nada (...). Por dentro do programa explodiu uma questão institucional muito além dele".

Esse relato é sobre uma localidade em que houve apenas um ciclo de implementação, mas que tem sido um desafio em outros locais também. Por mais que o programa seja algo necessário ao trabalho dos profissionais, a entrada do programa na rotina, por não ter sido institucionalizada, concorre com outras demandas. Um dos profissionais presentes em uma das reuniões observada assinalou que não pode cobrar de seus educadores (que estão implementando o programa) que cumpram com outras atividades da carta comum de aquisição de material dos serviços, pois os profissionais terão que ficar no contraturno sem receber por isso.

Dessa forma, percebe-se com os dados analisados um desafio relevante. Por mais que o programa venha suprir uma necessidade da assistência social, e diversos profissionais advoguem pelo programa devido aos bons resultados, faz-se necessária a institucionalização do programa. Como afirmam Shediac-Rizkallah e Bone (1998), um dos fatores que interfere na sustentabilidade do programa é a força da organização. Se a organização apresenta bases fortes em sua estrutura interna, as chances do programa se manter no local são altas, da mesma forma, se o programa se integra aos serviços existentes. Por isso, um dos desafios encontrados nesta análise para a sustentabilidade do programa reside em preparar o local para receber a inovação já no período de adoção. 
Não basta apenas formar os profissionais, mas é necessário também verificar se o local apresenta a maturidade necessária para receber o programa.

Um dos pontos fortes para a sustentabilidade do PFF nos locais reside em suas características metodológicas. O programa apresenta resultados imediatos em sua aplicação, o que advoga por ele mesmo na manutenção nos locais, como relatado pela Participante 6 e pelo Participante 3:

“Teve uma mãe em (local omitido) que falou assim: 'nossa, posso levar esse DVD para mim? Só para eu lembrar?' (...) teve outra que falou o quanto o programa estava impactando a família dela como um todo, por que ela usava com o marido 'eu me sinto assim quando você faz tal coisa"”. (Participante 6)

“(os pais) saem muito gratos (...), seis meses depois os pais continuam fazendo algumas atividades, algumas das atitudes dentro de casa, mesmo depois do programa ter terminado. As respostas imediatas são impressionantes”. (Participante 3)

\section{Conclusões}

Este estudo qualitativo teve como propósito analisar o processo de difusão do Programa Famílias Fortes (Strengthening Families Program) no Brasil, com o objetivo de retomar o histórico do PFF no Brasil, assinalar as características da inovação que foram determinantes para sua escolha e os desafios no processo de difusão do programa, caracterizado pelas etapas de disseminação, adoção, implementação e sustentabilidade.

Acerca do primeiro objetivo, pode ser destacado que a entrada do PFF na agenda política não foi ao acaso, mas se originou de uma demanda percebida pela sociedade. Porém, os coordenadores de saúde mental do MS pautaram sua decisão não por uma resposta fácil, mas por uma visão complexa de longo prazo. Por mais que existam 
iniciativas de prevenção do uso de drogas no Brasil, elas muitas vezes não são desenvolvidas sistematicamente e tampouco avaliadas adequadamente. É possível que estas deficiências nas bases e avaliação de iniciativas preventivas prejudiquem a sua eficácia, podendo resultar em efeito inócuo, ou mesmo iatrogênico. Ao buscar um programa comunitário para prevenção do uso, não se buscava "guerra às drogas", mas uma compreensão do fenômeno. Iniciativas como essa são fundamentais para o Brasil, pois investir em programas de prevenção baseados em evidências de efetividade evita o sofrimento desnecessário de muitas famílias e potencializa a saúde de adolescentes e cuidadores. Pode-se dizer que esta é, portanto, uma escolha ética, ademais de técnica e política.

Com relação à adoção, os resultados apresentados demonstram que ocorreram aspectos favoráveis e desfavoráveis à escolha do Programa Famílias Fortes para o Brasil. Os principais aspectos favoráveis foram referentes à vantagem relativa que o programa demonstrou em detrimento de outras propostas, compatibilidade com os valores vigentes na cultura e indícios de resultados positivos do programa. Os aspectos desfavoráveis foram os relacionados à complexidade e à viabilidade. Restrições em infraestrutura material, condições de trabalho deficitárias, custo elevado com planejamento das sessões e alta manualização do PFF parecem torná-lo de difícil implementação nos serviços de assistência social nos quais sua execução tem ocorrido. Uma possível evidência disso é o alcance relativamente restrito do PFF, expresso pelo pequeno número de famílias (563 famílias) atendidas ao longo de três anos de implementação.

Ganhos também resultaram da adoção, como mostram os resultados positivos já constatados nas primeiras aplicações do programa. Apesar da ausência de dados sobre o potencial impacto na prevenção do uso de drogas, foco do programa, percebe-se que o PFF segue um fluxo ao encontro das políticas sociais mais recentes que definem a pobreza 
além do nexo renda-consumo, mas como o suprimento de "necessidades básicas" (Calmon, 2007, p. 14). Os resultados já constatados suprem uma carência da população por estratégias de desenvolvimento positivo, que permitem às famílias se desenvolverem de forma mais saudável e com perspectivas de vida voltadas ao bem-estar. Isto está de acordo com o conceito mais amplo de saúde proposto pela OMS: saúde como um "estado de completo bem-estar físico, mental e social e não meramente a ausência de doença" (WHO, 2006, p.1).

Consoante a esse pensamento, está o fato de o programa ser uma resposta às necessidades de fortalecimento de vínculos familiares proposto em Políticas Sociais, tais como o PAIF, PNAD, as Diretrizes Internacionais sobre a Prevenção do Uso de Drogas proposto pela ONU. Igualmente, vem ao encontro da Lei 8.080/90 que estipula em seu artigo $2^{\circ}$ Parágrafo $1^{\circ}$ "O dever do Estado de garantir a saúde consiste na formulação e execução de políticas econômicas e sociais que visem à redução de riscos de doenças e de outros agravos e no estabelecimento de condições que assegurem acesso universal e igualitário às ações e aos serviços para a sua promoção, proteção e recuperação".

A respeito dos desafios enfrentados nas etapas de disseminação, adoção, implementação e sustentabilidade do programa, muitas barreiras têm sido contornadas e os ganhos advindos da adoção do programa parecem superar algumas dessas barreiras. $\mathrm{O}$ principal desafio, e o mais complexo deles, se relaciona ao contexto interno brasileiro, que têm apresentado altos e baixos, o que interfere na disseminação, adoção, implementação e sustentabilidade do programa. Um segundo desafio, remete à cultura da "guerra às drogas", de que o problema está no indivíduo, que o grande vilão por trás dos problemas é a droga em si, que o desvirtua e o demoniza. Somado a isso, há uma cultura que favorece o tratamento e não a prevenção, que valoriza a internação em detrimento da ressocialização. Dessa forma, a disseminação do programa para outros estados e 
municípios se torna complexa, pois é necessário romper uma barreira anterior: as crenças e conhecimentos nos quais a comunidade está imersa. Não se quer com isto culpabilizar aqueles que tão bravamente fazem seu trabalho, muitas vezes "jogados" nos serviços com pouco conhecimento sobre o que fazer. Mas, deve-se alertar que a educação sobre prevenção e drogas ainda não saiu de um círculo seleto de pesquisadores e gestores altamente capacitados.

Pode-se citar ainda como desafios a falta de institucionalização do programa nos locais de aplicação e de prontidão dos serviços para receber o programa (por falta de conhecimentos sobre os resultados e recursos para recebê-lo), falta de articulação com MDS, órgão ao qual a assistência responde. Alguns desses desafios podem ser sanados ao se desenvolver estratégias de marketing mais eficazes, de forma a atingir todos os atores envolvidos no processo de adoção e implementação do programa com informações claras e precisas sobre os principais aspectos relativos ao programa.

Se por um lado existem desafios, por outro notam-se perspectivas de mudança. Cursos como a capacitação em EAD "Prevenção dos Problemas relacionados ao uso de Drogas" promovida pela SENAD em parceria com a UFSC e NUTE, que chegou a sua $7^{\mathrm{a}}$ edição no ano de 2016; congressos especializados, como o PREVINE, que aconteceu no ano de 2014; e a formação da Sociedade Brasileira de Prevenção, que acontecerá em agosto de 2016, são marcos que sugerem uma mudança cultural. Nesta mesma linha, citase ainda o Curso de Prevenção do Uso de Drogas para Educadores de Escolas Públicas (Sudbrack \& Conceição, 2014), promovido pela SENAD junto ao MEC (Ministério da Educação), em parceria com a UnB, por meio do Programa de Estudos e Atenção às Dependências Químicas/PRODEQUI do Instituto de Psicologia (IP/PCL). É preciso aguardar o impacto destas ações empreendidas por gestores, educadores e pesquisadores 
na construção de novas práticas culturais acerca da prevenção ao uso abusivo de drogas no Brasil.

Este estudo apresenta contribuições para a área de estudos em difusão de programas preventivos. Destaca-se o caráter inovador do presente estudo ao descrever a história e analisar barreiras e facilitadores da difusão do PFF no Brasil. Adicionalmente, este é um dos poucos estudos brasileiros que abarcam o tema da difusão em programas preventivos (Melo, citado por Melo \& Izbick, 2015). Ao adotar uma abordagem qualitativa baseada em teoria fundamentada e na Teoria da Difusão de Inovações, evidenciou alvos relevantes para a compreensão e gestão da adoção, disseminação e implementação do PFF no Brasil. No conjunto, estes dados apontam perspectivas para a sustentabilidade, aparentemente a ser favorecida a depender do êxito da disseminação e adoção em nível local, da qualidade da implementação, da prontidão do território e maturidade dos serviços adotantes.

A principal limitação deste estudo é a ausência de procedimentos observacionais para a fase de implementação, bem como a coleta de dados sobre a fidelidade da implementação. Por isso, recomenda-se que novos estudos incluam avaliação da fidelidade, aderência e responsividade na implementação. Nesta mesma linha, a coleta de dados junto a profissionais da ponta, executores do PFF, e famílias participantes pode lançar luz sobre outras dimensões não evidenciadas neste estudo. Estes dados obtidos por múltiplos informantes e múltiplas medidas devem ser associados a estudos de efetividade do PFF, de modo a se identificar em que medida o PFF afeta as metas finais para as quais ele foi adotado. Ainda que existam indícios de sua compatibilidade com as necessidades locais, boa aceitação por parte das famílias e resultados iniciais positivos, são ainda desconhecidos seus efeitos sobre o padrão do uso de drogas entre adolescentes ao longo do tempo. 


\section{Referências}

Abreu, S. (2012). Prevenção em saúde mental no brasil na perspectiva da literatura e de especialistas da área (Dissertação de Mestrado não publicada) Universidade de Brasília, Brasília.

Allen, D., Coombes, L., \& Foxcroft, D. R. (2007) Cultural accomodation of the Strengthening Families Programme 10-14: UK Phase I study. Health Education Research. 22 (4), 547-560.

Barker, P.M., Reid, A., \& Schall, M. W. (2016) A fra. Africa. Implementation Science, 11(12), 1-11. DOI: 10.1186/s13012-016-0374-x.

Bartholomew, L. K., Parcel, G. S., Kok, G., \& Gottlieb, N. H. (2011). Planning Health Promotion Programs: An Intervention Mapping Approach. Third edition. San Francisco, CA: Jossy-Bass.

Bastos, F. I \& Bertoni, N. (2014) Pesquisa Nacional sobre o uso de Crack. ICIT/FIOCRUZ.

Baus, J., Kupek, E., \& Pires, M. (2002) Prevalência e fatores de risco relacionados ao uso de drogas entre escolares. Revista Saúde Pública, 36 (1), 40-46.

Benchaya, M. C., Bisch, N. K., Moreira, T. C., Ferigolo, M., \& Barros, H. M. T. (2011) Non-authoritative parents and impact on drug use: the perception of adolescent children. Jornal de pediatria, 87(3), 238-244.

Berry, F. S. \& Berry W. D. (2007) Innovation and Diffusion Models in Policy Research. In P. A. Sabatier (Ed.), Theories of the Policy Process. Boulder: Westview Press.

Broecker, C. Z., \& de Jou, G. I. (2007) Práticas educativas parentais: a percepção de adolescentes com e sem dependência química. Psico-USF, 12 (2), 269-279. 
Buchele, F., Coelho, E. B. S., \& Lindner, S. R. (2009) A promoção da saúde enquanto estratégia de prevenção ao uso das drogas. Ciência \& Saúde Coletiva, 14(1), 267-273.

Calmon, P. D. (2007) Três questões sobre as mudanças recentes nos programas sociais no Brasil. Sociedade em Debates, 13 (1), 9-26.

Carlini, E. L., Noto, A. R., Sanches, Z., Carlini, C. M., Locatelli, D. P. ... \& Moura, Y. G. (2010) VI Levantamento nacional sobre o consumo de drogas psicotrópicas entre estudantes do ensino fundamental e médio das redes pública e privada de ensino nas 27 capitais brasileiras. SENAD, Brasília- DF. $1^{\text {a }}$ Ed.

Claro, H. G., Oliveira, M. A. F., Ribeiro, A. R., Fernandes, C. C., Cruz, A. S., \& Santos, E. G. M. (2014) Perfil e Padrão de uso de crack de crianças e adolescentes em situação de rua: uma revisão integrativa. SMAD Revista Eletrônica Saúde Mental Álcool e Drogas, 10(1), 35-41.

Correa, M. L., Tamarazubarew, G., Valenzuela, M. T., \& Salas, P. F. (2012). Evaluación del programa "Familias Fuertes: amor y límites" en familias con adolescentes de 10 a 14 años. Rev Med Chile, 140, 726-731.

Durlak, J. A., \& DuPree, E. P. (2008). Implementation matters: A review of research on the influence of implementation on program outcomes and the factors affecting implementation. American Journal Community Psychology, 41, 327-350.

Dusenbury, L., Newman, J. Z., Weissberg, R. P., Goren, P., Domitrovich, C. E., \& Mart, A. K. (2015). Developing a blueprint for preschool to high school education in social and emotional learning: The case for state learning standards. In J. A. Durlak, C. E. Domitrovich, R. P. Weissberg, \& T. P. Gullotta (Eds.), Handbook of social and emotional learning: Research and practice (pp. 532-548). New York: Guilford Press. 
Etz, K. E., Robertson, E. B., \& Ashery, R. S. (1998). Drug abuse prevention through family-based interventions: future research. NIDA Research Monograph 177, 111.

Fagan, A. A., \& Mihalic, S. (2003). Strategies for enhancing the adoption of school-based prevention programs: lessons learned from the Blueprints for Violence Prevention replications of the Life Skills Training program. Journal of Community Psychology, 31(3), 235-253.

Flick, U. (2009) Introdução à pesquisa qualitativa. Porto Alegre, Artmed. $3^{\mathrm{a}} \mathrm{ed}$.

Fox, D. P., Gottfredson, D. C., Kumpfer, K. K, \& Beatty, P. D. (2004) Challenges in Disseminating Model Programs: a qualitative analysis of the Strengthening Washington DC Families Program. Clinical Child and Family Psychological Review, 7(3), 165-176.

Foxcroft, D. R., Ireland, D., Lister-Sharp, D. J., Lowe, G., \& Breen, R. (2003). Long-term primary prevention for alcohol misuse in young people: a systematic review. Addiction, 93, 397-411.

Gagnon, R. J., Franz, N. K., Garst, B. A., \& Bumpus, M. F. (2015). Factors impacting program delivery: The importance of implementation research in extension. Journal of Human Sciences and Extension, 3(2), pp. 68-82.

Glaser B. G., \& Strauss A. L. (1967) The discovery of grounded theory. Chicago: Aldine.

Gottfredson, D. C., Cook, T. D., Gardner, F. E. M., Gorman-Smith, D., Howe, G. W., Sandler, I. N., \& Zafft, K. M. (2015). Standards of evidence for efficacy, effectiveness, and scale-up research in prevention science: next generation. Prevention Science, 16, 893-926. 
Hosman, C., Jané-Llopis, E., \& Saxena, S. (2004). Prevention of mental disorders: effective interventions and policy options. World Health Organization (WHO), Geneva.

Jamison, T. B., Coleman, M., Ganong, L. H., \& Feistman, R. E. (2014) Transitioning to postdivorce Family life: a grounded theory investigation of resilience in coparenting. Family Relations, 63 (July), 411-423. DOI: 10.1111/fare.12074

Kumper, K. L., Pinyuchon, M., Melo, A. T., \& Whiteside, H. O. (2008) Cultural adaptation process for international dissemination of the Strengthening Families Program. Evaluation \& the Health Professions, 31 (2), 226-239. DOI: $10.1177 / 0163278708315926$

Kumpfer, K., Xie, J., \& O’Driscoll, R. (2012) Effectiveness of a Culturally Adapted Strengthening Families Program 12-16-Years for High-Risk Irish Families. Child \& Youth Care Forum, 41(2), 173-195.

Melo, M. H. S., \& Izbicki, S. (2015) Adoção, disseminação e sustentabilidade de programas preventivos e de promoção em saúde mental. In: S. G. Murta, C. LeandroFrança, K. B. Santos, \& L. Polejack, (Eds.) Prevenção e Promoção em Saúde Mental: Fundamentos, Planejamento e Estratégias de Intervenção (pp. 230-248). Novo Hamburgo: Sinopsys.

Meyers, D. C., Katz, J., Chien, V., Wandersman, A., Scaccia, J. P., \& Wright, A. (2012). Practical implementation science: Developing and piloting the quality implementation tool. American Journal of Community Psychology, 50, 481-496.

Moreira, A., Vóvio, C. L., \& De Micheli, D. (2015) Prevenção ao consumo abusivo de drogas na escola: desafios e possibilidades para a atuação do educador. Educação e Pesquisa. São Paulo. 41 (1), 119-135. 
Molgaard, V., \& Kumpfer, K.L. (1993). The Iowa Strengthening Families

Program: For families with pre- and early adolescents, Ames, IA: Social \& Behavioral Research Center for Rural Health, Iowa State University.

Mrazek, P. J., \& Haggerty, R. J. (1994). Reducing risks for mental disorders: frontiers for preventive interventions research. Washington: National Academy Press.

Murta, S. G. (2011). Aproximando ciência e comunidade: difusão de programas de habilidades sociais baseados em evidências. Em A. Del Prette \& Z. A. P. Del Prette (Orgs.) Habilidades sociais: intervenções efetivas em grupo (pp. 83-114). São Paulo: Casa do Psicólogo.

Murta, S. G., Nobre-Sandoval, L. A., Ramos, C. E. P. L., Pedralho, M. S., \& Tavares, T. N. G. (2014) Relatório de Avaliação do Processo de Implementação e de Adaptação Cultural do Programa Fortalecendo Famílias (SFP 10-14): Fase Pré-Piloto (Relatório FAPESP). Brasília-DF.

Okulicz-Kozaryn, K., \& Foxcroft, D. R. (2012) Effectiveness of the Strengthening Families Programme 10-14 in Poland for the prevention of alcohol and drug misuse: protocol for a randomized controlled trial. BMC Public Health, 12 (319).

Ortega, E., Giannotta, F., Latina, D., \& Ciarano, S. (2012). Cultural adaptation of the Strengthening Families Program 10-14 to italian families. Child Youth Care Forum, 41, 197-212.

Rogers, E. (1995) Diffusion of innovations. Free Press. New York. $5^{\mathrm{a}}$ ed. (1 ${ }^{\mathrm{a}}$ ed 1962).

Sanders, M. (2000) Community-based parenting and family support interventions and the prevention of drug abuse. Addictive Behaviors, 25 (6), 929-942. 
Santos, K. B., \& Murta, S. (2015). A implementação de programas de promoção e promoção no âmbito da saúde mental. Em Murta, S. G., Leandro-França, Santos, K. B., \& L. Polejack, (Eds.) Prevenção e Promoção em Saúde Mental: Fundamentos, Planejamento e Estratégias de Intervenção (pp.192-211). Novo Hamburgo: Sinopsys.

Schenker, M., \& Minayo, M. C. S. (2003) A implicação da família no uso abusivo de drogas: uma revisão crítica. Ciência \& Saúde Coletiva, 8 (1), 299-306.

SENAD (2016) Uma política sobre drogas é uma política sobre pessoas. Acessado em http://www.justica.gov.br/noticias/senad-mj-disponibiliza-relatorio-uma-politicasobre-drogas-e-uma-politica-sobre-pessoas/senad-relatorio-e-anexo.pdf

Shediac-Rizkallah, M. C. \& Bone, L. R. (1998). Planning for the sustainability of community-based health programs: conceptual framework an future directions for research, practice and policy. Health Education Research, 13, 87-108.

Silva, N. L. P., \& Dessen, M. A. (2005) Intervenção Precoce e família: contribuições do modelo bioecológico de Bronfenbrenner. In M. A. Dessen, \& A. L. Costa-Júnior (Eds.), A ciência do desenvolvimento humano: tendências e perspectivas futuras (pp. 152-167). Porto Alegre: Artmed.

Souza, J. (2009) A Ralé Brasileira como é e como vive. Belo Horizonte: Editora UFMG

Strauss, A. S., \& Corbin, J. (2008) Pesquisa qualitativa: técnicas e procedimentos para o desenvolvimento de teoria. Porto Alegre. Artmed.

Stolle, M. Stappenbeck, J., Wendell, A., \& Thamasius, R. (2011) Family-based Prevention Against Substance Abuse and Behavioral Problems: Culture-sensitive Adaptation Process for the Modification of the US-American Strenthning Families Programs 10-14 German conditions. Journal of Public Health, 19, 389-395. 
Sudbrack, M. F. O.; Conceição, M. I. G., \& Costa, L. F. (2014) Curso de Prevenção do uso de drogas para educadores de Escolas Públicas. 6. ed. Brasília: SENAD Turner, K. M. T. \& Sanders, M. R. (2006) Dissemination of evidence-based parenting and family support strategies: learning from the Triple $\mathrm{P}$ - Positive Parenting Program system approach. Aggression and Violent Behavior, 11, 176-193. DOI: 10.1016/j.avb.2005.07.005

WHO, World Health Organization. (2004). Prevention of mental disorders: effective interventions and policy options. Summary Report, Genebra.

WHO (2006) Basic Documents, Forty-fifth edition, Supplement, October 2006

Wiecha, J. L., Ayadi, A. M., Fuemmeler, B. F., Carter, J. E., Handler, S., Johnson, S., Strunk, N., Korzec-Ramirez, D., \& Gortmaker, S. L. (2004) Diffusion of an integrated health education program in an urban school system: planet health. Journal of Pediatric Psychology. 29(6) 467-474. 


\section{Conclusão}

Este estudo teve três objetivos principais, abordados em três manuscritos. No primeiro manuscrito, examinou-se o estado da arte da pesquisa em prevenção do abuso de substâncias no Brasil, situando os estudos no ciclo de pesquisa em prevenção, de forma a identificar lacunas e discutir direções futuras, por meio de análise integrativa da literatura. Os resultados encontrados indicaram lacunas e progressos no ciclo de pesquisa em prevenção. Na primeira etapa do ciclo, identificação do problema, constatou-se alta prevalência de uso de substâncias entre adolescentes no Brasil. Na segunda etapa, os fatores de risco e proteção analisados apontaram três eixos de análise: individual, familiar e comunitário. Para os fatores de risco foram identificados: carência de habilidades de vida, problemas familiares e ausência de oportunidade de lazer e trabalho como principais vulnerabilidades do uso de substâncias. Para os fatores de proteção, autoeficácia, resiliência, estilo parental autoritativo, vínculos fortes com pessoas de referência, protagonismo juvenil foram os principais pontos apresentados para o desenvolvimento saudável do indivíduo e proteção ao uso de substâncias. Na terceira, quarta e quinta etapas, desenvolvimento de intervenção, avaliação de eficácia e efetividade, poucos estudos foram encontrados. Na última etapa, difusão, nenhum estudo foi encontrado. Esses dados confirmam achados prévios (Abreu, 2012), revelando que persiste uma lacuna na pesquisa nesta temática, evidenciada pela escassez de publicações com avaliação sistemática de ações de prevenção no Brasil.

No segundo manuscrito, buscou-se discutir a transferência de conhecimento para a prática à luz da literatura a Teoria da Difusão, de forma a contribuir para sua compreensão no contexto da saúde mental. O texto foi construído de forma a contemplar os principais aspectos conceituais que definem a difusão, sua história conceitual, e suas principais etapas, quais sejam, disseminação, adoção, implementação e sustentabilidade. 
O conhecimento sobre difusão de programas preventivos se faz necessário por dois motivos. O primeiro consiste na necessidade atual do país por ações preventivas, tendo em vista os problemas enfrentados pela população. Segundo, é questionável a utilidade do conhecimento não comunicado para além do espaço acadêmico (Murta, 2011). Uma compreensão mais acurada sobre o processo de difusão pode otimizar esforços empreendidos no âmbito das políticas públicas e da implementação em larga escala de ações de promoção de saúde e prevenção do uso abusivo de drogas e outros problemas em saúde. Igualmente, este conhecimento pode qualificar a formação de recursos humanos e encorajar a comunicação entre pesquisadores e tomadores de decisão.

No terceiro manuscrito, é descrita a análise do processo de difusão do Programa Famílias Fortes para o Brasil. Esse programa foi adotado pelo Ministério da Saúde em 2013 e, desde então, vem sendo disseminado para todas as regiões do país. Buscou-se traçar a linha histórica do programa, as características da inovação que foram influentes em sua escolha, e detalhar as etapas do processo de difusão: disseminação, adoção, implementação e sustentabilidade do programa. O estudo compreendeu a consulta a gestores, supervisores, multiplicadores e facilitadores do programa, fontes documentais e observação direta de reuniões de equipes de trabalho, por meio de uma abordagem qualitativa baseada em teoria fundamentada.

Este estudo, de caráter inovador, descreveu facilitadores e barreiras para a disseminação, adoção e implementação do Programa Famílias Fortes e perspectivas para sua sustentabilidade. As principais barreiras são as do contexto interno brasileiro, uma cultura ainda voltada para tratamento, problemas institucionais na atenção básica, falta de recursos financeiros nos serviços, oscilação política em que a transição de governo não garante continuidade de ações do governo anterior, entre outros. Ademais, observou-se que há carência de iniciativas voltadas para as famílias e que visem à qualidade de vida 
da população. Se, por um lado o PFF encontrou certa resistência em sua difusão entre os profissionais da ponta por ser de origem estrangeira, por outro foi bem recebido pela população, que o percebeu como relevante frente às suas necessidades, conforme relatos das fontes consultadas neste estudo.

Este estudo apresentou contribuições científicas e sociais. Quanto ao primeiro aspecto, destaca-se a originalidade deste estudo. Seus achados contribuem para reduzir a lacuna nacional acerca de estudos relativos à difusão de programas preventivos em saúde mental. Além disto, oportunizou a compreensão de diversos aspectos da difusão na realidade do contexto brasileiro, indicando rumos para a pesquisa em implementação em larga escala de programas preventivos. A Teoria da Difusão de Inovações e abordagens qualitativas podem subsidiar novos estudos nessa temática, bem como sua combinação com métodos quantitativos ou mistos.

Quanto ao segundo aspecto, as contribuições sociais deste estudo apontam dados que podem subsidiar a expansão em larga escala do PFF no Brasil. Neste sentido, a vantagem relativa do PFF, seus resultados preliminares positivos, compatibilidade com as necessidades dos serviços de proteção social básica e atenção básica à saúde são elementos que podem favorecer sua adoção em novos territórios. Por outro lado, sua complexidade deve ser reduzida, para que possa ser percebido como mais viável. Destacase a institucionalização do PFF, articulação entre as políticas de âmbitos diversos, como assistência social e saúde, maturidade dos serviços e prontidão do território como requisitos relevantes para a sua sustentabilidade.

As principais limitações deste estudo são a ausência de escuta às famílias participantes do programa e de procedimentos observacionais para acesso à implementação do PFF. São necessários estudos mais aprofundados sobre a fase de implementação do PFF no Brasil. A avaliação do processo de implementação poderá 
revelar como o programa tem sido colocado em prática nos locais de aplicação e se é factível esperar os resultados previstos pelo programa. Evidências indicam que quando o programa não é implementado observando-se os seus elementos centrais, os resultados podem se mostrar negativos. Isto foi verificado nos estudos de Skarstrand, Sundell e Andréasson (2013), em que não foram encontrados dados de efetividade do programa, pois o mesmo foi alterado em sua estrutura e seus elementos centrais não foram seguidos.

São igualmente necessários estudos sobre a efetividade do programa. Os resultados encontrados neste estudo indicam pistas sobre as consequências positivas da intervenção na vida da população. Porém, esses dados preliminares devem ser acrescidos de outros provenientes de estudos mais abrangentes, com delineamento e amostras que possam responder adequadamente à pergunta relativa aos efeitos produzidos pelo PFF em adolescentes e famílias.

Por fim, reafirma-se a necessidade de se investir em políticas públicas baseadas em evidências voltadas à prevenção em saúde mental como uma forma de se atender uma demanda da população. Investir em ações preventivas com evidências de efetividade é investir em um futuro promissor para a população. Por isso, recomenda-se avaliação sistemática das propostas implementadas. Como há cada vez mais necessidade de programas efetivos para solucionar problemas sociais, a pesquisa avaliativa se torna extremamente importante como uma fonte de conhecimento e direção para as ações (Weiss, 1972). 


\section{Referências}

Abreu, S. (2012). Prevenção em saúde mental no brasil na perspectiva da literatura e de especialistas da área (Dissertação de Mestrado não publicada) Universidade de Brasília, Brasília.

Murta, S. G. (2011). Aproximando ciência e comunidade: difusão de programas de habilidades sociais baseados em evidências. In A. Del Prette \& Z. A. P. Del Prette (Eds.). Habilidades sociais: intervenções efetivas em grupo (pp. 83-114). São Paulo: Casa do Psicólogo.

Skarstrand, E., Sundell, K., \& Andréasson, S. (2013) Evaluation of Swedish version of the Strengthening Families Programme. European Journal of Public Health, $24(4), 578-584$.

Weiss, C. H. (1972) Evaluation Research: methods of assessing program effectiveness, New Jersey: Prentice-Hall. 
Apêndice A

Protocolo de Entrevista 
Perguntas para Coordenador de Saúde Mental do Mistério da Saúde

1. Como vocês ficaram sabendo do Programa?

a. Como o programa chegou até vocês?

2. Qual era a intenção ao escolher esse programa específico?

3. Por que esse programa foi escolhido dentre outras possibilidades?

a. Quais características foram centrais na escolha do programa?

4. Em que medida esse programa se mostrava compatível à realidade brasileira?

5. Qual era o contexto (político e social) em que o programa foi colocado em pauta?

6. Quais foram as principais barreiras encontradas no processo de adoção do programa?

7. Como vocês avaliaram na época as vantagens e desvantagens do PFF?

8. O que é feito para encorajar as cidades a adotarem o programa?

9. Quais são os planos para a sustentabilidade do programa?

10. Há relação de colaboração entre equipe que produz o programa e os equipamentos sociais da comunidade?

11. Há recursos disponíveis, incluindo espaço físico, tempo, dinheiro, formação e educação no local?

12. Está sendo pensado a incorporação do programa dentro das tarefas de trabalho dos facilitadores? Como?

Perguntas para Coordenadoras de Programas de Prevenção em Saúde Mental do Ministério da Saúde

1. Como tem sido a seleção dos locais (estados e municípios) aos quais o programa é apresentado para potencial adoção?

2. Como o programa é apresentado aos gestores locais (estaduais e/ou municipais)?

a. Como é realizada a pactuação com os estados e municípios? 
3. Há apoio local/ apoio das lideranças locais para a adoção do programa?

a. O programa foi bem aceito pelos gestores, líderes comunitários, usuários do programa e aplicadores?

4. Quem participa do processo decisório pelo programa nos locais de implementação?

5. Como é a assistência dada pelo MS a esses locais?

6. Quais recursos (físico, econômicos e humanos) esses locais dispõem para implementar o programa?

7. Qual a origem dos recursos financeiros para a implementação desse programa? (Federal? Municipal?)

8. Como foi formada a equipe de implementação e divulgação do programa?

9. Quais barreiras têm sido encontradas para implementar o programa?

10. Qual o perfil profissional é adequado para execução do programa/ que habilidades/conhecimentos e atitudes?

11. Qual a infraestrutura institucional (humana, recursos materiais, infraestrutura) local para o uso da intervenção foi construída?

12. Quais são as principais barreiras que você percebem para a sustentabilidade do programa?

13. Quais são os aspectos que podem facilitar a sustentabilidade do programa?

14. O que você considera mais importante para a sustentabilidade do programa nos locais?

Perguntas norteadoras para Supervisora Nacional do PFF no Brasil

1. Fale sobre o início do PFF no Brasil.

2. Como foi a formação dada pelos desenvolvedores do programa?

3. O que as pessoas pensam sobre o programa/intervenção?

4. Esse programa é familiar à prática cotidiana dos indivíduos no serviço?

5. O programa gera entusiasmo nos indivíduos? 
6. As pessoas se sentem capazes de implementar a intervenção?

7. O quão aberta a mudança as pessoas envolvidas estão em relação a usar o programa?

8. Como funciona os espaços de feedback e troca de experiências?

9. Há relação de colaboração entre equipe que produz o programa e os equipamentos sociais da comunidade?

10. Como é a receptividade da população ao programa?

11. Como vocês percebem a receptividade dos facilitadores ao programa?

12. Quais são as barreiras que vocês identificam para a sustentabilidade do programa nos locais?

13. Para o programa se sustentar nos municípios é necessário...

Perguntas para grupo focal com Formadoras Federais

1. Fale sobre a experiência de vocês com o programa.

a. Qual a experiência de vocês com o programa? O que aconteceu de mais marcante para vocês?

2. Para vocês quais são os pontos fortes do PFF?

3. Que dificuldades vocês percebem em relação ao programa?

a. O que vocês consideram ser mais difícil no programa?/ quais as principais barreiras do programa?

4. O que as pessoas pensam no primeiro momento sobre o programa quando vocês chegam nos municípios?

5. Vocês consideram que esse programa é adequado à prática cotidiana dos indivíduos no serviço?

6. Para o programa se sustentar nos municípios é necessário... 
Apêndice B

Parecer CEP-IH 


\section{INSTITUTO DE CIENCIAS HUMANAS / UNIVERSIDADE DE BRASILIA / CAMPUS}

\section{PARECER CONSUBSTANCIADO DO CEP}

\section{DADOS DO FRONETO DE FESQUISA}

Titulo da Pocqules: Avalsçto de programs preventho ao sbuso de drogs: difuelo do Frograma Fortalecendo Famillas no Eras:

Pacqulcador: Ana Aparsclda Vilela Mranda

Area Timatha:

Vortas: 2

CAAE: 5276015.7 .0000 .5540

Inctitulpso Proponanta: Instituto de Pyloologla -UNB

Patroolnador Prindpal: Financlamento Proprio

DADOS DO FAFECER

Nümaro do Paraor: 1.457 .351

\section{Aprecents,go do Projoto:}

Trab-se de uma pesqula de mestrado sobre fendmeno das trogas. 0 uso prejudicla de dogas esta assclado a fatores vunerablldsde socls|, ausencls de pollecss sodals consoldsuss, problemas famllares,

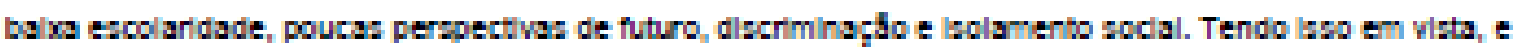
o carbter mulacetado e compleso da questo das drogs, apdes de curho preventho se mostram multo mals coerentes do que um foco extremamente probltivo. Dessa forms, as Interiengdes famllares tem-se mostrado efetlyas na prewenplo ao abuso de dropas entre adolescentes. Assim, o proposito do estudo qualistho e avalsr o proceses de difuso do Proprama Fortalecendo Famillas no Erasl. Por difusto conaldera-se o processo pelo quzl uma lnovagdo t transmitida entre os membros de um slatema soclal.

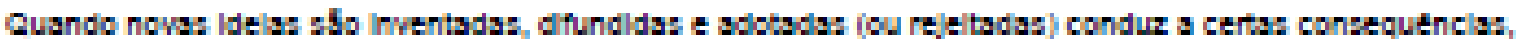
e com laso mudangas soclals. A pesqules serd reallzads com os pestores do programs no Bras |Coordenador Naclonal de Baude Mental do MInleterio da Babde e as coordenadoras de Frojetos de

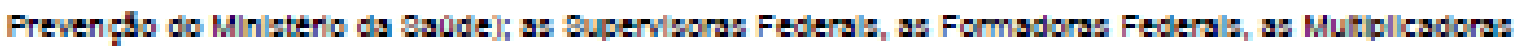
Locals, e aclltadores de grupo, que stuam dretamente com a Implementapto do Frograma na realdade

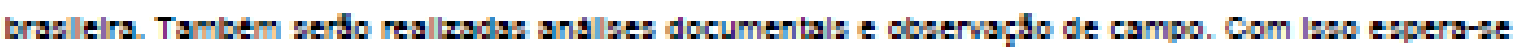
trapar uma lina do tempo da hatorla

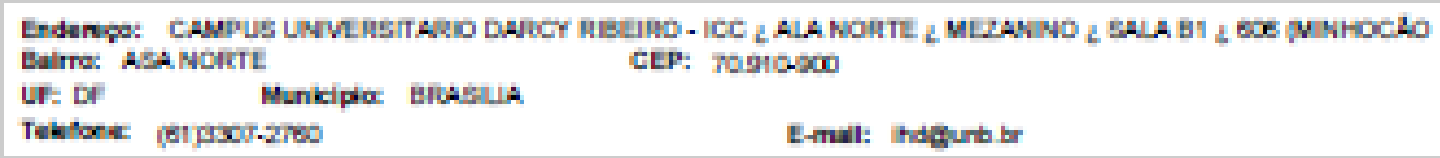




\section{INSTITUTO DE CIENCIAS HUMANAS / UNIVERSIDADE DE BRASILIA / CAMPUS}

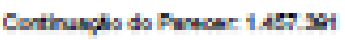

do proprams e zubeldar a subteribuldade e dasem/nacho do proprams para o Brasl.

objetivo da Pocqulca:

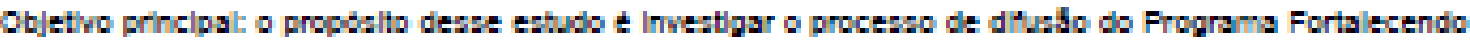

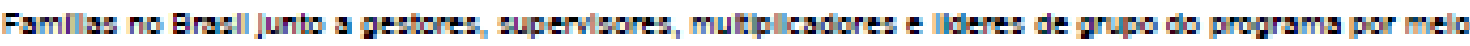
de ums abordspem qus tatha baseada em feorla fundamentada.

Objethos Secundario: Compresender as rabea que levaram o WS a Eco ha do FFF como proprama para prevengto ao uso abusho de dropas enire adolescentes; Explorar o processo de dlaseminapto

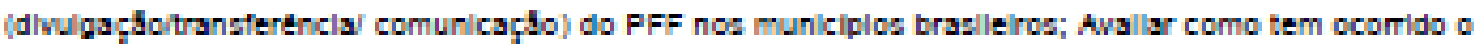
proceso de adoço do FFF pelos municiplos aos quals o proprams e proposto; Descrever as condlples

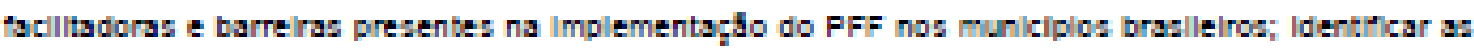
declades tomadas pelo MS relathas a cueteniablldade do FFF no Brasll.

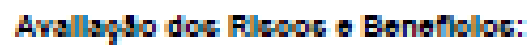

Aval splo doe Flacos:

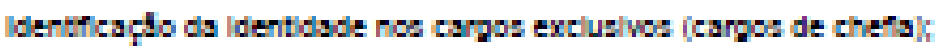

Eeneficlos:

(3) Auviliar os petores na tomada de dedsbo quanto as tuhro do programa no Enall.

b) Fromover a exponsto do FFF em lapa escala, a partir dos resultados encontrados.

(c) Fomecer subsidos que auxilem a sustentablldade do proprama, de toma a atingl o malor n:-mero de amillas no Brasll.

(d) Contribulr para o fortaleclmento de apdes dreclonadas a qualdade de vida damllar-

(e) Contribulr para a avs sp̧o de propramse povemamentals brasle|ros.

(f) Gerar conhecimento a cerca de difusbo de propramss preventhos em largs escala.

(a) Contribulr para ofora/ecimento de pollecs preventhas no Era:lL.

Comentarloc a Conciderapdec cobre a Pacqulca:

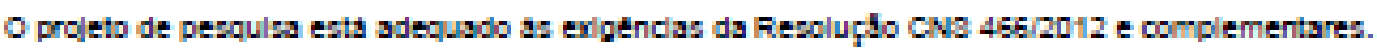

Coneldera,joc cobro es Temoc de spresentagso obrigatorla:

Todos os temoa obrlgherbe foram apresentsdo:

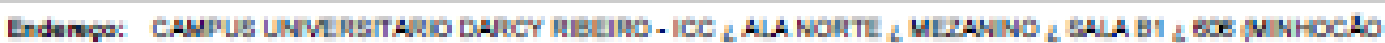

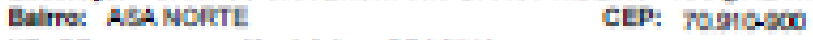

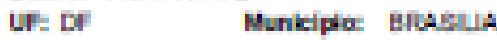

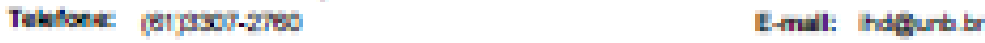




\section{INSTITUTO DE CIENCIAS HUMANAS / UNIVERSIDADE DE BRASILIA / CAMPUS}

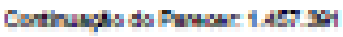

Recomondagles:

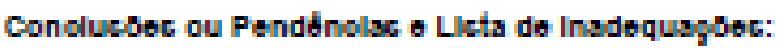

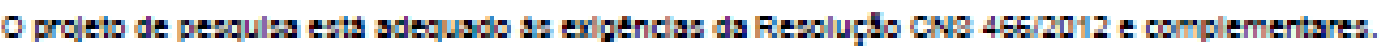

Coneldarayse Finale a orttarlo do ceP:

Ecte parecer fol taborado toceado noc dosumentoc abaho relablonadoc:

\begin{tabular}{|c|c|c|c|c|}
\hline Tlpo Documertio & Arquho & Fosibpem & Mutrer & Bt.uga \\
\hline $\begin{array}{l}\text { Informagdes Bdalcas } \\
\text { do Prouth }\end{array}$ & 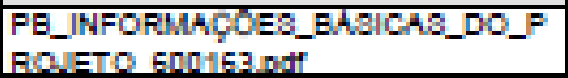 & $\begin{array}{c}\text { DENanO16 } \\
147245\end{array}$ & & Acelto \\
\hline 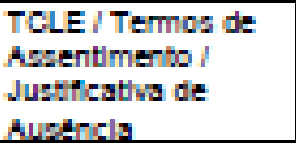 & telesholpdi & $\begin{array}{c}\text { Donazo16 } \\
142245\end{array}$ & $\begin{array}{l}\text { Mrs Apareclds Vilela } \\
\text { Mrands }\end{array}$ & Acelto \\
\hline $\begin{array}{l}\text { Declargho de } \\
\text { Insthulpho } \\
\text { Infrestrutur }\end{array}$ & termo_de_aceive_lnetudionalQsim/s.pdf & $\begin{array}{c}09032016 \\
147228\end{array}$ & $\begin{array}{l}\text { Mra Aparsclds Vilela } \\
\text { Mrands }\end{array}$ & Acelto \\
\hline Gronograma & cronogramsdeattyldsde.pdt & 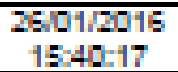 & $\begin{array}{l}\text { Mna Aparteclds Wilela } \\
\text { Mrands }\end{array}$ & Acelto \\
\hline 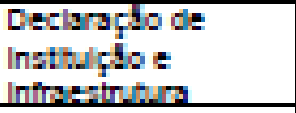 & 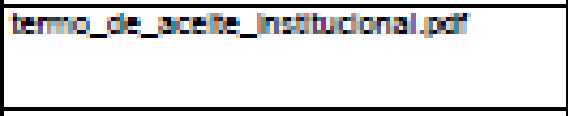 & $\begin{array}{c}1301 / 2016 \\
173542\end{array}$ & $\begin{array}{l}\text { Ars Apartelds Wile/s } \\
\text { Mrands }\end{array}$ & Acelts \\
\hline Dutroa & curiculblatterahe s.pdt & $\begin{array}{c}01122015 \\
160505\end{array}$ & $\begin{array}{l}\text { Ara Aparselds Vilela } \\
\text { Mrands }\end{array}$ & Acelto \\
\hline Dutros & cumiculolstierana.pdf & $\begin{array}{c}\text { D2127015 } \\
135984\end{array}$ & $\begin{array}{l}\text { Ma Apareclda Vilela } \\
\text { Mrands }\end{array}$ & Acelto \\
\hline Outros & $\begin{array}{l}\text { cep/hatadeencam|nhamentopreenchild } \\
\text { a.pdf }\end{array}$ & $\begin{array}{c}02122015 \\
159549\end{array}$ & $\begin{array}{l}\text { Ara Apareclds Wilela } \\
\text { Mrands }\end{array}$ & Acelto \\
\hline Dutros & Instrumerbodecoletadedodos pd' & $\begin{array}{c}2411 / 2015 \\
172840\end{array}$ & $\begin{array}{l}\text { Ma Aparselds Wilela } \\
\text { Mrands }\end{array}$ & Acelto \\
\hline Outros & Carsderevacetha.pd & $\begin{array}{c}2411 / 2015 \\
178010\end{array}$ & $\begin{array}{l}\text { Ars Aparselds vilela } \\
\text { Mrands }\end{array}$ & Acelto \\
\hline $\begin{array}{l}\text { TCLE / Temos de } \\
\text { Arsentmento i } \\
\text { Justicatha de } \\
\text { durthals. }\end{array}$ & 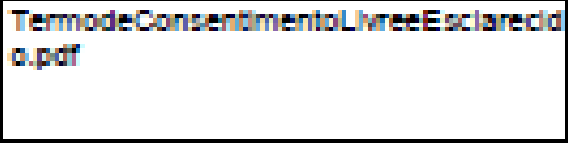 & $\begin{array}{c}2411 / 2015 \\
172514\end{array}$ & $\begin{array}{l}\text { Ara Apareclds Vilela } \\
\text { Mrands }\end{array}$ & Acelto \\
\hline $\begin{array}{l}\text { Declarapo de } \\
\text { Pespulgadore: }\end{array}$ & catadencam|nhamenib,pd' & $\begin{array}{c}2411 / 2015 \\
172054\end{array}$ & $\begin{array}{l}\text { Ara Apartslda Mlela } \\
\text { Mlrands }\end{array}$ & Acelto \\
\hline Orfamenib & Orameibut & $\begin{array}{c}2411 / 2015 \\
17: 1745\end{array}$ & $\begin{array}{l}\text { Ara Apars:lds Vils a } \\
\text { Mrands }\end{array}$ & Acelto \\
\hline $\begin{array}{l}\text { Proleto Deta hado i } \\
\text { Arochun }\end{array}$ & ArtipohuallacsodofFfaras .pdf & $\begin{array}{c}2411 / 2015 \\
1716 / 07 \\
\end{array}$ & $\begin{array}{l}\text { Ara Apareclds Vilela } \\
\text { Mrands }\end{array}$ & Acesto \\
\hline
\end{tabular}

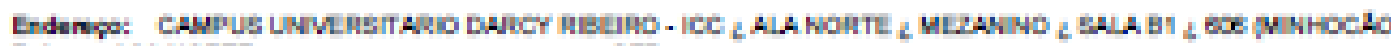
Bulna: ASA HOETL

UIF: DIF Mankipta Bnabia LEP: Fonsom

Tablore iflasurzos

Emul: indgutb br 


\section{INSTITUTO DE CIENCIAS HUMANAS / UNIVERSIDADE DE BRASILIA / CAMPUS}

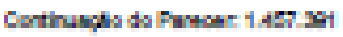

\begin{tabular}{|c|c|c|c|c|}
\hline Inveztgador & Artgohiallacsodofiffara: pdf & $\begin{array}{c}2411 / 2045 \\
17-1607\end{array}$ & $\begin{array}{l}\text { Mrs Apartselds Vilela } \\
\text { Mrgnds }\end{array}$ & Acesto \\
\hline Folha de Focto & folhaderostouseinada.pd' & $\begin{array}{c}\text { 79NENOAE } \\
123914\end{array}$ & $\begin{array}{l}\text { Mra Apareclda Vile/a } \\
\text { Mranda }\end{array}$ & Acesto \\
\hline
\end{tabular}

artuspo do Parbos:

Aprovade

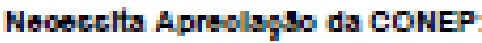

NHo

BFABLIA, 18 de Marpo de 2016

Acelnado por:

Llyla Earboca

(Coordenador)

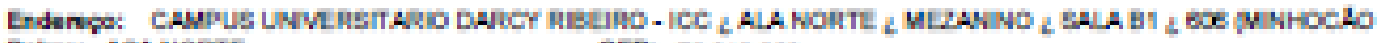

IIt: Munkipta buaty

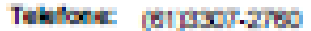

E-mul: hdguth b. 
Apêndice C

Termo de Consentimento Livre Esclarecido 


\section{Termo de Consentimento Livre e Esclarecido}

Você está sendo convidado a participar da pesquisa “Avaliação da Difusão do Programa Fortalecendo Famílias", de responsabilidade de Ana Aparecida Vilela Miranda, aluna de mestrado da Universidade de Brasília, sob orientação da $\operatorname{Prof}^{a} \operatorname{Dr}^{a}$ Sheila G. Murta professora adjunta do Departamento de Psicologia Clínica e Cultura da Universidade de Brasília. O objetivo desta pesquisa é avaliar a difusão do programa Fortalecendo Famílias no Brasil. Assim, gostaria de consultá-lo(a) sobre seu interesse e disponibilidade de cooperar com a pesquisa.

Você receberá todos os esclarecimentos necessários antes, durante e após a finalização da pesquisa, e lhe asseguro que o seu nome não será divulgado, sendo mantido o mais rigoroso sigilo mediante a omissão total de informações que permitam identificá-lo(a). No caso de dados em que seja possível a sua identificação, esses dados não serão transcritos de forma literal e ao final da pesquisa esses dados serão discutidos com você. Nesse caso, você terá total liberdade em opinar ou solicitar a retirada de tais trechos da pesquisa. Os dados provenientes de sua participação na pesquisa, tais como registros escritos e gravações de áudio de entrevistas, reuniões de equipe, reuniões de pesquisa, grupos focais ficarão sob a guarda do pesquisador responsável pela pesquisa.

A coleta de dados será realizada por meio de entrevistas, grupos focais e relatos de sua participação e interação em oficinas de trabalho do PFF. É para estes procedimentos que você está sendo convidado a participar. Sua participação na pesquisa não implica em risco mínimo, como observado anteriormente, mas trabalhados com sigilo e sua autorização.

Espera-se com esta pesquisa gerar conhecimentos que possam subsidiar a tomada de decisão e o registro histórico da expansão em larga escala do Programa Fortalecendo Famílias chegue a um maior número de famílias no Brasil.

Sua participação é voluntária e livre de qualquer remuneração ou benefício. Você é livre para recusar-se a participar, retirar seu consentimento ou interromper sua participação a qualquer 
momento. A recusa em participar não irá acarretar qualquer penalidade ou perda de benefícios. Esta é uma pesquisa de risco mínimo, não sendo previsto danos ou desconforto. Os dados passarão por checagem dos participantes antes da divulgação final da pesquisa, onde os informantes serão consultados sobre as interpretações realizadas pela pesquisadora.

Se você tiver qualquer dúvida em relação à pesquisa, você pode me contatar através do telefone 61. 8112-3239 ou pelo e-mail aavmiranda@gmail.com

A equipe de pesquisa garante que os resultados do estudo serão devolvidos aos participantes por meio de e-mails pessoais, reuniões e por meio eletrônico, com a publicação dos resultados dessa pesquisa estando disponível no banco de dissertações da Universidade de Brasília, e por meio do site www.geppsvida.com.br, podendo ser publicados posteriormente na comunidade científica.

Este projeto foi revisado e aprovado pelo Comitê de Ética em Pesquisa do Instituto de Ciências Humanas da Universidade de Brasília - CEP/IH. As informações com relação à assinatura do TCLE ou os direitos do sujeito da pesquisa podem ser obtidos através do e-mail do CEP/IH cep_ih@unb.br.

Este documento foi elaborado em duas vias, uma ficará com o(a) pesquisador(a) responsável pela pesquisa e a outra com o senhor(a).

Brasília, de de 